\title{
A Review and Assessment of Engineering Economic Studies of Dry Cooled Electrical Generating Plants
}

\author{
B. C. Fryer
}

March 1976

Prepared for the Energy Research and Development Administration under Contract E(45-1):1830 


\section{DISCLAIMER}

This report was prepared as an account of work sponsored by an agency of the United States Government. Neither the United States Government nor any agency Thereof, nor any of their employees, makes any warranty, express or implied, or assumes any legal liability or responsibility for the accuracy, completeness, or usefulness of any information, apparatus, product, or process disclosed, or represents that its use would not infringe privately owned rights. Reference herein to any specific commercial product, process, or service by trade name, trademark, manufacturer, or otherwise does not necessarily constitute or imply its endorsement, recommendation, or favoring by the United States Government or any agency thereof. The views and opinions of authors expressed herein do not necessarily state or reflect those of the United States Government or any agency thereof. 


\section{DISCLAIMER}

Portions of this document may be illegible in electronic image products. Images are produced from the best available original document. 
NOTICE

This report was prepared as an account of work sponsored by the United States Government. Neither the United States nor the Energy Research and Development Administration, nor any of their employees, nor any of their contractors, subcontractors, or their employees, makes any warranty, express or implied, or assumes any legal liability or responsibility for the accuracy, completeness or usefulness of any imformation, apparatus, product or process disclosed, or represents that its use would not infringe privately owned rights.

\author{
PACIFIC NORTHWEST LABORATORY \\ operated by \\ BATTELLE \\ for the \\ ENERCY RESEARCH AND DEVELOPMENT ADMINISTRATION \\ Under Contract E(45-1)-1830
}
Printed in the United States of America Available from
National Technical Information Service
U.S. Department of Commerce
5285 Port Royal Road
Springfield, Virginia 22151
Price: Printed Copy \$5.00; Microfiche $\$ 2.25$

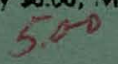


BNWL -1976

UC -12

\section{A REVIEW AND ASSESSMENT OF ENGINEERING ECONOMIC STUDIES OF DRY COOLED \\ ELECTRICAL GENERATING PLANTS}

by

B. C. Fryer

March 1976

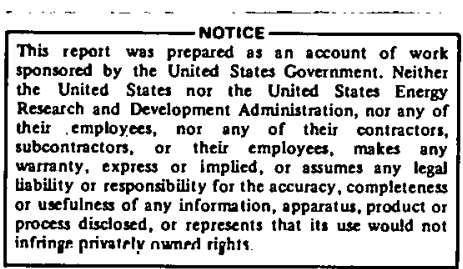

BATTELLE

Pacific Northwest Laboratories

Richland, Washington 99352 
THIS PAGE

\section{WAS INTENTIONALLY LEFT BLANK}




\section{CONTENTS}

LIST OF FIGURES . . . . . . . . . . . . . . . . vi

LIST OF TABLES. ...................... . . . . . . . . . . . .

1.0 SUMMARY. . . . . . . . . . . . . . . ....... 1

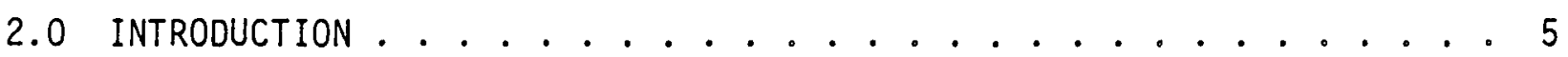

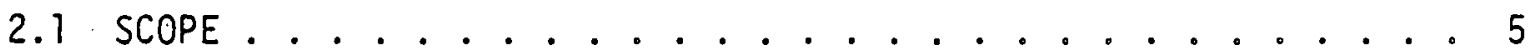

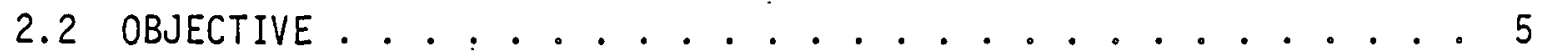

2.3 BACKGROUND. ................... . . . . . . 6

3.0 GENERAL DISCUSSION ........................ 15

3.1 IMPORTANT ENGINEERING AND ECONOMIC ITEMS. . . . . . . 15

3.1.1 Study Organizations. . . . . . . . . . . 16

3.1 .2 Sponsors ............... . . 16

3.1.3 Study Date/Year of Pricing . . . . . . . . . 16

3.1 .4 Fuel . . . . . . . . . . . . 18

3.1 .5 Plant size ................ 18

3.1 .6 Seasonal Peak. . . . . . . . . . 19

3.1.7. Plant Site.............. 19

3.1 .8 Load Profile . . . . . . . . . . . . 19

3.1 .9 Capacity Factor. . . . . . . . . . . . . 21

3.1.10 Reference and Alternative Plant Capital Costs. . . . . . 21

3.1.11 Reference and Alternative Plant Operation and

Maintenance Costs. . . . . . . . . . . . 22

3.1.12 Base Plant Fuel Costs. . . . . . . . . . . 22

3.1.13 Fixed Charge Rates ............... 23

3.1.14 Capacity Charge. . . . . . . . . . . . 23

3.1 .15 Energy Charge. . . . . . . . . . . . 24

3.1.16 Auxiliary Capacity Costs ............. 25

3.1.17 Auxiliary Energy Costs . . . . . . . . . . . . 25

3.1.18 Cooling System Operation and Maintenance Costs . . . . 26

3.1.19 Cooling System Capital Costs . . . . . . . . 26

3.1.20 Incremental Power Production Costs . . . . . . . . . 26

3.1.21 Reference Plant Power Production Costs . . . . . . . . 26

3.1 .22 Turbine Steam Conditions .............27 
3.1.23 Turbine Type/Vendor. . . . . . . . . . . . . 27

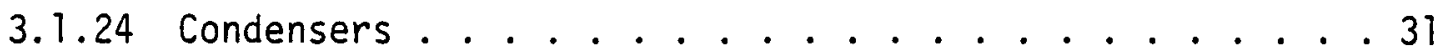

3.1 .25 Cooling System Type. . . . . . . . . . . . 31

3.1 .26 Draft. . . . . . . . . . . . . . . 33

3.1.27 Cooling System Ambient Design Temperature. . . . . . 33

3.1.28 Design Turbine Exhaust Temperature/Pressure. . . . . . 33

3.1.29 Terminal Temperature Difference at Condenser . . . . . 33

3.1.30 Initial Temperature Difference ......... 35

3.1.31 Range, Water............... . 37

3.1 .32 Range, Air . . . . . . . . . . . . 38

3.1 .33 Approach .................. . 38

3.2 TREATMENT OF LOST PERFORMANCE . . . . . . . . . . . 38

3.2.1 Reference or Alternate Plant Load or Demand. . . . . . 39

3.2.2 Maximum Ambient Temperature. . . . . . . . . . . . 41

3.2.3 Constraints on Analysis. . . . . . . . . . . 41

3.2.3.1 Fixed Demand/Fixed Heat Source. . . . . . . . . 42

3.2.3.2 Fixed Demand/Scalable Steam Source/Scalable Plant . . . . . . . . 49

3.2.3.3 Reduced Demand/Fixed Heat Source. ... . . . . . 52

3.2.4 Summary of the Treatment of Lost Performance . . . . 55

4.0 STUDY BASES AND METHODOLOGIES. . . . . . . . . . . . . . 69

4.1 GENERAL COMMENTS. . . . . . . . . . . . . . . 69

4.2 MIT METHUD OF ANALYSIS. . . . . . . . . . . . . 69

4.2.1 Major Assumptions and Constraints. . . . . . . . . 70

4.2.2 Optimization Procedure . . . . . . . . . . . 70

4.2.3 Data and Design Base .............. . . 71

4.3 BECHTEL METHOD OF ANALYSIS. . . . . . . . . . . . . 72

4.3.1 Major Assumptions and Constraints. . . . . . . 72

4.3.2 Optimization Procedure............ . . 73

4.3.3 Data and Design Base............. . . 73

4.4 R. W. BECK AND ASSOCIATES METHOD OF ANALYSIS. . . . . . . 73

4.4.1 Major Assumptions and Constraints. . . . . . . . 74

4.4.2 Optimization Procedure . . . . . . . . . . . 75

4.4.3 Data and Design Base............ . . 76 
4.5 WESTINGHOUSE METHOD OF ANALYSIS. . . . . . . 76

4:5.1 Major Assumptions and Constraints ......... 77

4.5.2 Optimization Procedure. . . . . . . . . . . 77

4.5.3 Data and Deșign Base. . . . . . . . . . . . . 77

4.6 UNITED ENGINEERS METHOD OF ANALYSIS. . . . . . . . . . 77

4.6.1 Major Assumptions and Constraints ......... 78

4.6.2 Optimization Procedure. . . . . . . . . . 78

4.6.3 Data and Design Base............ . . 78

4.7 GILBERT ASSOCIATES METHOD OF ANALYSIS. . . . . . . . . . . 79

4.7.1 Major Assumptions and Constraints . . . . . . . 79

4.7.2 Optimization Procedure. . . . . . . . . . . 79

4.7.3 Data and Design Base. . . . . . . . . . . . 80

5.0 CONCLUSIONS AND RECOMMENDATIONS ................ . . . . . .

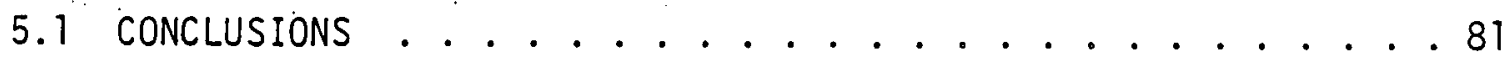

5.2 RECOMMENDATIONS. . . . . . . . . . . 82 REFERENCES ........................ . . . . . . . . . . . . . . 


\section{LIST OF FIGURES}

1 General Dry Cooled Plant Interactions 8

2 Detailed Dry Cooled Plant Interactions 9

3 Direct Dry Cooling System with Mechanical Draft Tower 10

4 Indirect Dry Cooling System with Direct Contact Condenser and Natural Draft Tower

5 Indirect Dry Cooling System with Surface Condenser and Mechanical Draft Tower

6 Heat Rate Versus Rark. Pressure--Fossil Turbines

7 Heat Rate Versus Back Pressurẹ= =Nuclear Turbinas

8 Temperature Relationships for Indirect Dry Cooling Systems

9 Annual Dry Bulb Temperature Duration Curve and Coincident Reference Plant Net Output

10 Typical Annual Performance of a Dry Cooled Plant

11 Relative Performance of a Dry Cooled Plant Utilizing a High Back Pressure Turbine Under the Fixed Demand/Fixed Steam Source Approach

12 Relative Performance of a Dry Cooled Plant Utilizing a Modified Conventional Turbine Under the Fixed Demand/Fixed Steam Source Approach

13 Relative Performance of a Dry Cooled Plant Utilizing a Conventional Turbine Under the Fixed Demand/Fixed Steam Source Approach

14 Relative Performance of a Dry Cooled Plant Utilizing a High Back Pressure lurbine Under the Fixed Demand/Fixed Steam Sourca/Scalable Plant Approach

15 Relative Performance of a Dry Cooled Plant Utilizing a High Back Pressure Turbine Under the Fixed Demand/Scalable Steam Source/Scalable Plant Approach with Maximum Required Scaling

16 Relative Performance of a.Dry Cooled Plant Utilizing a High Back Pressure Turbine Under the Reduced Demand/Fixed Heat Source Approach with Maximum Required Derating

17 United Engineers' Treatment of Lost Performance 56

18 Westinghouse's Treatment of Lost Performance--Approach I 57

19 Gilbert Associates' Treatment of Lost Performance 58

20 R. W. Beck and Associates' Treatment of Lost Performance-Conventional Turbine

21 R. W. Beck and Associates' Treatment of Lost Performance--Modified Conventional Turbine 
22 R. W. Beck and Associates' Treatment of Lost Performance--High Back Pressure Turbine

23 MIT's Treatment of Lost Performance

24 Bechtel's Treatment of Lost Performance

25 Westinghouse's Treatment of Lost Performance--Approach II 66

26a Dry Cooled Plant Output Characteristics

26b Optimized Load to Be Imposed on a Dry Cooled Plant/Gas Turbine Combination

\section{LIST OF TABLES}

1 Summary of Dry Cooling Tower Engineering Economic Studies

2 Treatment of Lost Performance 


\section{A REVIEN AND ASSESSMENT OF ENGINEERING ECONOMIC STUDIES \\ OF DRY COOLED ELECTRICAL GENERATING PLANTS}

\subsection{SUMMARY}

This topical report reviews the major engineering economic studies of dry cooled electrical generating plants conducted in the U.S. between 1970 and 1975. The review was conducted as part of a task on engineering economics of dry cooling under the Energy Research and Development Administration (ERDA) Dry Cooling Tower Program (DCT). The primary deterrent to the use of dry cooling by utilities as an alternate to once through or evaporative cooling is the increased power generation costs associated with dry cooling. A major goal of the ERDA Dry. Cooling Tower Program is to reduce the incremental costs of electrical power generation attributed to dry cooling. This can be accomplished in two ways: 1) reducing the costs of stateof-the-art dry cooling systems which utilize metal finned tubes, and/or 2) developing advanced concepts which have lower costs than current state-ofthe-art systems. The goals of this review were: 1) to collect, compare, and summarize, in narrative, tabular and graphic form, the approaches, assumptions, results, and other distinct features of several major studies on dry cooling engineering economics; and 2) to evaluate the computer codes associated with these economic studies in terms of availability, capability, and relevance to the DCT program.

Economic studies directed toward defining and minimizing the incremental power costs associated with dry cooling have been made by architect engineering firms, vendors of dry cooling and other electrical power generation equipment, academic institutions, and research and development organizations. Only those studies concerned with state-of-the-art metal finned tubes for the all-dry cooling towers were selected for review in this report. The selected studies were conducted by R. W. Beck and Associates, MIT, Bechtel, Westinghouse, United Engineers, and Gilbert Associates. Many other studies have been made but did not differ significantly from the above, or were not limited to all-dry systems employing metal finned tubes. 
The studies presented in this report differ in many respects, including, but not limited to, the following:

- limiting assumptions used to facilitate the analysis;

- treatment of lost performance--capacity and energy penalties, plant and component scaling, reference plant, etc.;

- plant type;

- sites;

- dry cooling system type;

- capital and fuel costs;

- turbine type;

- optimization procedure;

- component and/or component parameters optimized;

- the comprehensiveness of physical and cost modeling;

- optimum plant and cooling system design and operating parameters; and

- resulting increased power generation costs associated with dry cooling.

The following conclusions can be drawn from this study: 1) there is no unified approach to engineering economics analysis of dry cooling; 2) published information has not established that state-of-the-art metal finned tube dry cooling systems offered by the industry have been optimized; 3) coupled effects between economic approaches, underlying assumptions, detailed design and overall system designs are not well defined in many respects; 4) there apparently are no available computer codes which will perform a totally computerized optimization of the major components of a metal finned tube dry cooling system (i.e., optimize detailed design parameters for the tower, condenser, turbine, and piping); 5) there are codes available which will optimize the parameters in certain. major components-assuming that the other major components are of fixed design. 
The review made of the above-mentioned economic studies indicates that it is not clear if state-of-the-art metal finned tube dry cooling systems have been optimized--either in the above studies or by the vendors of dry cooling equipment. Therefore, in the future the DCT Program will conduct an analysis to determine if the metal finned tube dry cooling systems offered by the industry are near optimum. If these dry cooling systems are not currently near optimum, definition of cost effective improvements in design or operation will be made. Once the costs of optimum, or near optimum, metal finned tube dry cooling systems are defined and well understood, they will serve as bases from which to compare the costs of advanced concepts.

The review of the existing engineering economic studies clearly indicates that thorough evaluation of metal finned tubes will require extensive analysis based on a more comprehensive computer model than is currently available. This need is identified in the body of this report. Available computer programs contain some fundamental building blocks which can be used in the development of a more comprehensive model. It appears that advanced concepts such as plastic heat exchangers and fluidized bed heat exchangers can be analyzed in much the same way as metal finned tubes. However, thorough analys is of wet/dry, ammonia, and capacitance systems will require a more complex analysis due to the different physical parameters, physical processes, and costs involved.

Published values of the incremental power production costs assessed to dry cooling have apparently been the major deterrent to the use of dry cooling systems relative to wet systems by utilities. No published study rigorously addresses the problem of interfacing the dry cooled plant with the balance of the utility system in order to both meet system demands and minimize the total system power production costs. Calculation of incremental power production costs has, in most cases, been based on certain arbitrary constraints and certain capacity and energy penalties which do not reflect a rational approach to minimizing power production costs of the combined dry cooled plant and balance of the utility system. Since the resulting capacity and energy penalties have accounted for as much as 
two-thirds of the total incremental power production costs, it is obvious that efforts to reduce the cost of dry cooling must first define what the power production costs of a dry cooled plant would be in an actual utility system. A simplified example of how this might be done is presented within this report. 


\subsection{INTRODUCTION}

\subsection{SCOPE}

This report presents a review of some of the major engineering economic studies of dry cooled electrical generating plants conducted in the U.S. between 1970 and 1975. Several engineering economic studies directed toward defining and minimizing the incremental power costs associated with dry cooling have been made by architect engineering firms, vendors of dry cooling and other electrical.power generation equipment, academic institutions, and research and development organizations. Only those studies addressing state-of-the-art metal finned tubes for all-dry cooling towers are presented in this report. The studies selected for presentation were conducted by R. W. Beck and Associates, (1-4) MIT, (5-7) Bechtel, (8,9*) Westinghouse, (10) United Engineers, (11) and Gilbert Associates. (12) Many other studies have been performed but were not included in this review because of one or more of the following reasons: a) they were not significantly different from the above; b) they did not evaluate strictly all-dry cooling systems employing metal finned tubes; or c) they were not as comprehensive as the above.

\subsection{OBJECTIVE}

This review was conducted a.s part of a task on engineering economics of dry cooling under the ERDA Dry Cooling Tower (DCT) Program. (13) Currently, the primary deterrent to the use of dry cooling by utilities as an alternate to once through or evaporative cooling is the increased power generation costs associated with dry cooling. Two major goals of the ERDA Dry Cooling Tower Program are to identify improvements which will reduce the incremental costs of electrical power generation attributed to dry cooling and to demonstrate the reliability of cooling systems incorporating these improvements. The first goal can be accomplished in two ways: 1) reducing the cost of state-of-the-art dry cooling systems which

* The cooperation of WEST Associates, sponsors of the Bechtel work, in releasing this report $(9)$ for use in this study, is greatly appreciated. 
utilize metal finned tubes, and/or 2) developing advanced concepts which have lower costs than current state-of-the-art systems.

The objective of this review was to: 1) collect, compare, and summarize, in tabular, graphical and narrative form, the approaches, assumptions, results, and other distinct features of several major studies on dry cooling tower engineering economics; and 2) evaluate the computer codes associated with these studies as to their capability, availability, and relevance to the needs of the DCT Program. The information collected during this review has provided part of the basis from which engineering economic studies on cooling systems employing metal tubes and advanced concepts are proceeding under the DCT Program.

The purpose of this report is to present a summary and comparison of several major studies of dry cooling tower engineering economics, thereby providing a vehicle to facilitate a more thorough understanding nf this subject.

\subsection{BACKGROUND}

The subject of dry cooling engineering economics can be extremely complex, depending on the needs and interests of the investigator. For example, at the detailed research level the interest may center around the potential for cost reductions (or increases) in power generation costs due to the addition of turbulence promoters on the finned tubes of a dry cooling tower heat exchanger. On the other hand, the utility or architect engineering firm concerned with the near-term installation of dry cooling has a need for determining the optimum number of predesigned cooling tower modules (currently available from vendors) which will result in minimum power production costs at a particular gengraphical site.

The scope of the DCT Program is not limited to turbulence promoters, or constrained to using available modular state-of-the-art equipment. Identification of dry cooling cost reducing improvements in the cooling system, in the balance of the plant, or in the interface with the utility system is within the scope of the DCT Program. Prerequisite to identifying 
improvements which will reduce the power production costs of dry cooled electrical power plants (and subsequently successfully demonstrating the reliability of the improved cooling system) is a very detailed and comprehensive understanding of the engineering and economic aspects of three interacting levels in the power system. These levels are shown in Figure 1.

The first level involves interactions of the cooling system design and operating parameters and basic cooling system options. The second level involves the interaction of the cooling system and the balance of the plant. The third level involves the interaction of the dry cooled plant with the utility system. The third level is extremely important since the capacity of the dry cooled plant drops with increased ambient air temperature and some means must be included within the utility system to make up the loss in capacity. As documented in the studies reviewed, considerable progress has been made in attempts to describe the interaction of these three levels; however, many detailed aspects, which could be a means of reducing cost, are not well understood, if at all.

In order to give an investigator who is just becoming acquainted with the subject of dry cooling some perspective regarding the complexity of the engineering and economic aspects of dry cooling, figure 2 has been provided. It contains a list of options which include: 1) utility system interface options; 2) balance of plant design and operating options; and 3) cooling system design and operating parameter options, physical arrangements, system types. Schematics of the major types of dry cooling systems are presented in Figures 3,4, and 5. Options in terms of mechanical versus natural draft, forced draft versus induced draft, circular versus rectilinear tower arrangement, horizontal versus vertical versus "A"-frame orientation of heat exchange bundles are interchangeable combinations in most cases:

No published engineering and economic studies provide detailed coverage of all the options presented in Figure 2. In fact, there is no published engineering and economic study which adequately details any one component 


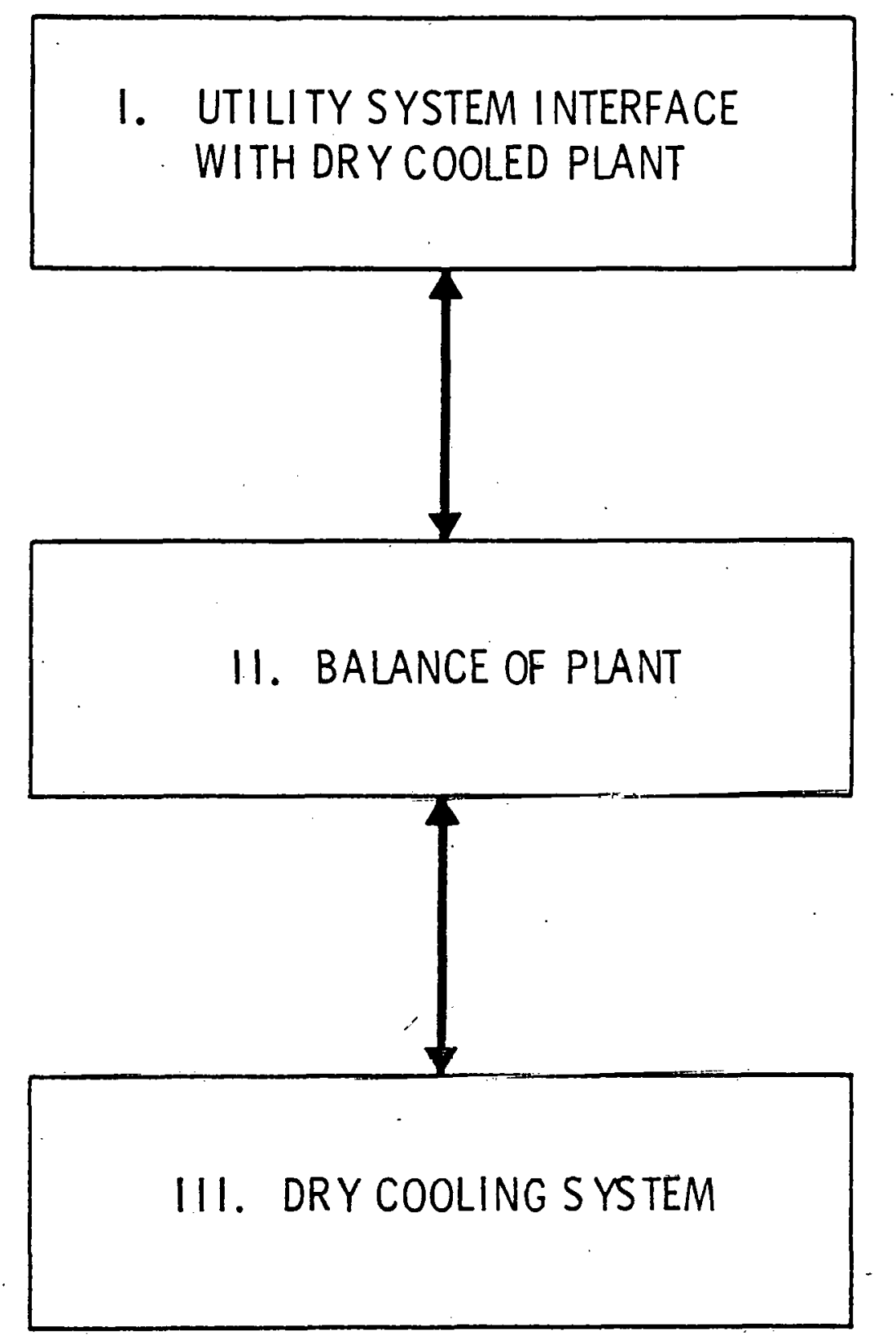

FIGURE 1. General Dry Cooled Plant Interactions 


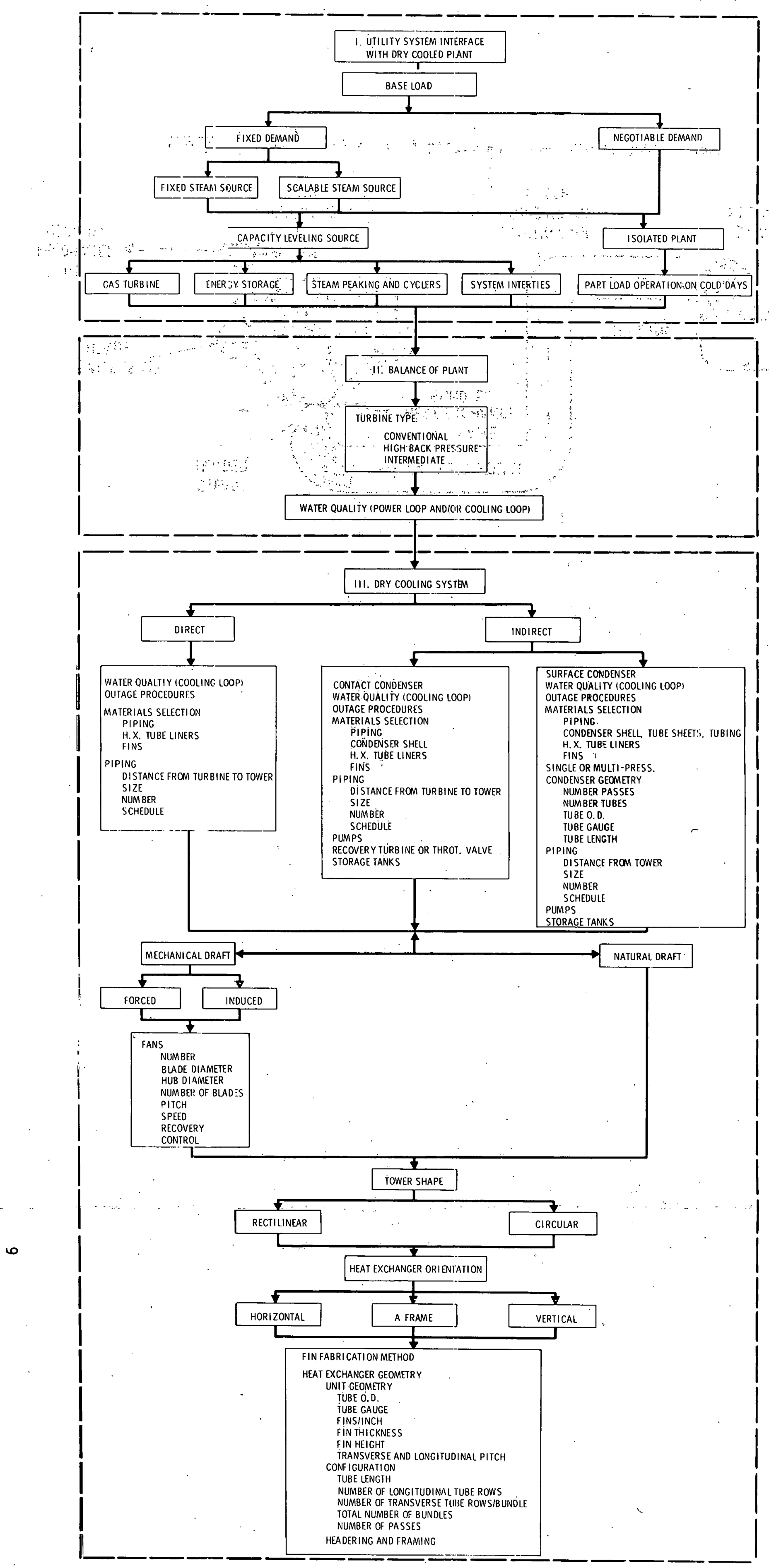




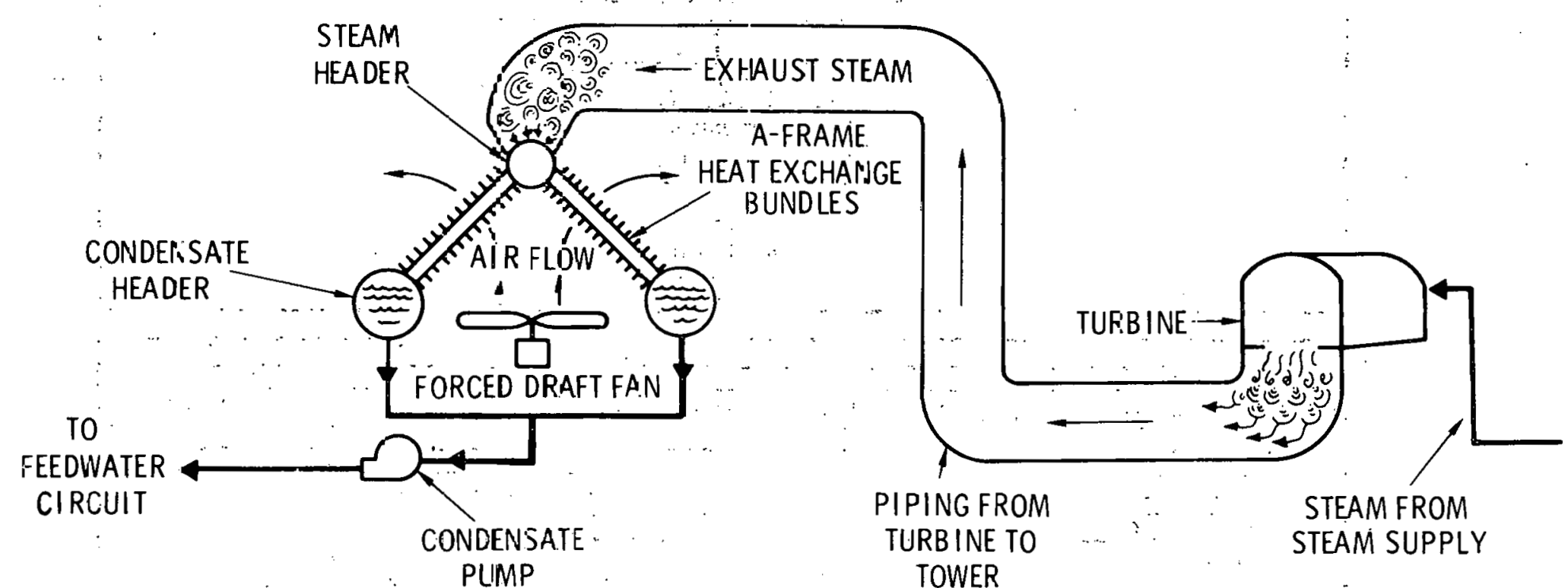

FIGURE 5. Direct [iry Cooling System with Mechanical Craft Tower 


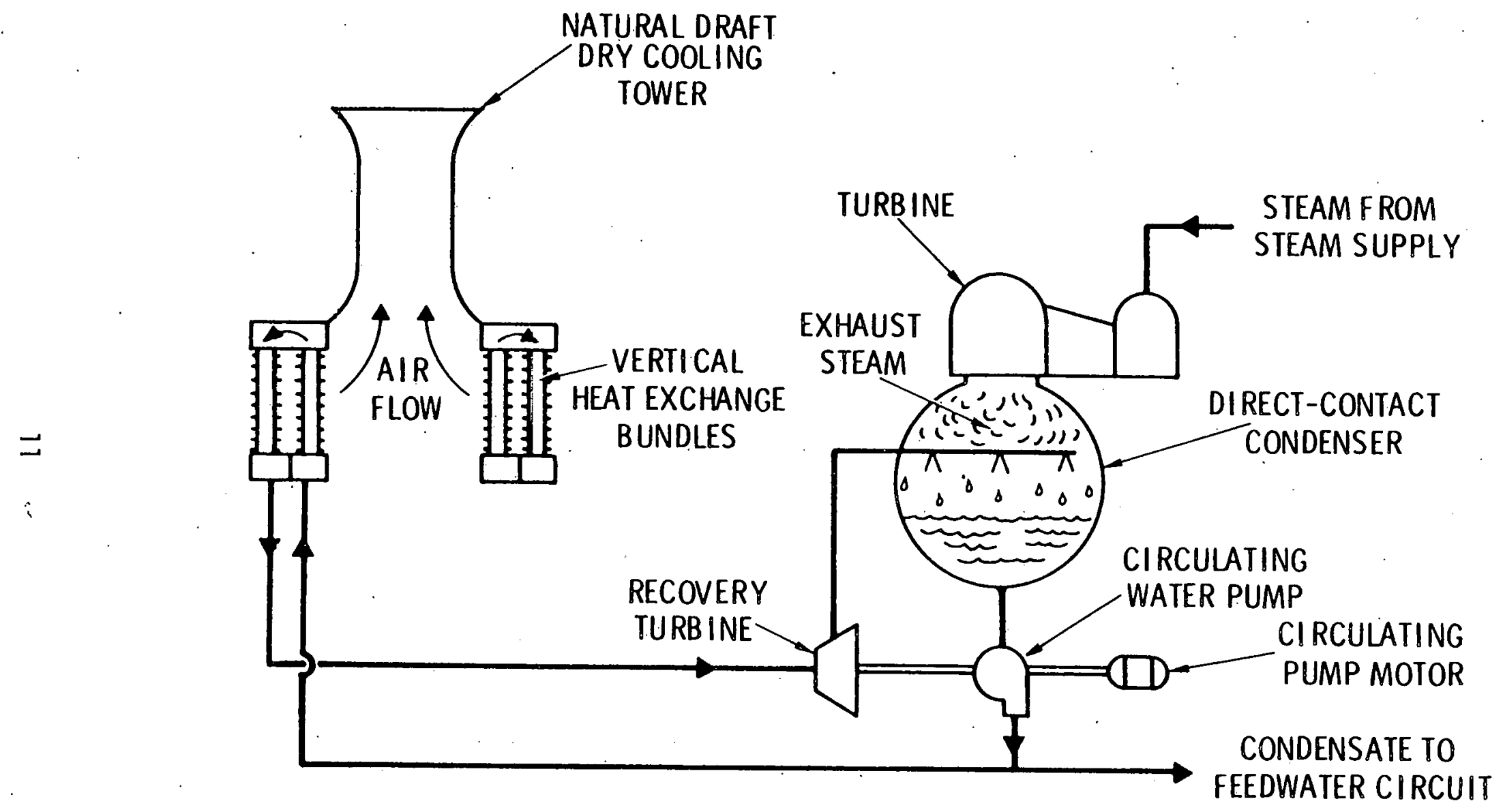

FIGURE 4. Indirect Dry Cooling System with Direct Contact Condenser and Natural Draft Tower 


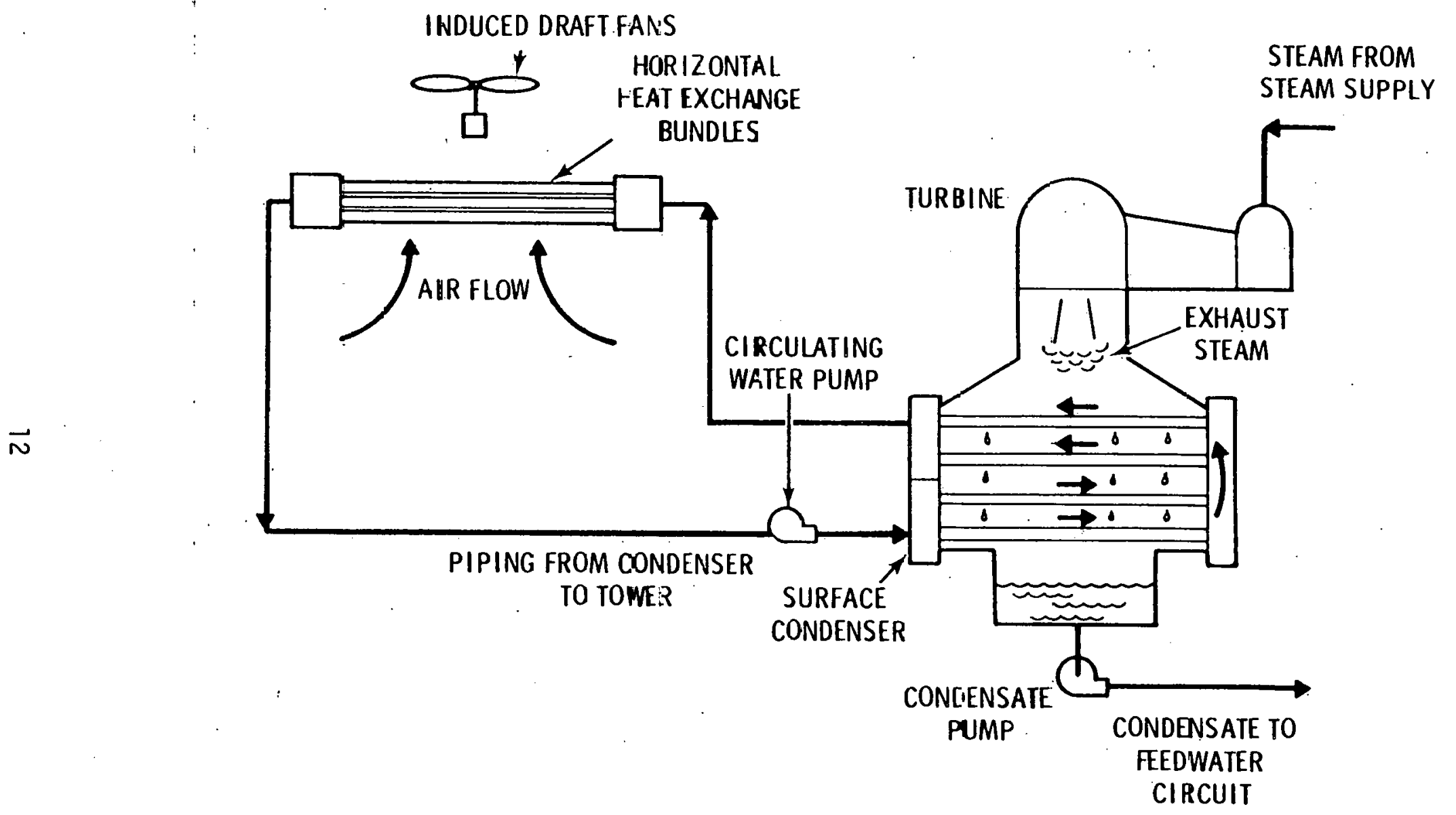

FIGURE 5. Indire:t Dry Cooling System with. Surface Condenser and Mechanical Draft Tower 
and option path of Figure 2 from the utility system, through the balance of the plant, and on through the cooling system. However, the reader may find Figures 1 through 5 useful as "road maps" to delineate the detail to which various investigators have delved, the cooling system options considered, the balance of plant factors evaluated, and the type of utility system interface constraints imposed on the particular studies. 
THIS PAGE

\section{WAS INTENTIONALLY \\ LEFT BLANK}




\subsection{GENERAL DISCUSSION}

\subsection{IMPORTANT ENGINEERING AND ECONOMIC ITEMS}

The engineering and economic studies reviewed herein were, in most cases, conducted to compare dry-cooled plants with wet-cooled plants in terms of increased power generation costs. In all the studies presented, optimization of some plant and cooling system operating parameters and/or general cooling system was conducted. In most of the studies, optimization of the cooling tower details was not done. These studies were for stateof-the-art cooling systems and therefore used vendor data for available cooling tower equipment. Optimization of the number of modules to be used for a particular plant was conducted. In some cases, an additional parameter, water range, was optimized for the available cooling tower modules. In the R. W. Beck and Associates studies, both air and water flow rates per module were optimized for natural draft towers. The most recent R. W. Beck

and Associates report ${ }^{(4)}$ is a user's manual for an updated version of the computer program used in previous studies. In its updated form, the BECKDRY program optimizes fan brake horsepower per mechanical draft module for each combination of tower ITD and water range. No studies have been published based on the updated version of the program.

As mentioned before, there are no published engineering and economic studies which cover in detail all the options presented in Figures 2 through 5. In addition, none of the published engineering and economic studies cover in adequate detail any one component and option train from the utility system, through the balance of the plant, and on through the cooling system as illustrated in Figure 2. However, Westinghouse has conducted detailed proprietary studies using the surface condenser and mechanical draft option train. Because these studies are unpublished, and publicly unavailable, conclusions regarding the detail of the resulting cooling systems cannot be made.

In addition, MIT published the first studies dealing with detailed optimization of the cooling system. This study concentrated on heat 
exchanger configuration and selection of the heat exchanger unit geometry. Limited treatment of the balance of the cooling system, component costs, and the limited evaluation of unit geometries that could be used in dry cooling systems have resulted in conclusions which, in practice, may not be cost effective. However, the MIT study did point out the need to conduct very comprehensive.systems optimization of dry cooling systems employing metal finned tubes or advanced concepts in order to minimize power production costs.

Comparing one study to another is difficult because of differences in sites, year of pricing, components in the cooling systems, and amounts of detail in the cooling system design. In order to make comparisons, the use of tables appeared to be somewhat effective. Many of the factors which can have an important effect (direct or indirect) on any study of the engineerIng and economic aspects of dry cooled generating plants are listed in Table 1. This table contains three types of information: 1) general background; 2) fundamental economics parameters; and 3) design and operating parameters.

These items will be discussed in their order of appearance in Table 1. Some will be discussed in depth because of their particular importance. Others will be touched on only briefly beçause they are self-explanatory.

\section{1 .1 Study Urganizations}

Many different organizations have been involved in studies on dry c001ing. Three types are represented in this review--academia, architect engineering firms, and a power generation equipment vendor.

\section{1 .2 Sponsors}

Dry cooling studies have been sponsored by individual utilities, organized groups of utilities, government agencies, and private industrial organizations who have a vested interest in the cooling industry. Each is represented in this review. 
IABLE 1. Summary of Dry Cooling Tower Engineering Economic Studies

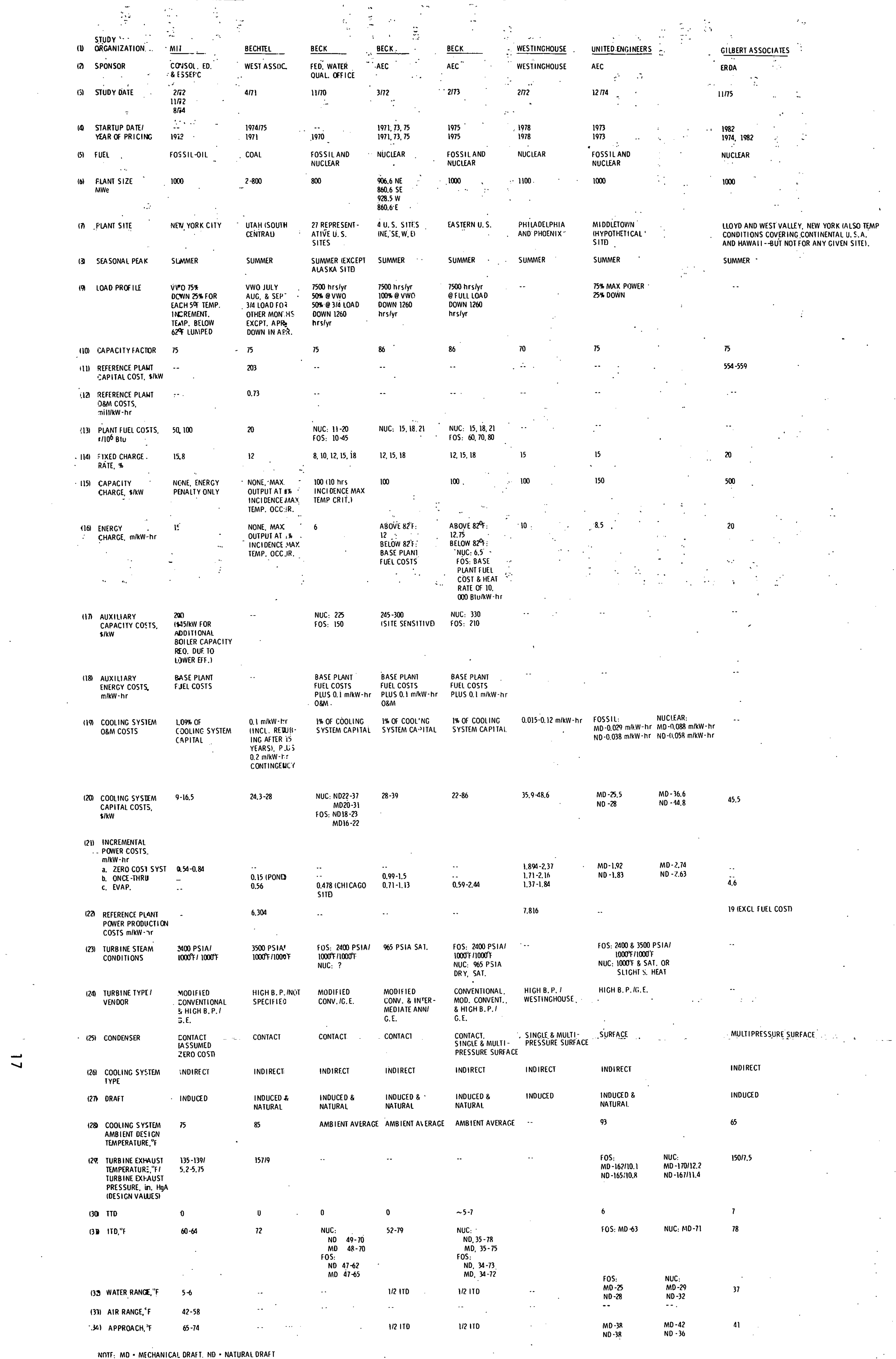




\subsubsection{Study Date/Year of Pricing}

Studies included in this review were made between 1970-75 as a result of considerable interest by utilities, architect and engineering firms, government regulatory bodies, and individual researchers. The year of pricing varied from 1970 to 1982. Comparisons of incremental power production costs assessed to dry cooling from one study to another should not be made without consideration for the year of pricing and its relationship to inflation, interest during construction, and the construction schedule. Fuel, interest, anu equipment costs have not a.ll changed in price at the same rate; therefore, conclusions drawn using one year's pricing may not hold a few years into the future.

\section{1 .4 Fuel}

Dry cooling tower studies have been made for $0 i 1$, coal, and nuclear base-loaded plants. Although oil fired plants (non-dry cooled) are under construction, only one U.S. plant is scheduled to begin operation after 1979. All other base-loaded plants are coal or nuclear after that year. Utilization of dry cooling for coal plants will probably occur first at mine mouth plants in the arid West. The 330 MWe plant. at. Wyorak, Wyoming, is an example. However, studies have been made at other locations for coal plants. The fuel, and therefore type of plant, can impact dry cooling tower studies through plant capital and fuel costs, plant efficiensy or heat rate, and quantity of heat rejected. The extent of the impact depends on the assumptions used in the analysis, as will be discussed further.

\subsubsection{Plant Size}

Study plant size has varled from 800 to 1000 MWe for coal plants, and from 800 to 1100 MWe for nuclear plants. Only eight future coal fired plants. above 900 MWe are planned to the year 1985. Most of the remaining plants. planned for the future are in the 100 to 600 MWe range. $(14,15)$ The majority of nuclear plants to be coming on line in the late 1970's and early 1980's will be in the 1100 to 1300 MWe range. (14) Larger 1 ight water reactor. (LWR) plants will not be constructed until the current Nuclear Regulatory Commission (NRC) limits on thermal power are raised. 
If economies of scale are important and if coal plant sizes where dry cooling may be applied are expected to be typical of the industry, then general studies on dry cooling should consider smaller coal fired plants. On the other hand, the studies on nuclear plants have been within the range of practical application.

\subsubsection{Seasonal Peak}

Output from dry cooled plants goes down as the ambient dry bulb temperature goes up. This can have a major effect on the economics of dry cooling, particularly if the utility system demand peaks during hot weather, since the loss in output from the dry cooled plant must somehow be made up, if it is to be used as a base loaded plant having a constant capacity. Some methods of accomplishing this are shown in Figure 2. With the exception of those in the Pacific Northwest, most U.S. utilities have a summer peaking season. All studies presented were of summer peaking systems, except that of the Alaska site in the R. W. Beck study.

\subsubsection{Plant Site}

Dry cooling studies have been conducted for many different sites. The most comprehensive evaluation, an assessment of 27 sites, was made by $R$. $W$. Beck and Associates. (1) Meteorology and local labor costs are the primary site economic factors that should be considered. The effect of these factors on the cooling system size and some operating parameters has been evaluated. However, their effect on the detailed design of the cooling system has not been investigated adequately.

\subsubsection{Load Profile}

The load profile describes the load imposed on a plant, or the plant output, as an instantaneous function of time. The combined load profiles of all plants in a utility system add up at any given time to match the demand imposed on the utility system. Some factors which can extensively affect the system demand are the wet and dry bulb temperatures, the time of day, the day of the week, and the season of the year. The type of plants, or generation mix, used to meet the demand at any instant of time depends 
on utility system economics which, in turn, depend on many interrelated factors. These include scheduled and unscheduled outages, system demand growth, system capacity growth, technological and regulatory changes, etc.

Most dry cooling studies have been for base loaded plants. Ideally, a utility would operate a base loaded plant at full rated capacity except during scheduled outages when the plant would be down for routine maintenance (and/or refueling in the case of nuclear plants). Ideally then, the base loaded plant's load profile would be made up of either full capacity, or completely down, segments of time. Unscheduled outages and any required system load-following would alter the ideal profile. Hower coastown at the end of core life in nuclear plants would also factor into the actual load profile.

With the exception of the Bechtel study (and possibly the Westinghouse study--details unpublished), the load profile for the dry cooled base loaded plants has been defined in the following way. If the capacity factor is fixed at $70 \%$, then the plant is assumed to be at full load, part load, or completely down, for specified percentages of the year such that the sum equates to a $70 \%$ capacity factor. This is done without regard to the time of day, season of the year, years of operation, or dry bulb temperature. This assumption could result in nonoptimized cooling system designs. A second result could be an underestimation of the incremental costs of dry cooling for summer peaking utility systems. A more rigorous treatment of the load profiles that a dry cooled plant would encounter would eliminate the above uncertainties and add to the credibility of future studies on this subject. (It should be noted that the computer program used in the $R$. $W$. Beck and Associates studies has been updated. (4) In the current version, the load profile is defined by specifying the number of operating hours each month with consideration for scheduled and forced outages. Part lodd uperation on a monthly basis is also considered.) 


\subsubsection{Capacity Factor}

Capacity factor is defined as the power generated over a given reporting period expressed as a percentage of the power that would have been generated had the plant operated at rated capacity during that period. Study capacity factors have ranged from 70 to $86 \%$.

The average capacity factor for all U.S. nuclear plants from beginning of commercial operation until March 1975 was 59\%. The maximum capacity factor for any given plant (over any meaningful period of operation) was $80 \%$, while the minimum was $25 \%$ (16) A recent review of this subject indicates that fossil fuel plants have operated with a capacity factor of $75 \%$; however, this included a 11 fossil plants regardless of type or age. Capacity factors for certain fossil plants at maturity may be considerably higher than $75 \%$. In the future, the new fossil base loaded plants will be coal fired. Recent evidence indicates that, on the average; these coal fired plants have capacity factors similar to the nuclear plants. Plant availability has typically been about $10 \%$ above the average capacity factors. (17) Plant availability is defined here as the percentage of time that the plant is available to produce rated capacity.

Based on the above averages, study values for capacity factor have been too high. However, other evidence indicates that dry cooled plants can have availabilities as high as 80 to $97.5 \%$. (18) since the capacity factor can have a large effect on the absolute and relative costs of dry cooling, additional evaluation of appropriate values to use would appear warranted. of particular-importance would be the relationship between the type of cooling system and the amount of scheduled and unscheduled outage time, or reduction in availability, that could be assessed to that cooling system.

\subsubsection{Reference and Alternative Plant Capital Costs}

One method of defining the relative power production costs of dry cooled plants and wet cooled plants is to establish a reference plant to which both types of plants are first compared. In many studies, this reference plant has been specified as a plant with a zero cost cooling system, employing a conventional turbine which operates at a low, but fixed, back 
pressure throughout the year regardless of changes in ambient temperatures, etc. In other studies, such a reference plant was not specified. A direct comparison between the wet and dry cooled plants was made in this case.

For the purposes of discussion, in this report the reference plant will be defined as above. All wet cooled plants will be defined as "alternative" plants.

The power production costs from an electrical generating plant consist of the plant fixed costs, fuel costs, and operation and maintenance costs. The fixed costs consist of the cost of money, depreciation and interim replacements, insurance, and taxes. Comparing one study result with another and determining the percentage increase in power production costs due to dry cooling requires specification of the above-mentioned costs. These costs also serve as a reference for comparing the amount of cost escalation that has occurred or has been accounted for between studies. Unfortunately, the reference and/or alternative plant capital cost information was excluded from most of the published reports.

\subsubsection{Reference and Alternative Plant Operation and Maintenance Costs}

Operation and maintenance (O\&M) costs appear difficult to define for the plant itself, as well as for the cooling system. Scheduled routine maintenance should be costable in a relatively accurate manner. Unscheduled outages and resulting maintenance can be approached only by some statistical basis. For base loaded plants, this cost on the average, is apparently a small part of the overall power production costs, ${ }^{(19)}$ provided maintenance is routine. Plant component failures resulting in unscheduled outages could result in significant O\&M costs.

\subsubsection{Base Plant Fuel Costs}

Study fuel costs for coal have varied between $\$ 0.1$ and $\$ 0.8 / 10^{6}$ Btu. Values of $\$ 0.50$ to $\$ 1.00 / 10^{6}$ Btu have been used for oil. Nuclear fuel costs have varied from $\$ 0.11$ to $\$ 0.21 / 1.0^{6}$ Btu. The spread reflects inflationary trends and parametric evaluation of the effect of fuel cost. The national average steam coal price for January 1975 was $\$ 0.81 / 10^{6}$ Btu. However, new contracts are in excess of $\$ 1.00 / 10^{6}$ Btu. Nuclear fuel cycle 
costs for 1975 have been estimated at $\$ 0.36$ to $\$ 0.43 / 10^{6}$ Btu. (17) Studies assuming the same size heat source and turbine inlet steam flow for both the reference plant and the dry cooled plant do not require knowledge of fuel prices to define the incremental costs due to dry cooling. For this reason, they are not listed in Table 1 . Studies which incorporate scaling, (i.e., increasing the size of the steam supply system or entire plant to offset lost performance) or reduced turbine steam flow to avoid exceeding back pressure limits must define the plant fuel costs.

\subsubsection{Fixed Charge Rates}

Study fixed charge rates have varied from 8 to 20\%; their effect has been evaluated parametrically. The fixed charge rate can affect the incremental costs of dry cooling through both the absolute magnitude and the percentage increase in power production costs due to changes in cooling system design and operating parameters.

\subsubsection{Capacity Charge}

The capacity penalty is a cost penalty. It is the product of the capacity charge and the difference between the capacity available to the utility system of the reference plant and the dry cooled plant at the specified maximum ambient temperature considered in the study. Study capacity charges varied from zero to $\$ 500 / \mathrm{kWe}$. Most studies used $\$ 100$ to $\$ 150 / \mathrm{kWe}$, which represents making up lost capacity through use of gas turbine generating units. Gas turbine generating units including switchyard, transformers, and installation, are currently in the $\$ 110 / \mathrm{kWe}$ plus range. (20)

In some studies, loss in capacity is partly made up by scaling the plant up. This incurs additional costs which, in general, have been accounted for; however, the label "capacity penalty" has not been associated with this method of making up for lost performance.

The treatment used to account for, or make up for, lost performance is extremely important since as much as two-thirds of the incremental cost of power production assessed to dry cooling is attributable to combined energy and capacity penalties. No studies completed to date have rigorously 
treated the problem of integrating a dry cooled plant into the utility system in a way that minimizes system power production costs. This would undoubtedly vary from utility to utility, but would probably involve one of the options shown in Figure 2. Thorough consideration of this problem in general or specific terms has been lacking. The interactions among cooling system design, operating parameters, and methods for treating lost performance are also not well understood. This matter will be further discussed in Section 3.2.

\subsubsection{Energy Charge}

The energy penalty is a cost penalty. The annual energy penalty is the yearly integrated product of the energy charges and the difference between the energy delivered to the utility system by the reference plant and by the dry cooled plant. Energy charges in the studies presented have varied from zero to $20 \mathrm{mill} \mathrm{s} / \mathrm{kW}-\mathrm{hr}$. If the energy charges were to be assessed unl the basis of simple cycle gas turbine fuel costs, then current values in excess of 24 mills $/ \mathrm{kW}-\mathrm{hr}$ would seem appropriate. This reflects a nominal heat rate of $12,000 \mathrm{Btu} / \mathrm{kW}-\mathrm{hr}(21)$ and recent gas turbine fuel sales at about $\$ 2.20 / 10^{6}$ Btu. $(22)$

For studies assuming the same size heat source for both the reference plant and the dry cooled plant, there can be loss in generating capacily throughout the year (even on the coldest day) depending on both the turbine selected and the capacity of the cooling system. The subsequent difference in the amount of energy generated between the reference plant and the dry cooled plant must be accounted for throughout the year. In studies assuming that the dry cooled plant could be scaled up, a similar energy penalty is assessed during the hot parts of the year; however, during the colder portions of the year the dry cooled plant can generate more energy than the reference plant. This is generally accounted for by backing out (in the costing) the appropriate amount of fuel that would be used to generate this excess, since the electrical energy is assumed not salable and therefore would not be generated.

In the Bechtel study the entire plant was scaled up to meet required demand at the maximum design temperature. In this case excess capacity 
would exist at the plant at any but the maximum design temperature. Additional fuel per kilowatt of output and additional capital costs are incurred and accounted for. However, these were not labeled "energy penalties" and "capability penalties" as such.

The R. W. Beck and Associates latest studies use a two-part energy penal.ty. For lost performance at temperatures below $82^{\circ} \mathrm{F}$, makeup energy from other base loaded plants in the system is assumed available at fuel cost, due to low utility system load. Above $82^{\circ} \mathrm{F}$, the air conditioning load is assumed to significantly increase the utility system load. At this point, the lost energy and capacity must be made up with gas turbines.

Due to the importance of this subject, additional discussion will follow in Section 3.2 on treatment of lost performance.

\subsubsection{Auxiliary Capacity Costs}

In some studies the fans and pumps are assumed to operate at a fixed capacity throughout the plant's annual operation. This therefore represents a base ioad to the utility power system and could be accommodated by a base plant somewhere else in this utility system or by possibly scaling up the dry cooled plant to handle this additional load. The cost for doing this with fossil plants has been taken as $\$ 150$ to $\$ 200 / \mathrm{kWe}$; for nuclear plants, values of $\$ 225$ to $\$ 330 / \mathrm{kWe}$ have been used.

In the R. W. Beck and Associates studies, the dry cooled plant has been scaled up to provide for the maximum auxiliary power requirements. However, the reduction in fan power requirements during cool weather is considered in evaluating auxiliary energy costs.

\subsubsection{Auxiliary Energy Costs}

When the fan and pump power is accommodated as described above, an auxiliary energy cost is assessed to the dry cooled plant which accounts for the fuel and additional operation and maintenance required to provide the energy for the fans and pumps. These costs are the base plant fuel costs, plus operation and maintenance, which have been $0.1 \mathrm{mills} / \mathrm{kW}-\mathrm{hr}$ for the R. W. Beck and Associates studies. 


\subsubsection{Cooling System Operation and Maintenance Costs}

Cooling system O\&M costs have been assessed as annual costs at about $1 \%$ of the cooling system capital costs or on the basis of unit energy costs at 0.04 to $0.1 \mathrm{mill} / \mathrm{s} / \mathrm{kW}-\mathrm{hr}$. Routine anticipated 0\&M costs would appear to be relatively easy to define. However, the actual total 0\&M costs would appear difficult to define exactly until several years of widespread use of dry cooling had been logged.

\subsubsection{Cooling System Capital Costs}

Study cooling system capital costs have variad from $\$ 9$ to $\$ 86 / \mathrm{kWe}$. These are optimized costs. This variation reflects a wide range in year of pricing, cooling system options, turbine types, utility interface options, geographical locations, level of study detail, study methodology, and cost data. Although the actual capital cost of the cooling system represents only a part of the total costs which can be assessed to dry cooling, it is an important factor in the tradeoff of a 11 cost components to arrive at the optimum cost effective system.

\section{1.20 Incremental Power Production Costs}

Incremental power production costs are the additional costs incurred to produce power when dry cooling is used in comparison to some reference plant, or alternative plant as defined in Section 3.1.10. For comparisons to zero cost cooling system plants, the incremental costs have varied from 0.54 to $2.74 \mathrm{mills} / \mathrm{kW}-\mathrm{hr}$. For comparisons to once through cooling system plants, the incremental costs have varied from 0.99 to $2.16 \mathrm{mi} 11 \mathrm{~s} / \mathrm{kW}-\mathrm{hr}$. For comparisons to evaporative towers, the incremental costs have varied from 0.478 to $4.6 \mathrm{mi} 77 \mathrm{~s} / \mathrm{kW}-\mathrm{hr}$. This spread in incremental power production costs reflects the many factors, approaches, and assumptions considered by various investigators in attempts to both define and minimize incremental power production costs.

\subsubsection{Reference Plant Power Production Costs}

The electric energy customer and the utility are interested in both the absolute increase in power production costs and the percentage increases. 
The reference power production cost is a basis for determining the percentage increases. Reference power production costs have varied from 6:304 to $7.816 \mathrm{mills} / \mathrm{kW}-\mathrm{hr}$ where all costs have been included. The recent Gilbert Associates report gives power production costs (excluding fuel costs) at $19 \mathrm{mills} / \mathrm{kW}-\mathrm{hr}$. (12)

\subsubsection{Turbine Steam Conditions}

There are three areas to consider in attacking the waste heat management problem: the source, the sink, and the conversion device. Increasing the availability of steam energy at the turbine inlet can result in higher plant efficiency and, therefore, less heat rejected per kWe generated. Efforts to accomplish this with fossil plants have not been fully successful; the result has been a decreasing percentage of new plants in the supercritical range planned for future expansion. LWR nuclear plants, on the other hand, are limited by certain regulations on the thermal aspects of the plants and, therefore, their efficiency and heat rejected per kWe is fixed pending regulatory changes. Studies of dry cooling have been made for High Temperature Gas Reactors (HTGRS); 11,12$)$ however, their development in this country has recently been seriously crippled and the marketing effort stopped. The values used for fossil and LWR turbine inlet steam conditions are apparently typical of those the power industry will see for several years to come.

\subsubsection{Turbine Type/Vendor}

Four basic turbine types have been discussed for both fossil fuel and nuclear plants in the studies reviewed. These are: 1) the conventional turbine; 2) the modified conventional turbine; 3) the high back pressure turbine (referred to as an "intermediate annulus" turbine in some reports); and 4) an ultra-high back pressure turbine. Normalized heat rate performance of these four basic types as a function of back pressure is shown in Figures 6 and $\%$. These curves were adapted from Reference 23 and are presented for illustrative purposes only. The reader should consult the turbine vendors for actual data. 


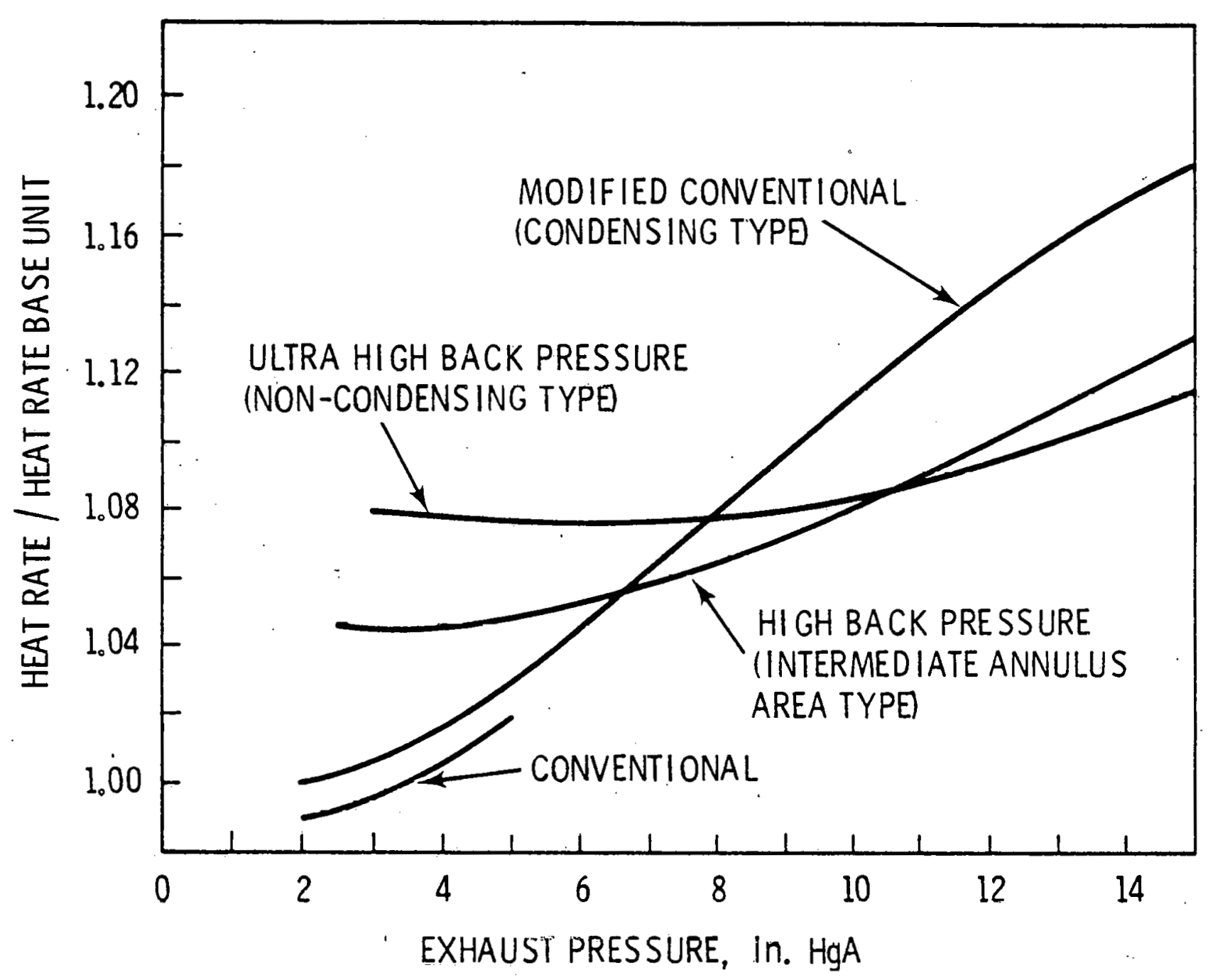

FIGURE 6. Heat Rate Versus Back Pressure--Fossil Turbines 


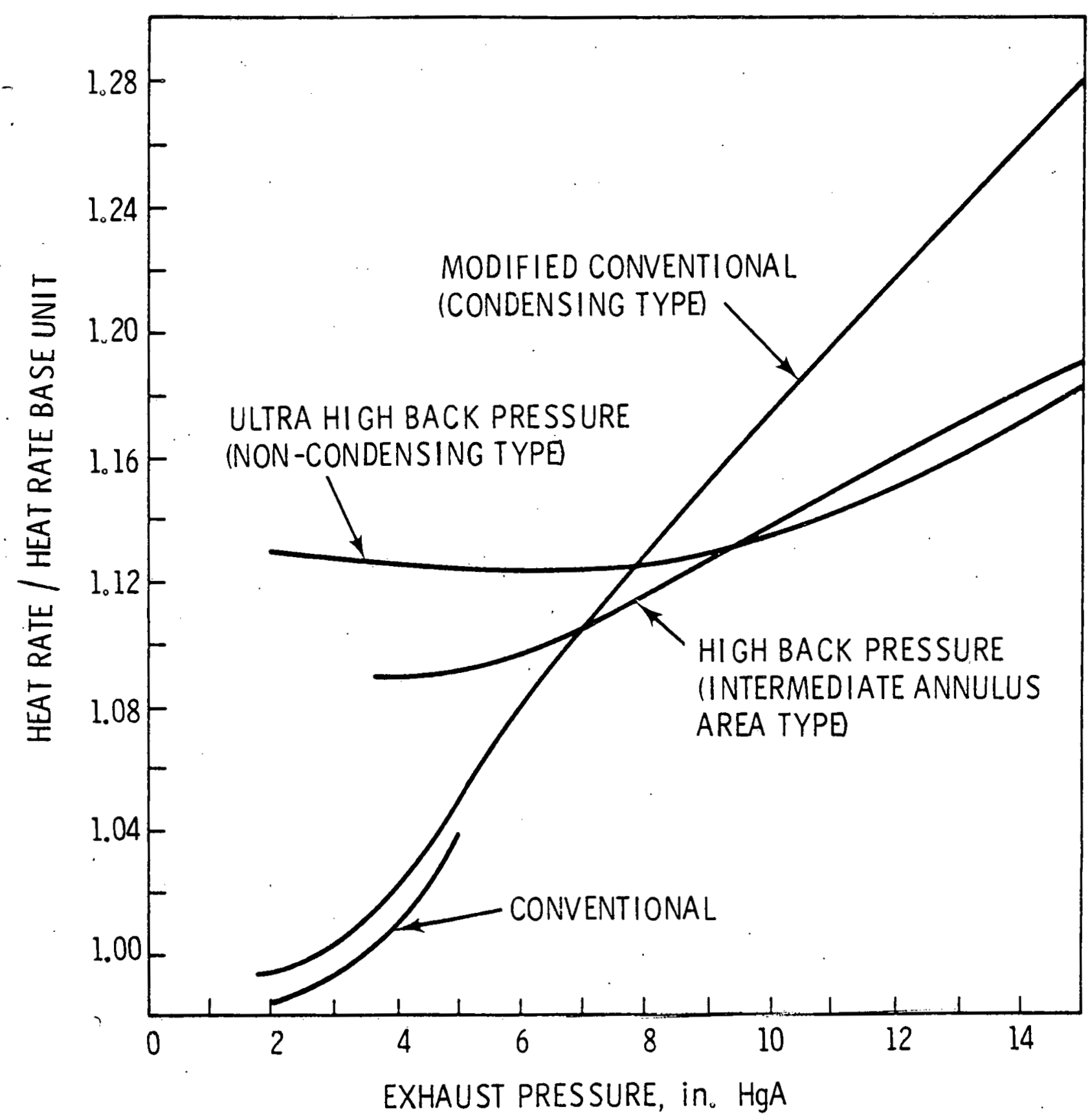

FIGURE 7. Heat Rate Versus Back Pressure--Nuclear Turbines 
The conventional turbines are those which would typically be used in a once through or evaporative cooled plant. Back pressure is typicalty 1 imited to 5 to $6 \mathrm{in}$. $\mathrm{HgA}$ depending on the manufacturer.

The modified conventional turbine is assumed to be capable of operation over a wide range of back pressures, i.e., 2 to $14 \mathrm{in.} \mathrm{HgA}$. It is characterized by a $1 \%$ higher heat rate than the conventional turbine at the rating condition of the conventional turbine (usually specified as 3.5 in. $\mathrm{HgA}$ and $3 \%$ makeup by G.E., Westinghouse, and Allis-Chalmers). It was termed. "condensing type" in some studies and some G.E. 11terature. The "rating back pressure" and percentage of makeup are specifications required to establish pricing of turbines on a $\$ / k$ We basis.

The high back pressure turbine illustrated in Figures 6 and 7 was termed an "intermediate annulus" turbine in an original G.E. publication on the subject and the term was used in some subsequent $R$. W. Beck and Associates reports. $(1,2)$ Presumably it was so-called since its performance characteristics and low pressure discharge annulus size were between those of the modified conventional turbine and the ultra-high back pressure machine.

The ultra-high back pressure turbine illustrated in Figures 6 and 7 was originally termed "noncondensing" in the G.E. literature. It was termed "high back pressure" in the early R. W. Beck and Associates reports. Tur= bines with characteristics between those $i 11$ ustrated in Figures 6 and 7 have been investigated by Bechtel and Westinghouse in their studies.

Only two machines are currently being marketed in the U.S. They are the conventional màchines for bolh fussil and nuclear plants offored by all steam turbine vendors and the high back pressure turbine (i.e., intermediate annulus) for foss11 plants iurperiliy offered by C.E. The high back pressure turbine offered by G.E. has a rating condition of $8 \mathrm{in}$. HgA and $3 \%$ makeup. The G.E. turbine is suitable for operation at exhaust pressures up to $15 \mathrm{in}$. $\mathrm{Hg} \Lambda$. This type of turhine will be installed in the dry cooled plant at Wyodak, Wyoming. (24) Recent discussions with Westinghouse personnel ( 25$)$ and a published announcement ${ }^{(26)}$ indicate they expect to market a modified 
conventional type turbine with capability to accommodate up to $8 \mathrm{in}$. HgA for a limited number of hours for 1976-77 shipments. These units have $1800 \mathrm{rpm}$ LP elements and would be suitable for nuclear plants or very large fossil plants (1000 to 1100 MWe range). Correspondence with Allis-Chalmers indicated that permission can be obtained to operate their conventional units at

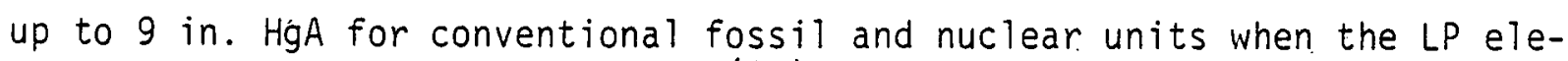
ments have been properly modified. (27)

The turbine picture is ever-changing. Since it is a key interface component to dry cooling systems, continued appraisal must be made to define the most economic dry cooling system. The modified conventional machine (back pressure capability of 2 to $14 \mathrm{in}$. $\mathrm{HgA}$ ) initially presented in the G.E. literature ${ }^{(23)}$ was then termed "hypothetical" and at this date essentially remains as such. It seems improbable that a modified conventional type turbine in the 1000 MWe size can be built to operate over that large a swing in back pressure. This is because of the resulting swing in the LP stage exit Mach numbers and the ensuing off-design aerodynamics which become a potential source of severe mechanical damage. Evaluation of dry cooled plants based on modified conventional type turbines such as the proposed Westinghouse turbine which can operate at up to 8 or 9 in. HgA have not appeared in the literature.

Most steam turbines installed in the U.S. are built by G.E. or Westinghouse. The balance are supplied by All is-Chalmers, Brown Boveri, DeLaval, MAN, and Turbodyne.

\section{1 .24 Condensers}

Three types of condensers have been considered for the indirect systems examined in the studies reviewed. They are contact condensers, single pressure surface condensers, and multipressure condensers. The most recent studies on dry cooling have considered only the surface condenser. The latest R. W. Beck and Associates study focused primarily on an economic comparison of the use of contact versus surface condensers. (3) This study indicated that there was little economic incentive to use contact condensers in place of surface condensers. Contact condensers also seem to have 
additional operational problems associated with deareation and water quality control. Their use in nuclear plants is highly questionable from a safety standpoint; however, their use apparently has not been rigorously addressed in the literature or by the Nuclear Regulatory Commission.

There are no large contact condenser installations in U.S. nuclear and fossil generating plants. In view of the lack of operating experience and the uncertainty associated with the economic and technical aspects of contact condensers, there appears to be little incentive for further investigation.

Thorough evaluation of cost savings in the surface condenser through selection of inexpensive condenser tube materials is a possible means of enhancing the position of surface condensers in comparison to contact condensers. This type of study has not been found in the literature.

\subsubsection{Cooling System Type}

There are two basic types of cooling systems, direct and indirect. These are shown in Figures 2 to 5 . A 11 studies were based on indirect systems for plants in the 800 to 1100 MWe size. Qualitative judgments appear to have been made in many cases, eliminating quancitative evaluation of direct. systems, Statements abounding in the literature to the effect that direct systems are not applicablc to plants over 200 Mwe appear to be the basis for these judgments. The requirement for lar'ge stealn ducts has been the basis for these statements. However, the 330 MWe dry cooled plant at Wyodak, Wyoming will use the direct cooling system. 'Two steam. ducts 13.5 feet in diameter are required for this plant. ${ }^{(24)}$ As previously pointed uul, iliust fossil plants are in the 100 to 600 MWe range. Perhaps the decision to discard direct systems as a study option has been somewhat premature, especially for coal fired plants.

In the case of nuclear plants, the direct condensing system has safety problems similar to indirect systems which use a contact condenser. As previously stated, this subject apparently has not been rigorously addressed in the literature or by the Nuclear Regulatory Commission. 


\section{1 .26 Draft}

The studies reviewed have evaluated both mechanical and natural draft. Only induced draft mechanical systems have been considered. Cost differences between the mechanical and natural draft systems have not been large. There could be cost tradeoffs between forced and induced draft fan systems, particularly as they relate to tower support structure. This subject has not been treated adequately in the literature.

\subsubsection{Cooling System Ambient Design Temperature}

The cooling system ambient design temperature is a rather arbitrary parameter. Primarily it serves as a base temperature from which to define other "design" parameters. In actual operation a dry cooling tower is at the "design" operating conditions for only a small number of hours a year. The remainder of the year the tower is at values above or below as it responds to the ambient dry bulb fluctuations. It is mentioned here only to guard the reader against its misinterpretation. The reader should consult each study regarding the definition of the ambient design temperature and its implications. The ambient design temperature $\left(T_{A}\right)$ and six other important design temperatures which will now be discussed are illustrated in Figure 8.

\subsubsection{Design Turbine Exhaust Temperature/Pressure}

The design turbine exhaust temperature (see figure 8 ) and pressure simply reflect the exhaust conditions that would be present for the given design ambient dry bulb temperature and the cooling system initial temperature difference (ITD) and terminal temperature difference (TTD). It in no way defines either the maximum or minimum back pressure that the turbines will see. It is presented here primarily to clarify that particular point. In some studies, the design turbine exhaust pressure is used as a basis for determining a nominal heat load for the dry tower.

\subsubsection{Terminal Temperature Difference at Condenser}

The terminal temperature difference (TTD) is the difference between the turbine exhaust saturation temperature $\left(T_{\text {sat }}\right)$ and the hot water leaving the 


\section{TSAT - TURBINE EXHAUST TEMPERATURE}

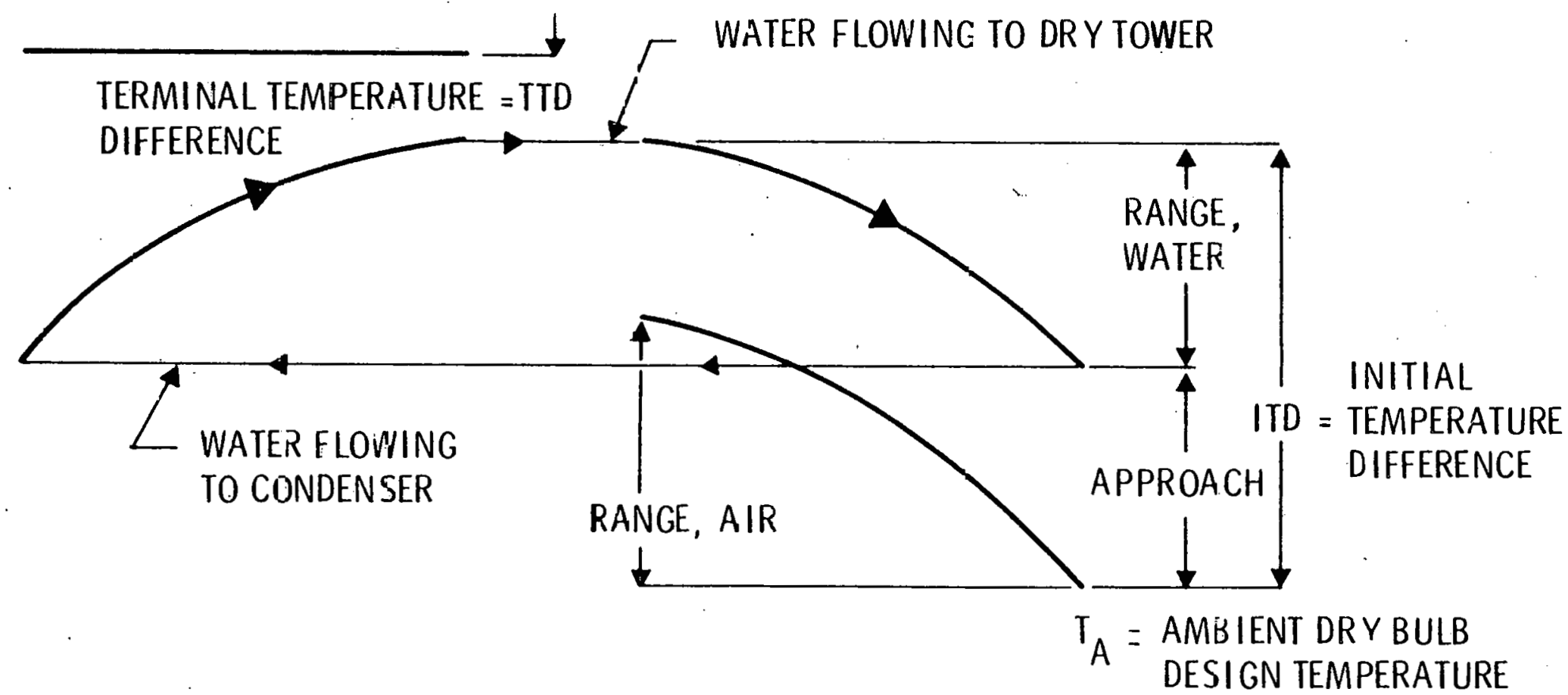

FICURE 8. Temperature ReTationships for Indirect Dry Cooling Systems 
condenser (see Figure 8). For the contact condenser, published values of TTD have been zero. In actual operation it may approach values similar to the surface condenser depending on the design and the deareation. For the surface condenser the values have been both fixed (values of 6 and $7^{\circ} \mathrm{F}$ have been used) and optimized. Optimized values presented have been in the range of 5 to $7^{\circ} \mathrm{F}$. A lower 1 imit of $5^{\circ} \mathrm{F}$ has been set by the Heat Exchange Institute standards. (28)

\subsubsection{Initial Temperature Difference}

The initial temperature difference (see Figure 8 ) is one of the most important parameters in engineering and economic discussions of dry cooling. Certain economic and physical constraints 1 imit ITD values. These will now be discussed.

For a given mechanical tower with fixed total water and air mass flow rates, the heat rejection capability is linearly related to the ITD, neglecting physical property changes with temperature. Using this as a base, and fixing the amount of heat rejection required, two or more towers of similar design (same heat exchange configuration and air and water mass fiuxes) can be compared on a size basis simply by comparing the ITDs for the given heat rejection. Here the ITD would be inversely proportional to size.

ITD is also a value which can be used to determine the maximum back pressure on the hottest day employing the following simple relations:

$$
\begin{aligned}
P_{\text {sat }} & =e^{A+\frac{B}{T}} \text { sat } \\
T_{\text {sat }} & =T T D+I T D+T_{\text {ambient }} \\
I T D & =Q / C \\
Q & =f\left(T_{\text {sat }}\right)
\end{aligned}
$$

where

$$
P_{\text {sat }}=\text { Turbine exhaust saturation pressure }
$$


$T_{\text {sat }}=$ Turbine exhaust saturation temperature

$A, B=$ Constants defining the pressure/temperature saturation relation

TTD = Terminal temperature difference of condenser (see Figure 8)

ITD = Initial temperature difference (see Figure 8)

$T_{\text {ambient }}=$ Ambient dry butb temperature

$Q=$ Cooling tower heat rejection rate

$f\left(T_{\text {sat }}\right)=$ Function expressing rate of heat rejection at turbine exhaust as a function of the saturation temperature

Since $Q$ is a function of $T_{\text {sat }}$, an iterative solution is required. However, since $Q$ is a rather weak function of $T_{\text {sat }}$, an approximate estimate of $T_{\text {sat }}$ can be obtained by assuming $Q$ to be constant, using the design value for ITD and calculating $T_{\text {sat }}$ and, subsequently, $P_{\text {sat }}$.

Limits on tower size can also be established by employing the above expression. Consider the examples which follow.

For a geographical site where the maximum ambient temperature is $100^{\circ} \mathrm{F}$, if a conventional turbine 1 imited to $5 \mathrm{in}$. HgA back pressure were to be used and run at full load on the hottest day, then the maximum design ITD fur the tower would be limited to:

$$
\begin{aligned}
\text { ITD } & \leq T_{\text {sat }}-\text { TTD }-T_{\text {ambient }} \\
\text { ITD } & \leq T_{\text {sat }}\left(P_{\text {sat }}=5 \mathrm{in.} \mathrm{HgA}\right)-\text { TTD }\left(\text { assume } 5^{\circ} \mathrm{F}\right)-T_{\text {ambient }}\left(100^{\circ} \mathrm{F}\right) \\
& \leq 134-5-100 \\
& \leq 29^{\prime \prime} \mathrm{F} .
\end{aligned}
$$

If a high back pressure turbine were to be used, then performance does not increase significantly at back pressures less than 8 in. HgA. Hence, in this case, economics would probably limit the minimum design ITD to: 


$$
\begin{aligned}
\text { ITD } & \geq T_{\text {sat }}-\text { TTD }-T_{\text {ambient }} \\
\text { ITD } & \geq T_{\text {sat }}\left(P_{\text {sat }}=8 \mathrm{in.} \mathrm{HgA}\right)-\text { TTD }\left(\text { assume } 5^{\circ} \mathrm{F}\right)-T_{\text {ambient }}\left(100^{\circ} \mathrm{F}\right) \\
& \geq 152-5-100 \\
& \geq 47^{\circ} \mathrm{F} .
\end{aligned}
$$

On the other hand, the upper limit on back pressure must not be exceeded. Hence, in addition to the lower limit, an upper limit for the high back pressure turbine could be calculated as follows:

$$
\begin{aligned}
\text { ITD } & \leq T_{\text {sat }}-\text { TTD }-T_{\text {ambient }} \\
\text { ITD } & \left.\leq T_{\text {sat }}\left(P_{\text {sat }}=15 \mathrm{in.} \mathrm{HgA}\right)-\text { TTD (assume } 5^{\circ} \mathrm{F}\right)-T_{\text {ambient }}\left(100^{\circ} \mathrm{F}\right) \\
& \leq 179-5-100 \\
& \leq 74^{\circ} \mathrm{F} .
\end{aligned}
$$

Although the range of expected values depends on the maximum ambient temperature considered, the turbines selected, whether or not part load operation is an optional possibility, and the type of condenser used (affecting assumptions on TTD), these examples do indicate that study ITDs will probably not be much less than about $29^{\circ} \mathrm{F}$, nor much greater than about $74^{\circ} \mathrm{F}$ in most locations in the U.S.

For all studies reviewed; the optimized values for all parameters considered ranged between $34^{\circ} \mathrm{F}$ and $78^{\circ} \mathrm{F}$, reflecting a wide range of condensers, turbines, part load operation, site meleorology, and economic factors.

\subsubsection{Range, Water}

The change in water temperature across the condenser is the same as across the dry tower (Figure 8). This parameter reflects a tradeoff between condenser size and desigri, tower size and design, and the piping system. In most studies reviewed, values of range varied from about 0.4 to 0.5 ITD. In the MIT study the range varied from 0.07 to 0.09 ITD. The MIT study did not include a comprehensive treatment of the tradeoffs between tower, condenser, and piping. The other studies have not, however, provided documentation 
supporting the selection of their values. Since this is a major operating parameter affecting the design of the entire cooling system, further treatment of this area seems warranted.

\subsubsection{Range, Air}

The change in air temperature across the heat exchanger is a major parameter in the design of the heat exchanger (Figure 8 ). This parameter is given as $42^{\circ} \mathrm{F}$ to $55^{\circ} \mathrm{F}$ in some of the optimized designs considered in the

MIT studies. Values were not given in the other reports published. Further treatment of this area also seems warranted.

\subsubsection{Approach}

Approach is the difference between lie ITO arid the water range. It is presented in Table 1 as a matter of convenience for those readers who think in terms of "approach" as a basis for comparing one system against another.

\subsection{TREATMENT OF LOST PERFORMANCE}

Studies on dry cooling have been directed toward base loaded plants. Ideally, utilities would like to be able to operate base loaded plants at constant maximum power output except for scheduled outages, as discussed in Section 3.1.8, without regard to changes in the environment. Once through cooled plants can produce essentially constant maximum output since there are relatively small swings in the temperature of the water bodies used for cooling. Evaporative cooled plants can approximate the constant output characteristic except for combinations of high dry and wet bulb temperatures. Dry cooled plants, on the other hand, can be highly sensitive to the ambient dry bulb temperature with output dropping off sharply at high temperatures.

To account for this difference or loss in performance, several methods have been used and will be discussed in the following sections. Four major items useful in attempting to describe the different methods are: 
1. the definition of the reference plant and/or alternative plant load;

2. the maximum dry bulb temperature considered;

3. the constraints to the analytic method in terms of a) demand or load placed on the dry cooled plant; b) the scaling of the plant steam supply system; and c) scaling of the entire plant;

4. the magnitude of the capacity and energy penalties.

These have been tabulated in Table 2 and will now be discussed in turn, except for item (4). The capacity and energy penalties have already been discussed in Sections 3.1.14 and 3.1.15.

\subsubsection{Reference or Alternate Plant Load or Demand}

The reference or alternate plant load or demand is defined at some point in the studies reviewed to account for the difference in performance and resulting power production costs between the reference or alternate plant and the dry.cooled plant. In most studies reviewed, the reference plant is considered to be an idealized plant with a fixed size heat source, employing a conventional turbine and a zero cost cooling system. The reference plant load or demand becomes the conventional turbine constant output at some specified back pressure. The small losses in performance that once through cooled plants incur during high water temperature, or somewhat larger losses that evaporative plants incur during combined high wet bulb/dry bulb temperatures can be referenced to a plant with the zero cost cooling system just as can the dry cooled plant. Comparisons of wet plants to dry plants can subsequently be made.

As discussed in Section 3.1.10, in some studies reviewed reference plants were not defined as discussed above. Rather, a direct comparison was made to once through or evaporative cooled plants. For example, in some of the R. W. Beck and Associates studies $(2,3)$ the demand was defined as the power output of an "alternate" once through or evaporative cooled plant with a conventional turbine. The power output was defined or fixed for each ambient temperature condition considered over the year. 
TABLE 2. Treatment of Lost Performance

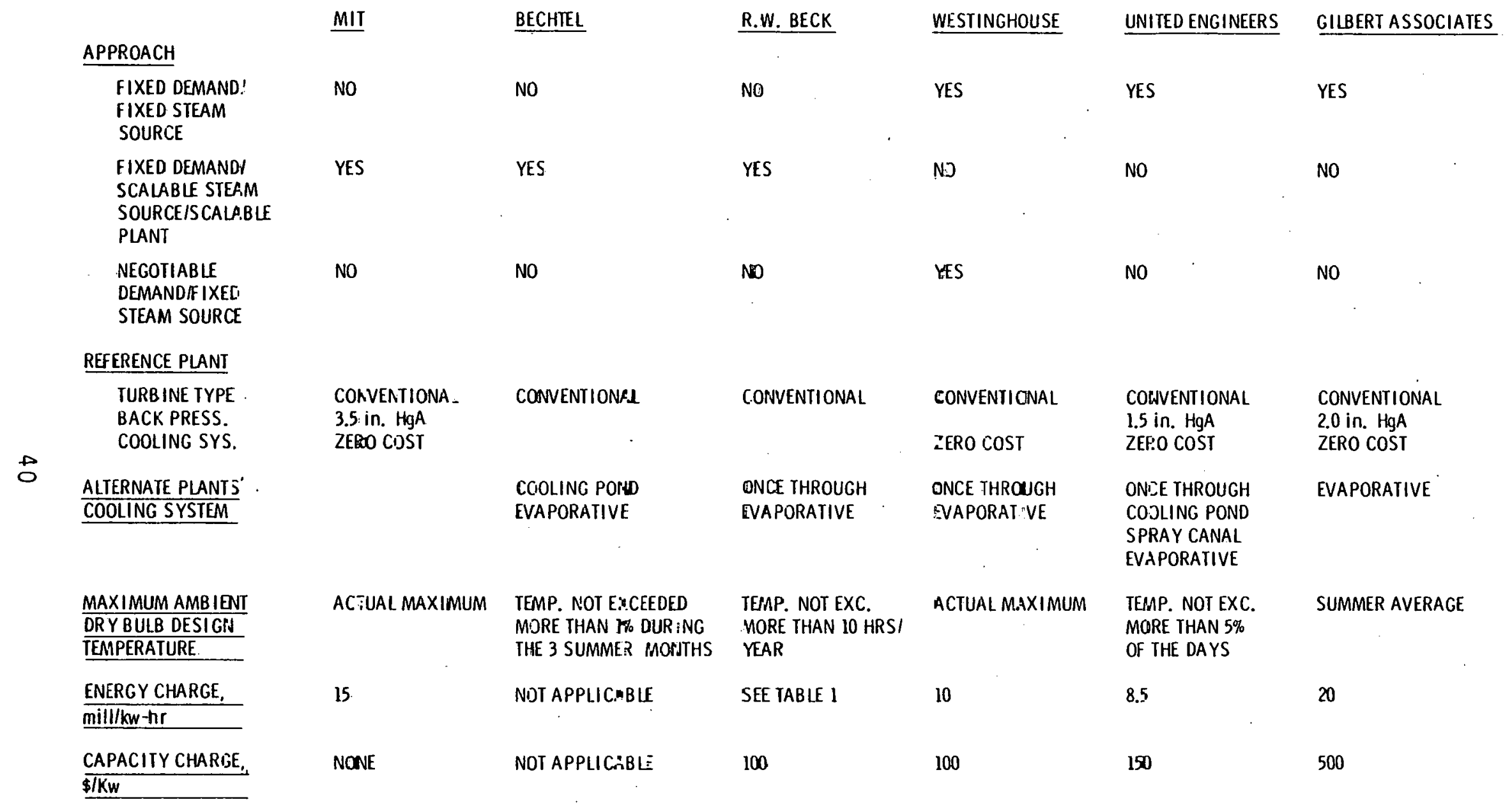




\subsubsection{Maximum Ambient Temperature}

Since most utility systems in the U.S. currently have summer peaks, and since the performance of the dry cooled plant can be significantly reduced during high ambient dry bulb temperatures, the maximum ambient operating. temperature the dry cooled plant will experience is extremely important, particularly in regard to capability penalties.

In the studies reviewed, the ambient dry bulb temperature at which capability penalties were evaluated varied from the actual maximum to the summer average. Other specific criteria included the following: 1) the temperature that was not exceeded more than $1 \%$ during the three summer months; 2) the temperature that was not exceeded on more than $5 \%$ of the days; 3) the temperature that was not exceeded more than 10 hours of the year. In the studies reviewed, the maximum design temperature selected ranged from $66^{\circ} \mathrm{F}$ to $116^{\circ} \mathrm{F}$ reflecting the above criteria and different sites. Certainly no common procedure exists in defining this parameter.

\subsubsection{Constraints on Analysis}

Engineering economic studies of dry cooled plants must eventually establish a basis from which to account for lost performance. Hence, the demand or load to be imposed on the dry cooled plant, and on other utjlity system plants (peaking, cycling, base, or otherwise) which will make up for the loss in capacity of the dry-cooled plant on hot days, must somehow be set. In most published studies, the demand has been rather arbitrarily fixed at a constant value as the power sutput of the reference plant operating with a conventional turbine of specified capacity at a fixed back pressure. In a few studies, however, the demand has been fixed as the output of a once through or evaporative cooled plant. For a once through cooled plant, the demand would be nearly constant. For an evaporative cooled plant, the demand would decrease during periods of increased wet and dry bulb temperatures. (In this report, wet cooled plants are termed "alternate" plants. See section 3.1.10 for a brief discussion of this terminology.) This apriori setting of the demand or load to be imposed is 
hereafter referred to as "fixed demand" in contrast to a different method, "reduced demand," to be discussed later.

Once the demand has been established, the next step is to decide how to meet that demand (on paper, in a hypothetical way in order to make cost comparisons, or on a rational basis directed toward actually minimizing the power production costs of the utility system). Four methods have been pursued and, together with the demand, will now be discussed. The discussion will be supplemented with some illustrations. Figure 9 is the base illustration to which additional information will be added as the discussion proceeds. Two curves are presented in Figure 9. The lower curve is an annual dry bulb temperature duration curve somewhat typical of the northeastern part of the U.S. Such temperature curves vary with geography. This curve is presented for illustration purposes only. The upper curve is the output of the reference plant coincident with the particular temperature (or temperature range) and corresponding duration in hours at that temperature (or temperature range). The reference plant is assumed to be a plant utilizing a conventional turbine and operating at a fixed and relatively low back pressure. The output of the reference plant is therefore constant regardiess of the ambient dry bulb temperature. (A similar discussion would apply to "alternate". plants. However, demand would drop off with adverse combinations of wet and dry bulb temperatures.) Ihe output is presented in normalized terms to simplify subsequent discussion. Addittons to this base illustration will now proceed.

\subsubsection{Fixed Demand/Fixed Heat Source}

If the demand is fixed, and the heat source for the dry cooled plant and the reference plant are constrained to be equal, then the method might be called the "fixed demand/fixed heat source" method. In this cise lite net output of the dry cooled plant relative to the reference plant (assumed constant) can be as depicted in Figure 10.

Figure 10 illustrates the loss in performance, or turbine output, due to both back pressure effects and power required by fans and pumps. The 
DRY BULB TEMPERATURE, ${ }^{0} \mathrm{~F}$

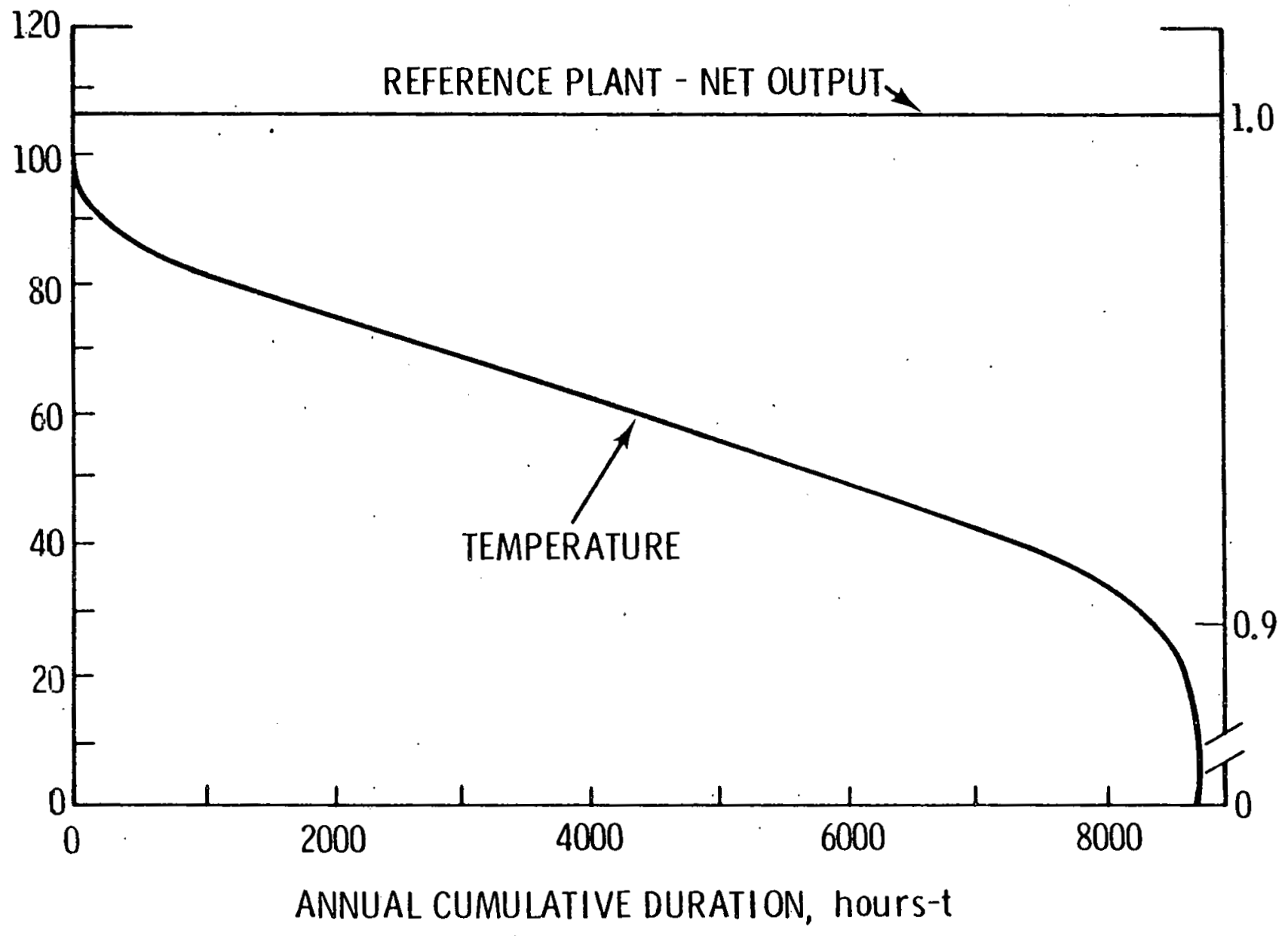

FIGURE 9. Annual Dry Bulb Temperature Duration Curve and Coincident Reference Plant Net Output 


$$
\text { DRY BULB TEMPERATURE, }{ }^{\circ} \mathrm{F} \quad \sim \text { NORMALIZED PLANT OIJTPUT, P/P reference plant }
$$

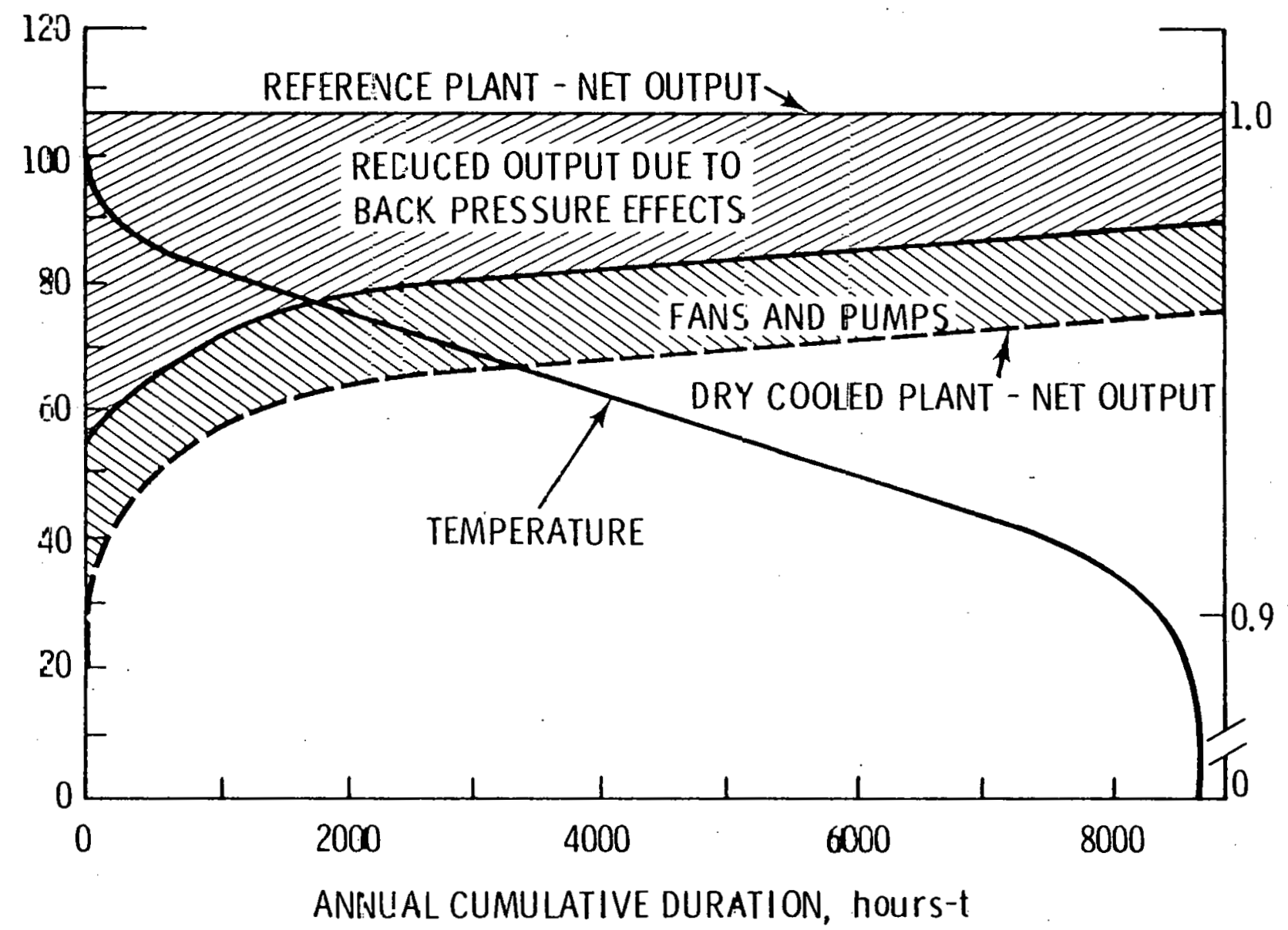

FIGURE 10. Typical Annual Performance of a Dry Cooled Plant 
reduced output is coincident with the particular dry bulb ambient temperature and for the duration in hours over which that temperature occurs. The output is again normalized to simplify the presentation. The magnitude of the loss in performance shown is somewhat typical of what could occur using a high back pressure turbine. The net output of the dry cooled plant can be significantly different, however, depending on the type of turbine employed, the size or capacity of the cooling system and the fan and pump power required. This will now be discussed with the aid of Figures 11, 12, and 13.

As indicated in Figure 11, when high back pressure turbines are used, the output of the dry cooled plant will always be significantly less than the reference plant or the wet cooled plant, even on the coldest days, under the assumptions of "fixed demand/fixed heat source." This is due in part to the performance characteristics depicted in Figures 6 and 7, as well as to further reductions in net plant output due to fans and pumps for the cooling system. This is an extremely important point, especially when the difference in the energy produced and the capacity required to produce that energy are made up by energy and capacity penalties which reflect peaking or cycling costs. Increasing the cooling system capacity can reduce the difference in performance between the dry and wet cooled plants. However, increasing the cooling system capacity beyond a certain point does not bring an economical return in performance, as discussed in Section 3.1.30. In fact, for mechanical draft systems, if increasing the capacity of the cooling system requires increasing the fan and pump power, then a point will be reached where an increase in cooling system capacity will result in a decrease in net plant output.

Dry cooled plants utilizing a modified conventional turbine will have a net output significantly less than the reference plant for small capacity cooling systems (see Figure 12). As the cooling system capacity is increased, the output of the plant will more closely approach that of the reference plant. Dry cooled plant output may even exceed reference plant output during cold temperature operation, depending on the fixed back pressure at which the reference plant is specified to operate. However, for 
DRY BULB TEMPERATURE, ${ }^{\circ} \mathrm{F}$

120

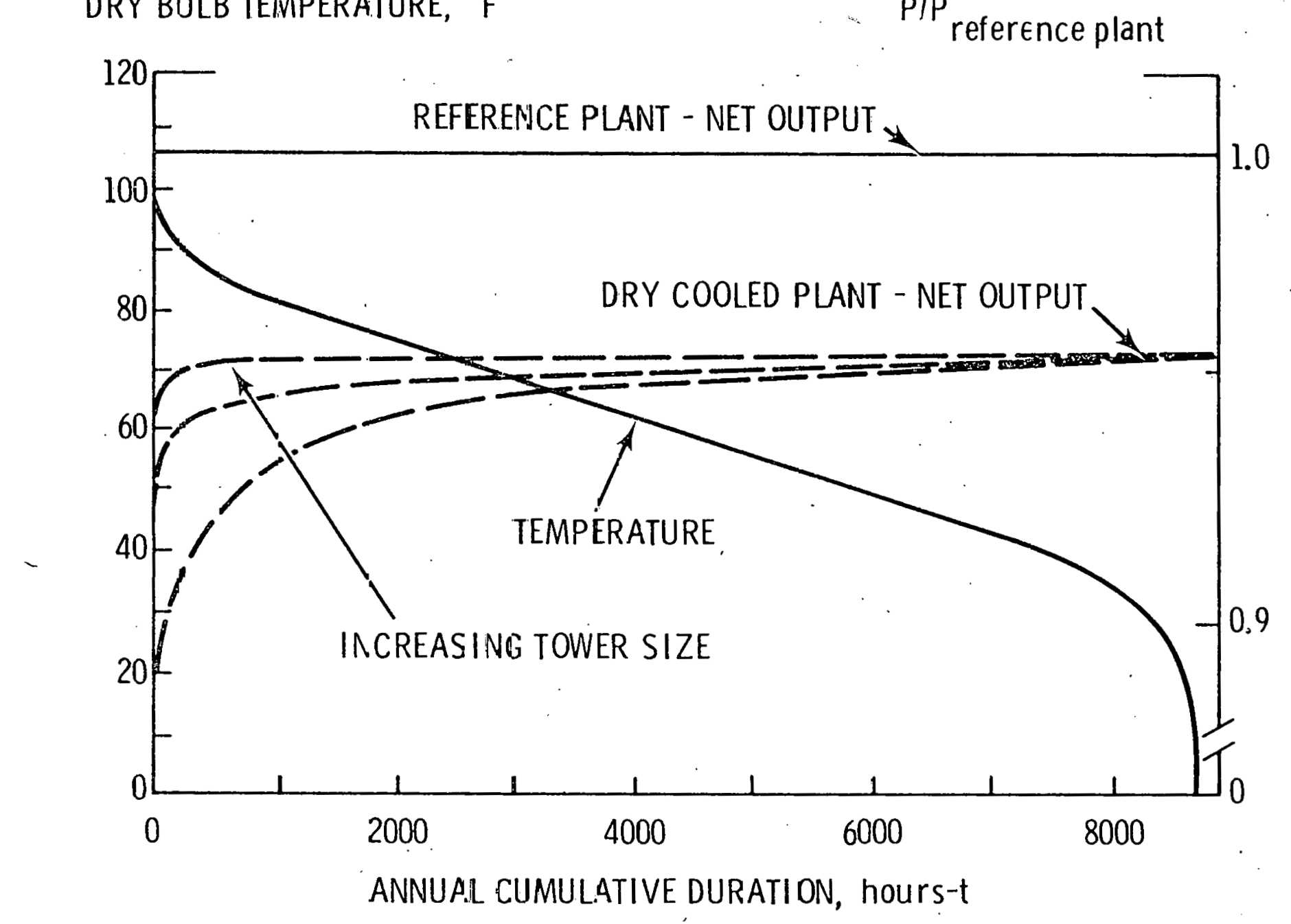

${ }^{P I P}$ reference plant

FIGURE 11. Relative Perfornance of a Dry Cooled Plant Utilizing a High Back Pressure Turbine Under the Fixed Demand/Fixed Steam Source Approach 
DRY BULB TEMPERATURE, ${ }^{0} \mathrm{~F} \quad \sim$ NORMALIZED PLANT OUTPUT, P/P reference plant

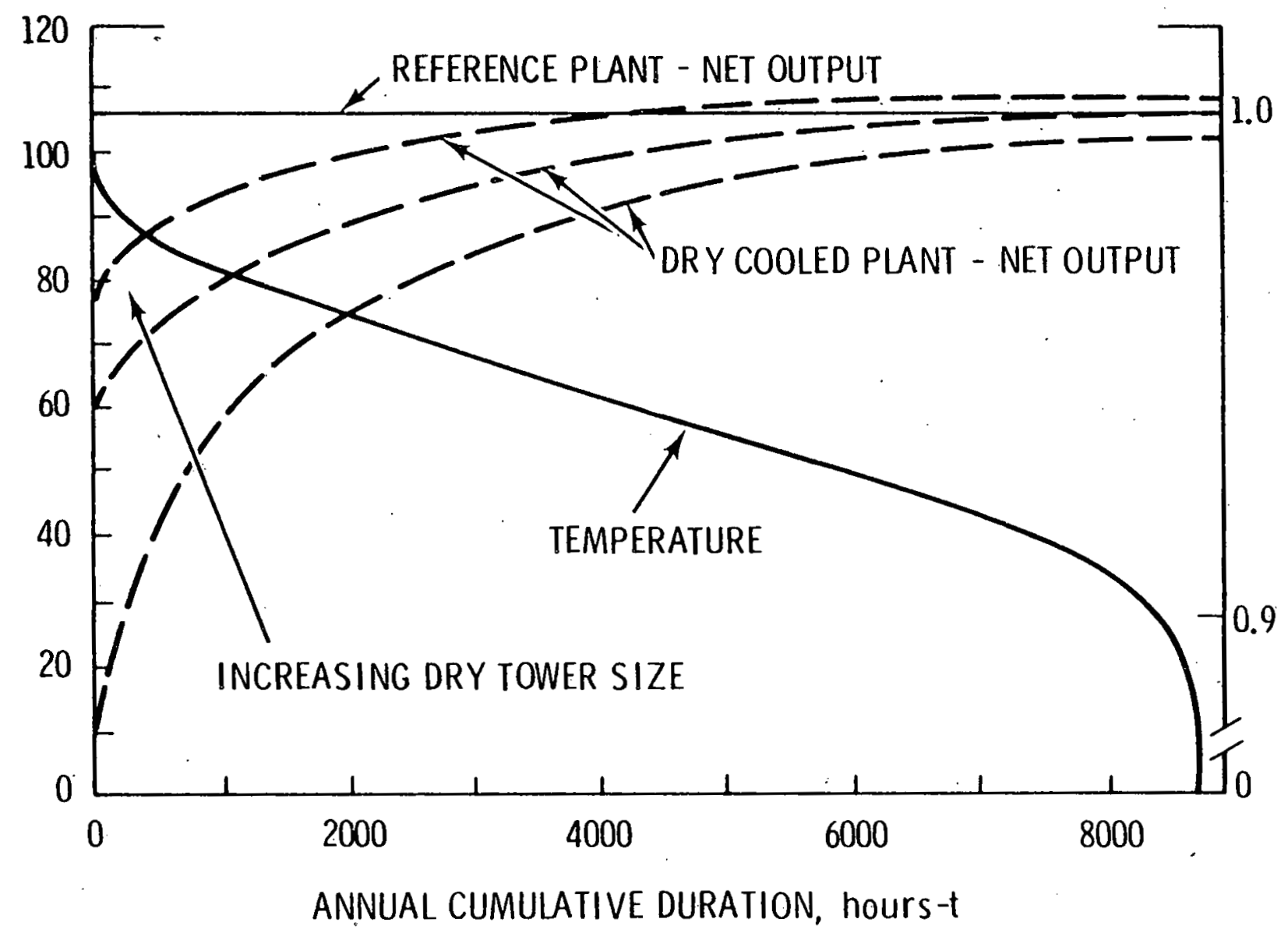

FIGURE 12. Relative Performance of a Dry Cooled Plant Utilizing a Modified Conventional Turbine Under the Fixed Demand/ Fixed Steam Source Approach 
DRY BULB TEMPERATURE, ${ }^{0} \mathrm{~F}$ $\sim$ NORMALIZED PLANT OUTPUT,

$P / P$ reference pilant

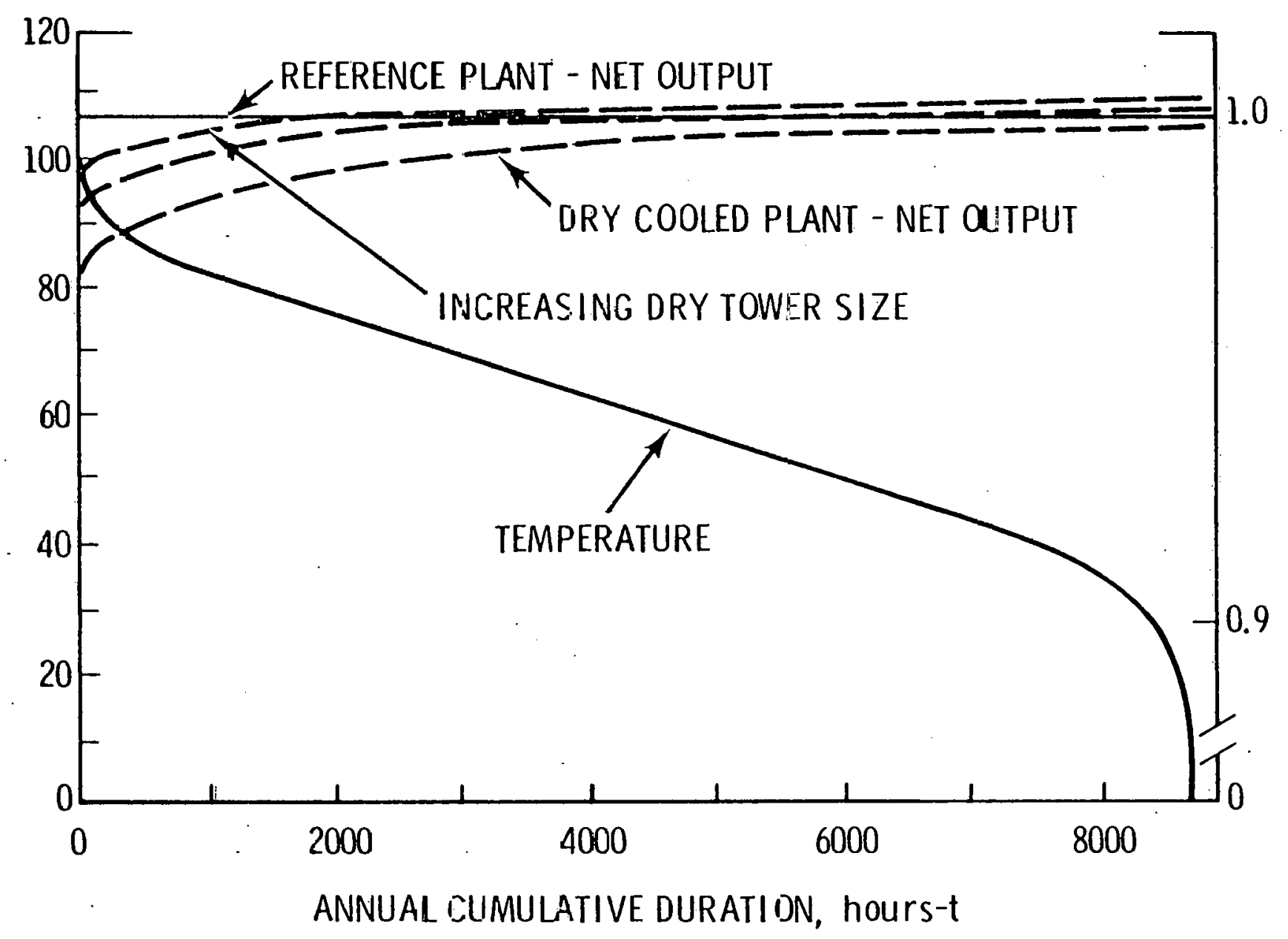

FIGURE 13. Relative Performance of a Dry Cooled Plant Utilizing a Convent onal Turbine Under the Fixed Demand; Fixed Steam Source Approach 
mechanical draft systems, increasing the cooling capacity with a simultaneous increase in fan and pump power will eventually result in reaching a point of diminishing returns, where further increases will not yield increased output. The point at which this begins to occur will depend on the ambient temperature under consideration, the performance characteristics of the turbine, and the power requirements of the cooling system.

When conventional turbines are used in dry cooled plants, the relationship between the plant output and dry cooling system capacity will be similar to that discussed for the modified conventional turbine (Figure 13). However, if the plant is to run at full steam flow throughout the year and yet not exceed the warranted back pressure, then there is a minimum capacity cooling system which can be used. The same is true for the high back pressure and the modified conventional turbine; however, there is a tremendous difference in the minimum size of the cooling system required by each turbine type to allow full steam flow operation on the hottest day of the year. This is due to the differences in maximum warranted back pressure.

\subsubsection{Fixed Demand/Scalable Steam Source/Scalable Plant}

The "fixed demand/scalable steam source/scalable plant" method assumes that while the demand is basically set by the reference plant, the heat source or the entire plant can be scaled up in size to accommodate part or all of the loss of performance of the dry cooled plant. Scaling up the steam source should include scaling up those plant components which must be increased to accommodate an increased steam flow. For fossil plants this would include the boiler, superheater, reheater, feedwater heaters, coal handling equipment, etc. For the nuclear plant it would include the core, steam supply system, etc.

As an example, scaling of the steam source has been accomplished in the $R$. W: Beck. studies by the following procedure. for a conventional turbine, no steam supply scaling is done. For a modified conventional turbine which has a heat rate approximately $1 \%$ worse at the "rating back pressure" (see Figures 6 and 7 ), the steam supply is scaled by $1 \%$. Thus, the dry cooled plant operating at the rating condition of the modified conventional turbine 
(with a scaled steam source) would deliver the same output as a wet cooled plant using a conventional turbine but running at the same back pressure. For dry cooled plants operating with high back pressure turbines, the same process is used relative to the conventional turbine. However, in this case the steam supply system must be scaled up by 8 to $10 \%$, as shown in figures 6 and 7 .

This scaling process ultimately results in plants employing different turbines (conventional, modified conventional, and high back pressure) with different sized steam sources. However, each plant has the sallie turtine capacity at the rating back pressure for that particular turbine. For fossil plants the cost of the turbine is estimated to be approximately constant for a given capacity at that turbine's particular rating back pressure, regardless of whether it is a conventional, modified conventional, or high back pressure unit. For the nuclear units a 15\% price increase for the modified conventional and high back pressure units has been estimated. (3) Steam source scaling is thus a convenient way for increasing capacity without having to account for cost increases in the turbines for fossil plants. It is also a way of raising the capacity of the dry cooled plant (which employs a high back pressure turbine) to a level approaching the demand except for the very hot periods.

Plant scaling involves scaling up the entire plant to increase the total output of the plant. This has been done to make up for the loss in performance due to cooling system fan and pump power requirements and also to back pressure effects. The use of an auxiliary energy and capacity charge could be viewed as either plant and fuel scaling costs to accommodate fans and pumps, or the cost associated with the capacity and energy provided by another base loaded plant used to supply this energy.

Figure 14 illustrates the relative performance of a dry cooled plant employing a high back pressure turbine which has undergone both steam source scaling and plant scaling. The steam source has been scaled so that the turbine has adequate steam to put out the same capacity as the reference plant at their respective rating back pressures. In addition, the entire plant has 


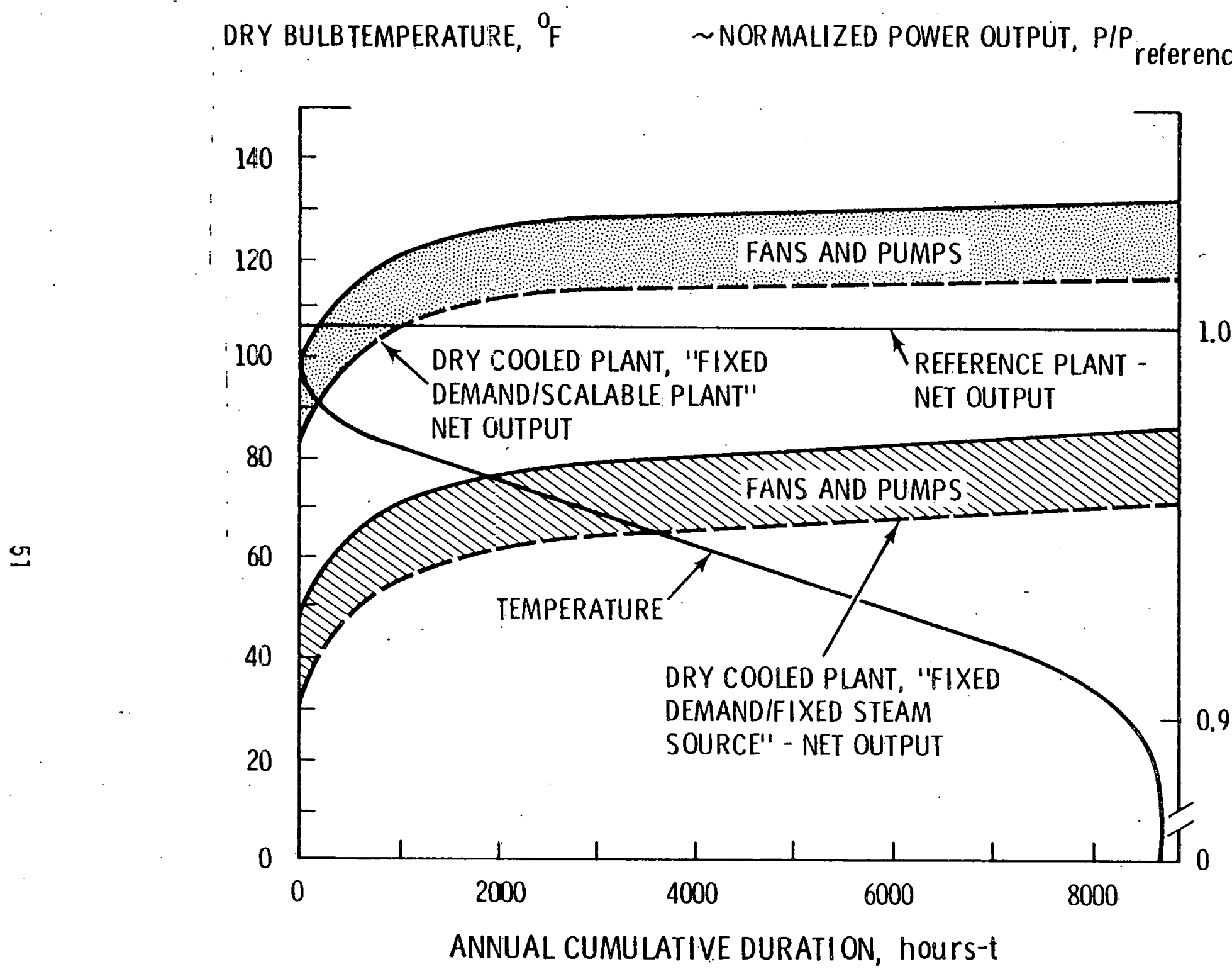

FIGURE 14. Relative Performance of a Dry Cooled Plant Utilizing a High Back Pressure Turbine Under the Fixed Demand/Scalable Steam Source/Scalable Plant Approzch 
been subsequentiy scaled to provide adequate capacity to power the dry cooling system fans and pumps. This is basically the approach used by R. W. Beck and Associates.

In the preceding discussion, the amount of scaling can be such that during the coldest temperatures some excess capacity above demand imposed on the reference plant would exist. However, during the hottest temperature periods a shortage would result, which would have to be made up by some capacity leveling means such as gas turbines, etc. (Figure 14). In some studies, the entire plant, including necessary additional steam supply, has been scaled up so that the dry cooled plant will meet the demand or load imposed on the dry cooled plant even during the highest maximum ambient temperature, as shown in Figure 15. This represents the maximum amount of scaling that could be required. Excess capacity would exist at all temperatures less than the maximum.

Steam source and plant size scaling of fossil plants appears entirely possible, barring problems of scaling between discrete standard sizes of certain equipment. Scaling of the steam source of a nuclear plant or the entire plant may not be at all possible if the reference plant is at the current NRC limits for the thermal power.

An alternative method which circumvents this problem is to reduce the load or demand imposed upon the dry cooled plant. This will be discussed in the following section.

\subsubsection{Reduced Demand/Fixed Heat Source}

The "reduced demand/fixed heat source" method involves a derating process rather than a size scaling process. Barring economies of scale, derating or scaling, if done to the same proportion, should result in the salle unit costs. In the studies reviewed thus far, decreasing the load imposed on the dry cooled plant has involved derating the dry cooled plant to the output that it can produce at maximum steam flow during the maximum ambient temperature. Figure 16 illustrates this procedure. Derating to this level would be a rational approach if the dry cooled plant were isolated and had to meet a constant base load. However, in an actual utility system, this procedure 


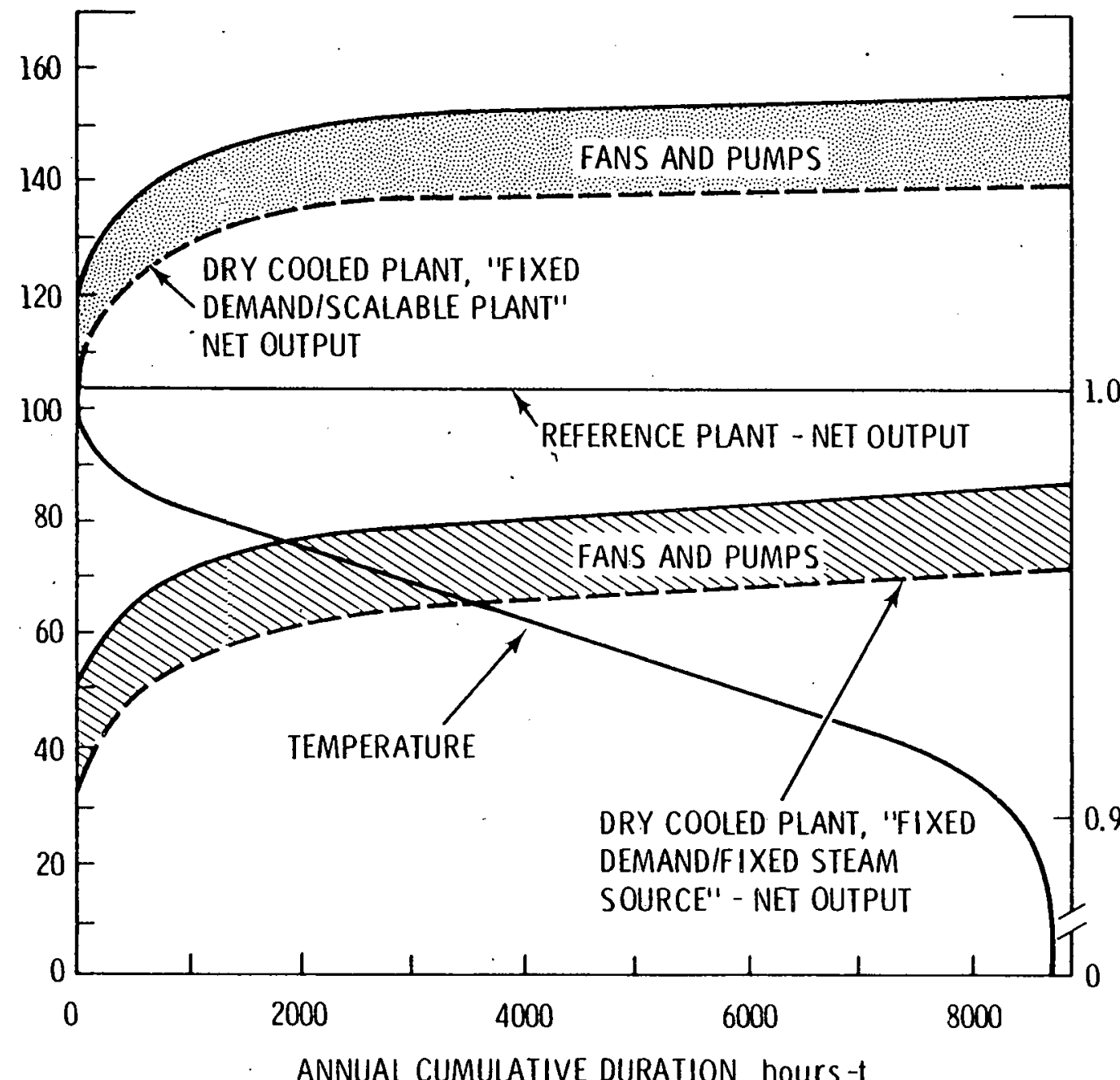

FIGUFiE 15. Relative Performance of a Dry Cooled Plant Utilizing a High Back Pressure Turbine Under the Fixed Demand/Scalable Steall Source/Scalable Plant Approach with Maximum Required Scaling 
:DRY BULB TEMPERATURE, ${ }^{0} \mathrm{~F}$

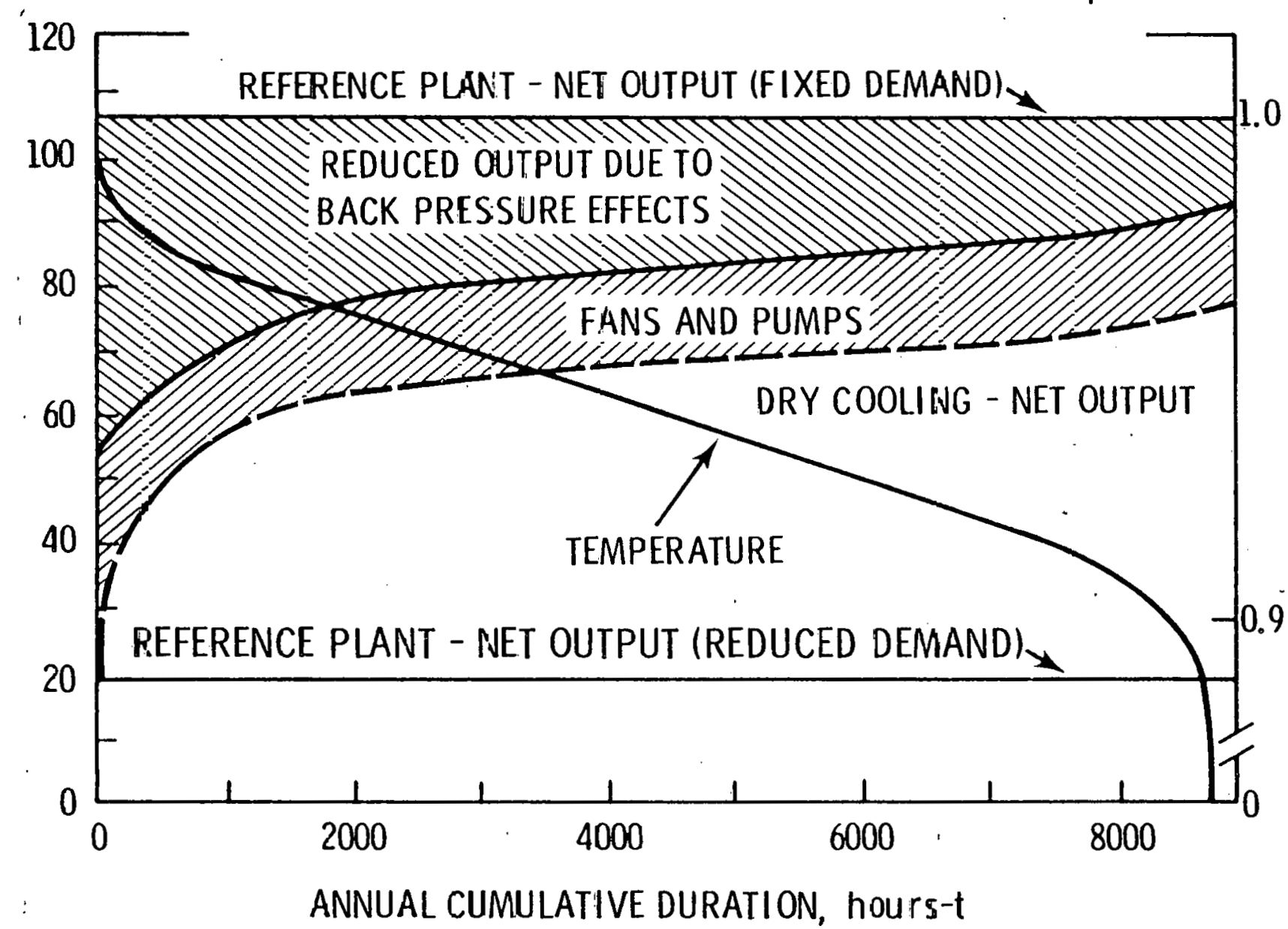

FIGURE 16. Relative Performance of a Dry Cooled Plant Utilizing a High Back Pressure Turbine Under the Reduced Demand/Fixed Heat Source Approach with Maximum Required Derating 
would result in significant and uneconomic excess capacity during the cold periods. On the other hand, no direct energy or capacity must be made up, thereby greatly simplifying the analysis.

\subsubsection{Summary of the Treatment of Lost Performance}

Studies of dry cooling systems have been made using wet cooling systems for comparison. The difference has been termed the incremental power production costs assessed to dry cooling. In order to define the incremental power production costs, various methods have been used. None of these adequately addresses the problem of optimizing a dry cooling system for a dry cooled plant while simultaneously determining the most cost effective way to operate the dry cooled plant within the utility system. A thorough treatment of the tradeoffs between excess dry plant capacity on cold days and making up the shortage on hot ones has not been made. This is best pointed out by summarizing the treatment of capacity and energy penalties for the specific studies reviewed. Figures 17 through 25 will be used to aid this summary. The reader should note that these figures are only schematics; the source reports should be consulted for the actual values of parameters presented.

The United Engineers, Gilbert Associates, and Westinghouse-I treatments are basically the fixed demand/fixed heat source method; each employs high back pressure turbines. This method was discussed in general in Section 3.2.3.1. (Note that the Westinghouse-I method distinctly differs from the Westinghouse-II method to be discussed later.) Figures 17, 18, and 19 illustrate the relative dry cooled plant performance and resulting capacity and energy penulties for each of these treatments. The energy and capacity differences due to both back pressure effects and auxiliary power are assessed at large peaking or cycling plant capacity and fuel costs. In an actual utility system, it would not be cost effective to make up the bulk of the energy decrement with a peaking or cycling unit. The bulk of the decrement represents a base load and would be made up with base plant units. The balance would be made up with peaking or cycling units. Determining the most cost effective split between the types of units to make up the decrement would require an optimization in and of itself. 


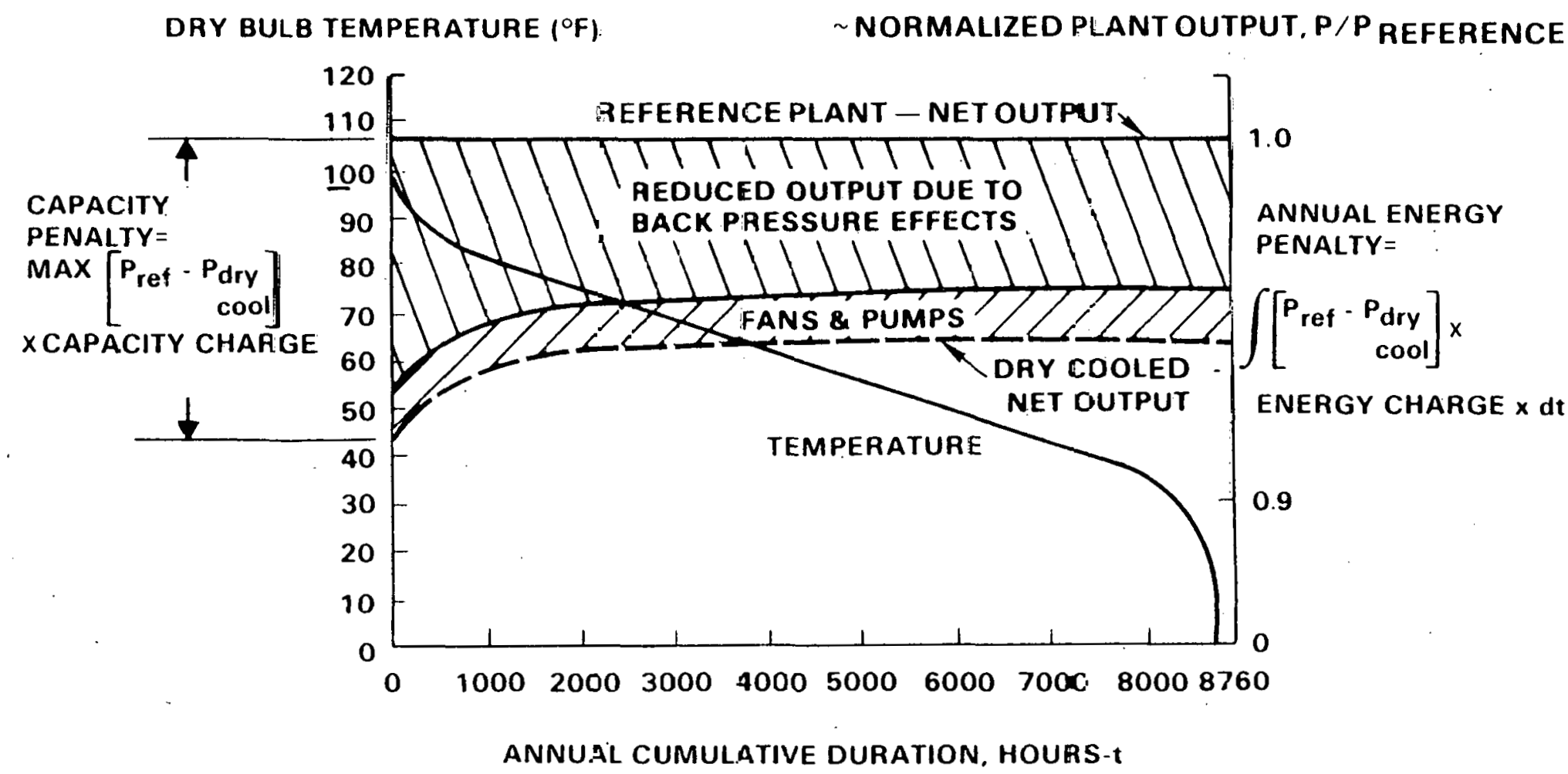

FIGUFE 17. United Engineers' Treatment of Lost Performance 


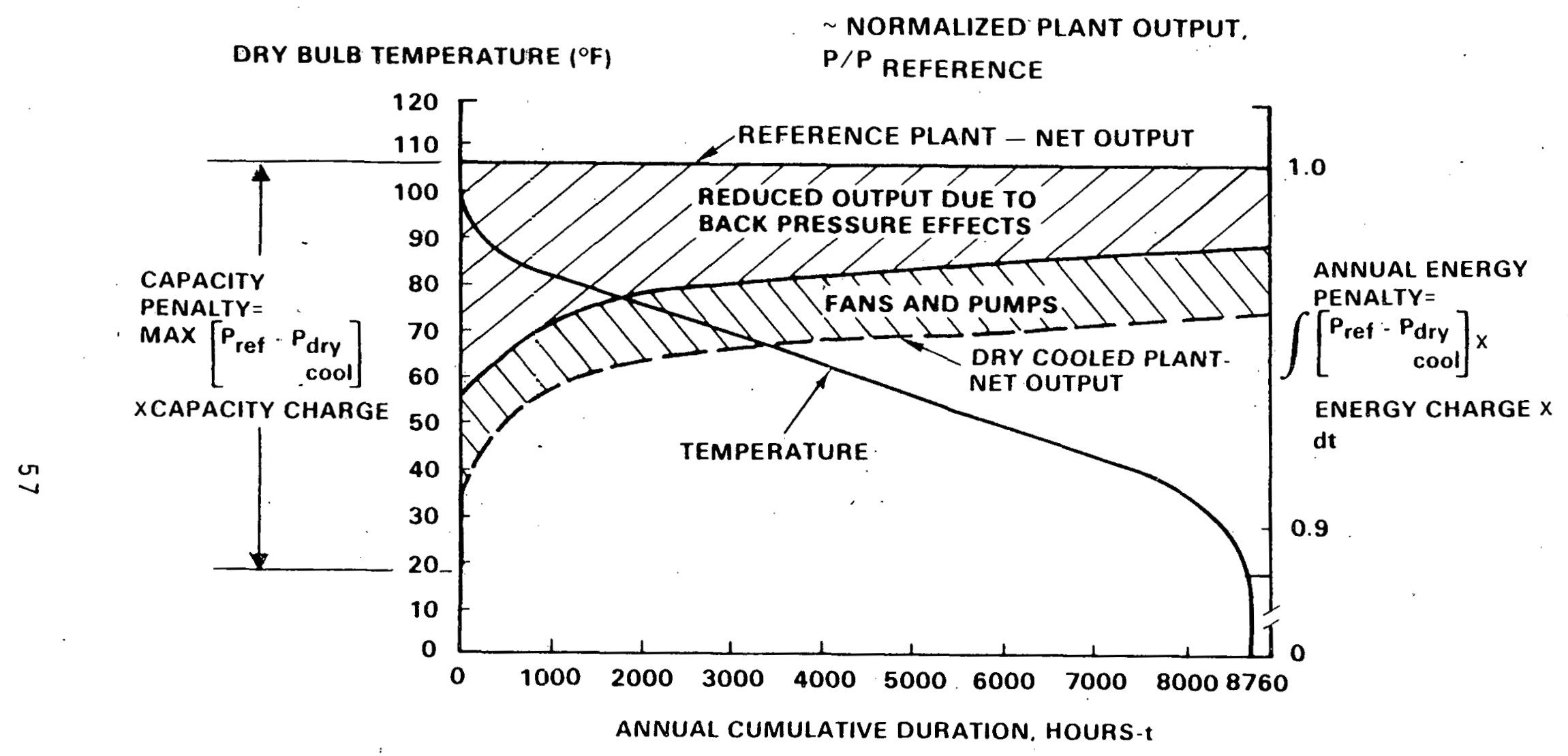

FIGURE 18. Westinghouse's Treatment of Lost Performance---Approach I 


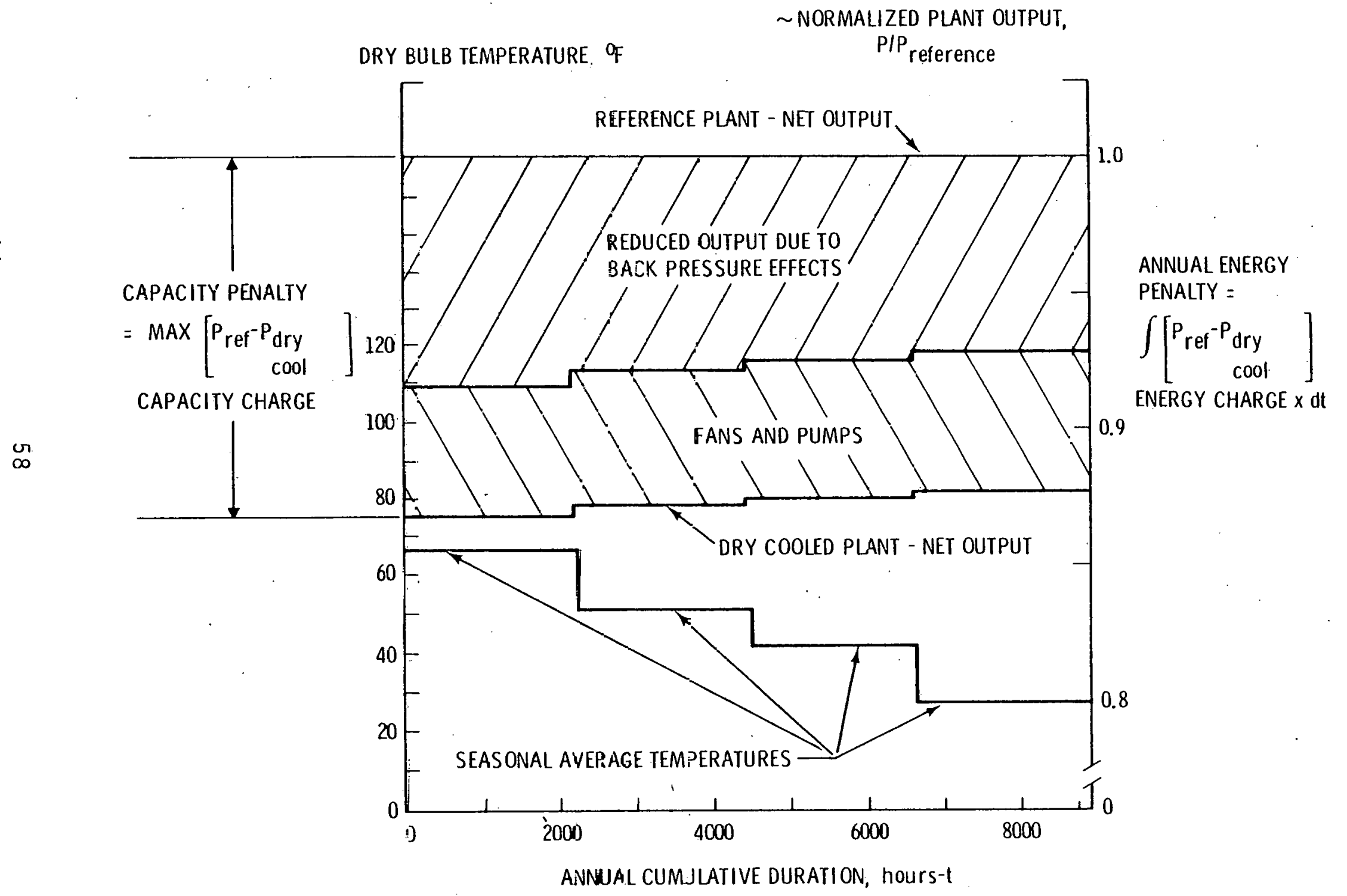

FIGURE 19. Gilbert Associates' Treatment of Lost Performance 
The treatment used by R. W. Beck and. Associates is a version of the fixed demand/scalable steam source/scalable plant method. This method was discussed in general in Section 3.2.3.2. The R. W. Beck and Associates version employs steam supply scaling. It also employs auxiliary capacity and energy costs to account for the fan and pump power and energy requirements. This is equiva-. lent to plant scaling. This version does not employ plant scaling for back pressure effects. A two-part energy penalty is employed, wherein base plant energy charges are used during the cold hours of plant operation and peaking type energy charges are used during the hot hours. This method indirectly results in a somewhat reasonable tradeoff between base plant and peaking plants in making up the decrement in capacity and energy. However, it is not an optimized tradeoff. Figures 20 through 22 illustrate the relative dry cooled plant performance and resulting capacity and energy penalties for conventional, modified conventional, and high back pressure turbines utilizing the R. W. Beck and Associates treatment. An "alternate" plant of constant output is shown to simplify the illustration. The reader, should note that direct comparison to "alternate" plants of nonconstant output was made in some R. W. Beck and Associates studies.

The method used by MIT, shown in Figure 23, is another version of the fixed demand/scalable steam source/scalable plant method. It differs from the R. W. Beck and Associates version in that plant scaling is employed for both the back pressure effects and for the fan and pump power and energy requirements. However, the MIT approach does not use capacity penalties. The method used by MIT would appear, in theory, to arrive at the most cost effective tradeoff between base and peaking power in making up the decrement if the analysis were to include capacity penalties. However, the scaling processes involved are complex in logic and oversimplified. in terms of the plant components requiring scaling.

The Bechtel treatment is yet another version of the fixed demand/ scalable steam source/scalable plant methiod. It differs from the previous two versions in the following way. The plant is assumed to be isolated, i.e., uncoupled from the utility system. The steam supply and plant are 


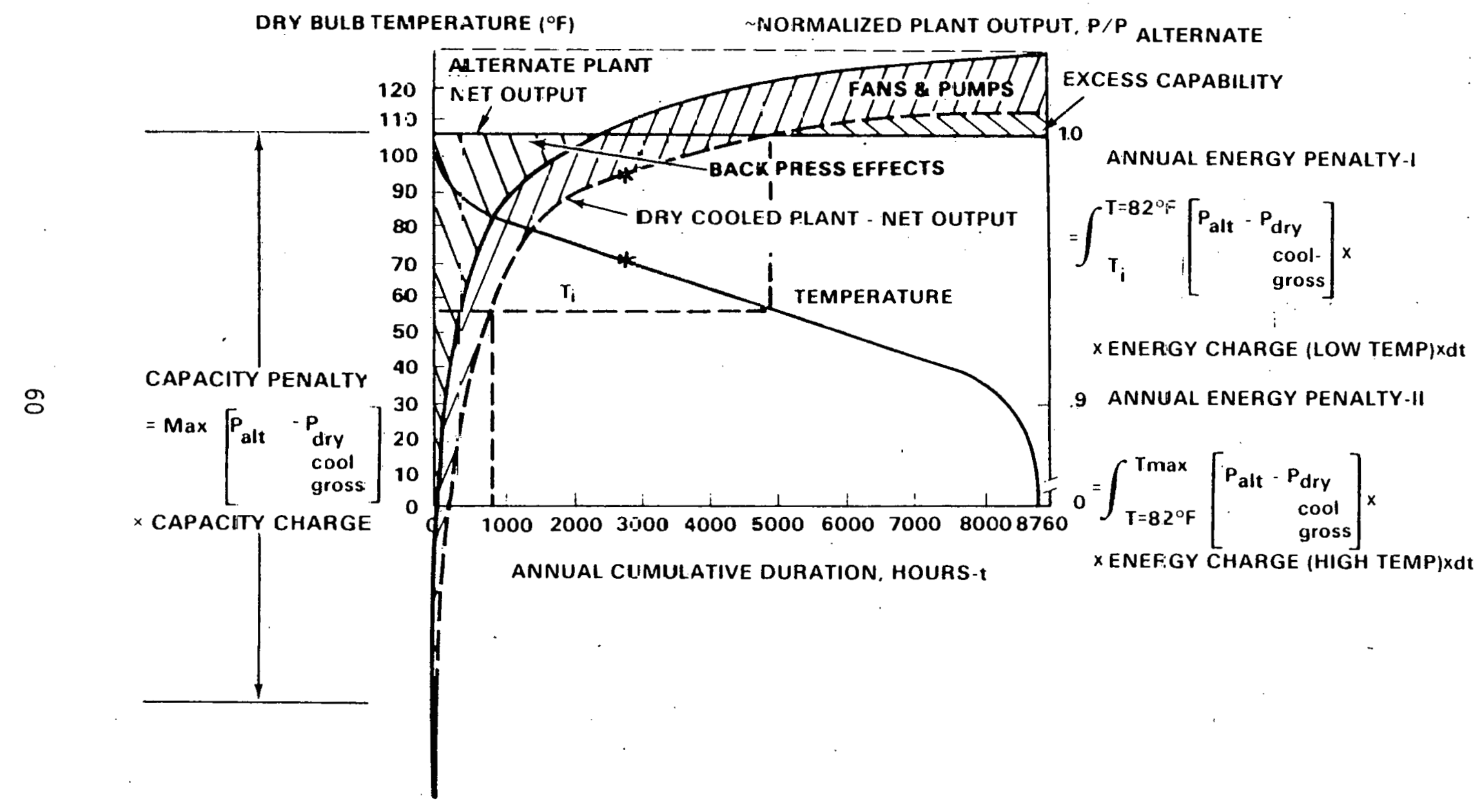

FIGURE 20. R. W. Bezk and Associates' Treatment of Lost Performance--Conventional Turbine 


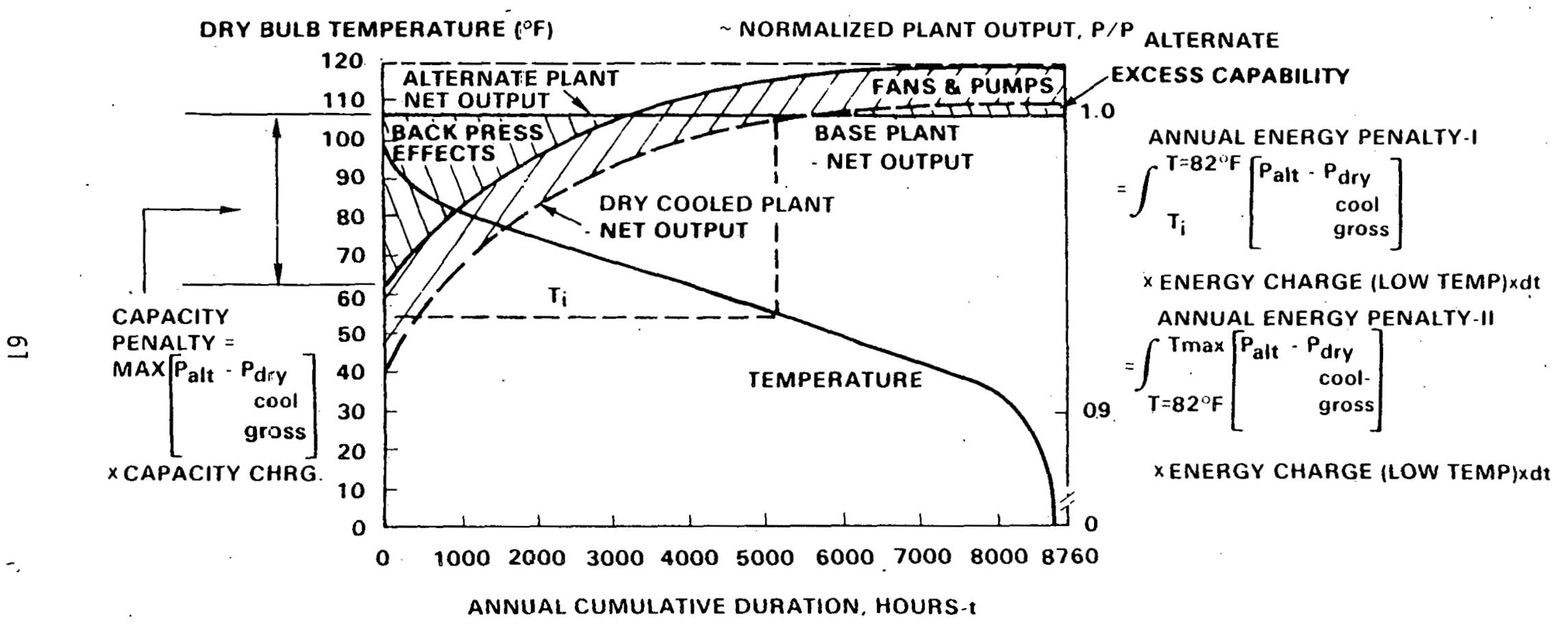

FIGURE 21. R. W. Beck and Associates' Treatment of Lost Performance--Modified Conventional Turbine 


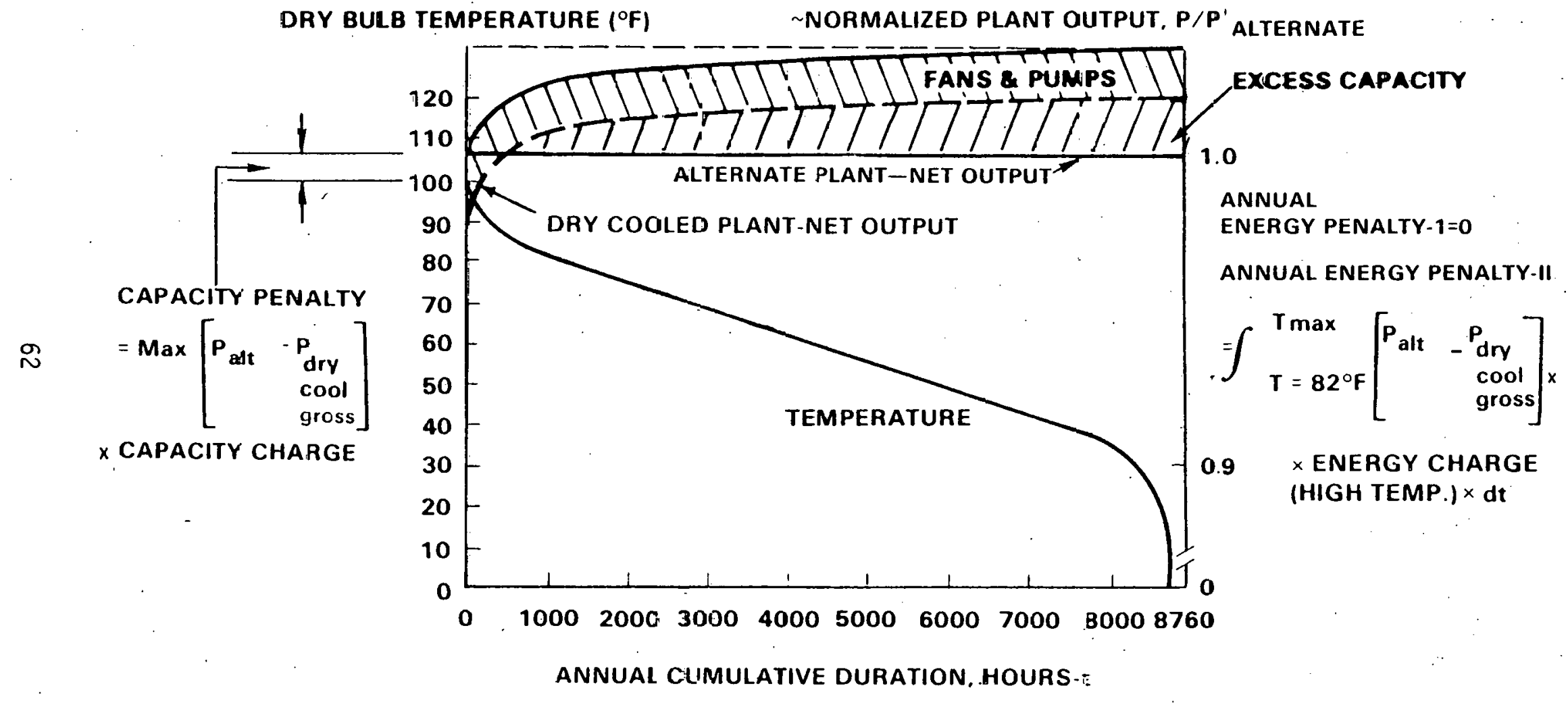

FIGURE 22. R. W. Beck and Associates' Treatment of Lost Penformar.ce--High Back Pressure Turbine 


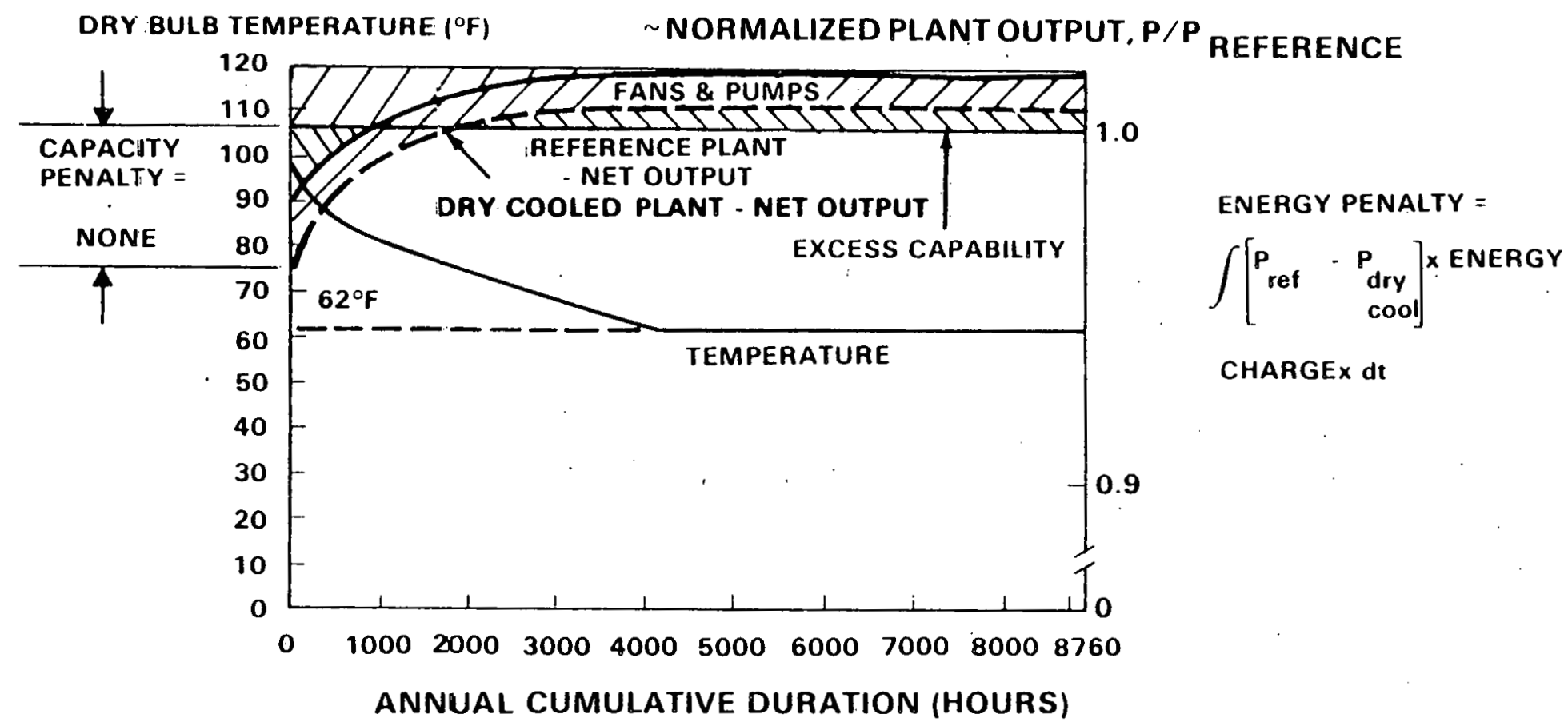

FIGURE 23. MIT's Treatment of Lost Performance 
scaled such that the plant can meet the required demand at the maximum design ambient temperature. The relative plant performance is illustrated in Figure 24. and, as indicated, there are no capacity and energy penalties as previously defined. However, there is an uneconomical amount of excess capacity during the cooler hours. The resulting increased power production costs are reflected in the scaling costs in this case. An "alternate" plant of constant output is shown to simplify the illustration. The reader should note that direct comparison to "alternate" plants of nonconstant output was made in the Bechtel study.

The Westinghouse-II treatment is a version of the reduced demand/fixed heat source method. In this version, the demand is set as the dry cooled plant capacity at the maximum design ambient temperature. The relative plant performance is illustrated in Figure 25. There are no capacity and energy penalties as previously detined. Un a normalized basis, il is efreclively the same as the Bechtel treatment, with the same uneconomical excess capacity during the cooler hours.

A fundamentally simpler process of optimizing dry cooling systems and minimizing the actual power production costs of dry cooled plants operating in utility systems is needed. The following stepwise procedure is suggested.

1. Select a turbine type and capacity and define costs.

2. Fix the design and cost of the balance of the plant (including any steam supply scaling required by the dry cooled plant turbine to match its capacity relative to a conventional plant).

3. Select a physically-consistent set of cooling system design and operating parameters and define related costs, etc.

4. Define the dry cooled plant net maximum capability over the annual meteorological cycle.

5. Determine the most cost effective way to interface this base loaded plant into the utility system for minimum power production costs.

6. Repeat Steps 3 through 5 until definition of the most cost effective cooling system and the most cost effective way to interface the dry cooled plant into the utility is accomplished. 


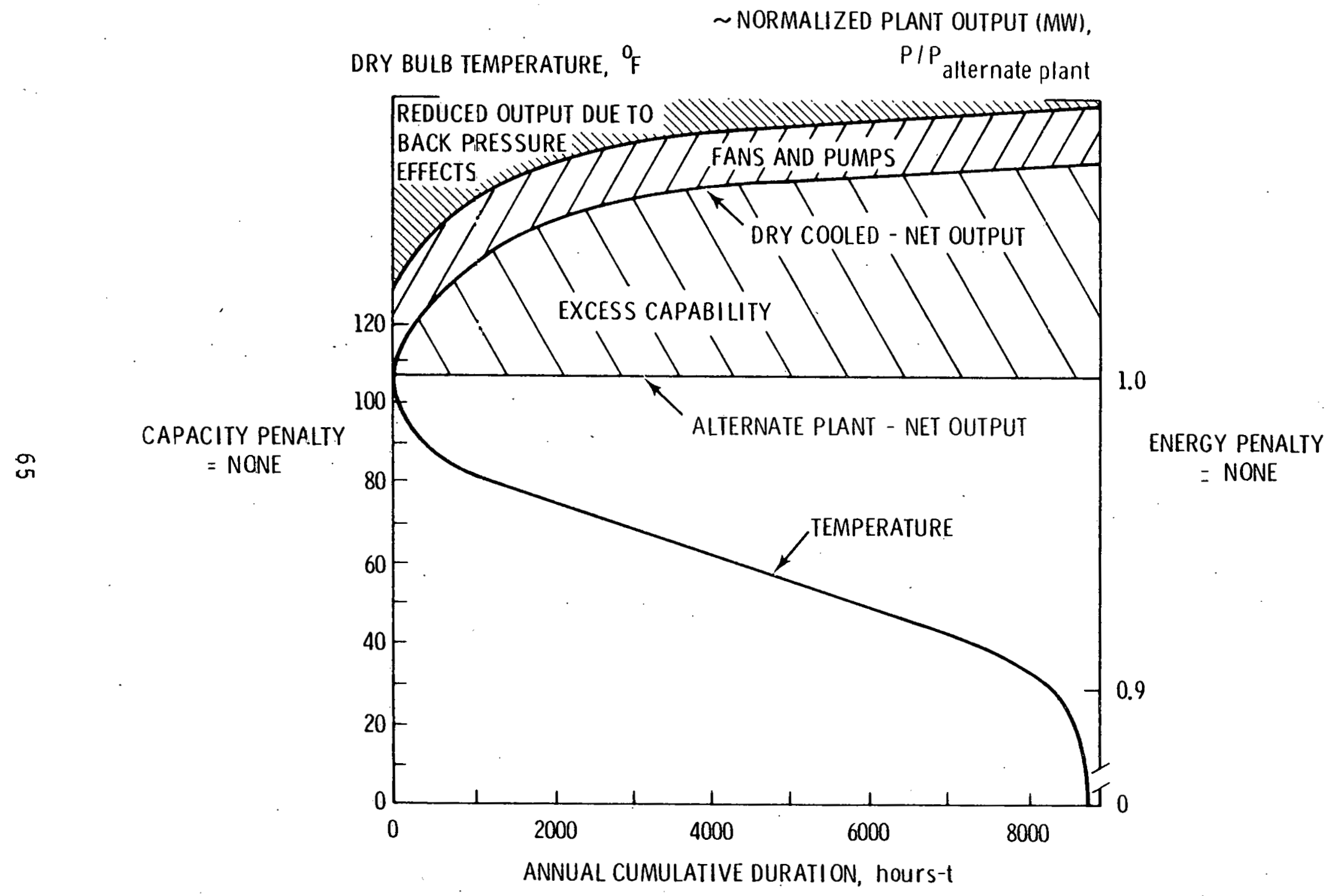

FIGURE 24. Bechtel's Treatment of Lost Performance 


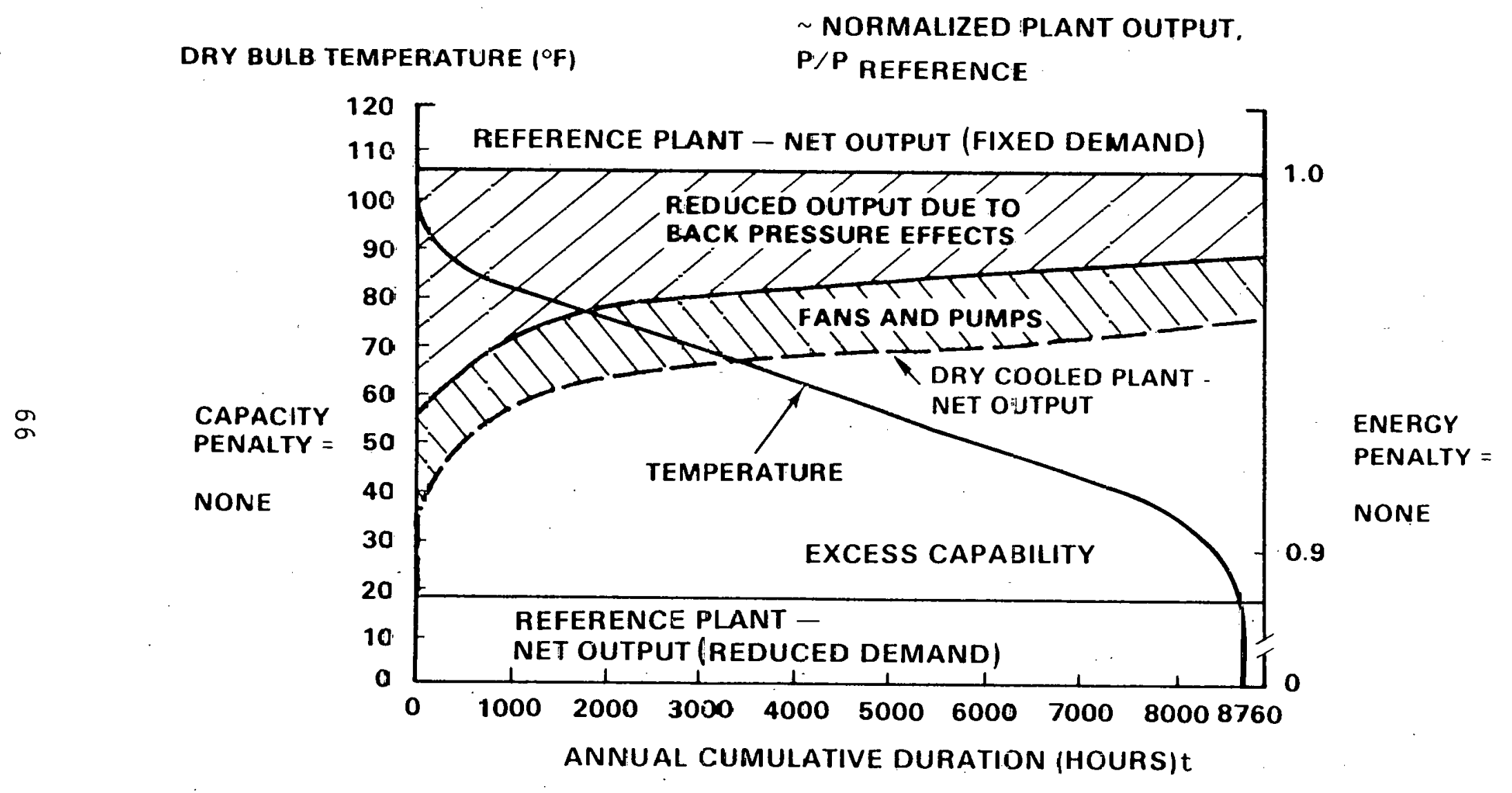

FIGLRE 25. Westinghouse's Treatment of Lost Performance--Approach-II 
Step 5 requires further elaboration. In simplest terms, suppose the dry cooled plant has a power output versus temperature (and hours) characteristic as illustrated in Figure 26a (Step 4). Suppose this dry cooled plant, coupled with a peaking gas turbine of undetermined size, constitute the utility system and must meet a base load of undetermined constant demand. The problem becomes that of simultaneously determining 1) the magnitude of the demand or load that this combination can meet most cost effectively; and, 2) the capacity of the gas turbine. As shown by Figure 26b, defining one of these quantities defines the other. This determination essentially involves a tradeoff between the amount of gas turbine capacity, gas turbine fuel, dry cooled plant fuel, and total power generated. Obviously, the utility system will consist of more than the dry cooled plant and a peaking gas turbine. However, it may be possible to effectively reduce the utility system to this simplicity for study purposes.

Once Step 6 is complete, the power production costs can be compared to those of a wet cooled plant and the incremental cost computed. Problems of scaling are avoided and the subject of treating lost performance relative to some reference is dispelled. The approach boils down to defining the optimum cooling system for a power plant and determining the optimum way to interface this plant's characteristics into the utility generation mix.

Considerable effort has been expended in this review in an attempt to understand the detailed logical process whereby various investigators have attacked the engineering economics. It appears worthwhile to describe the proresses used for the benefit of other investigators having similar needs. This is the subject of the next section. 


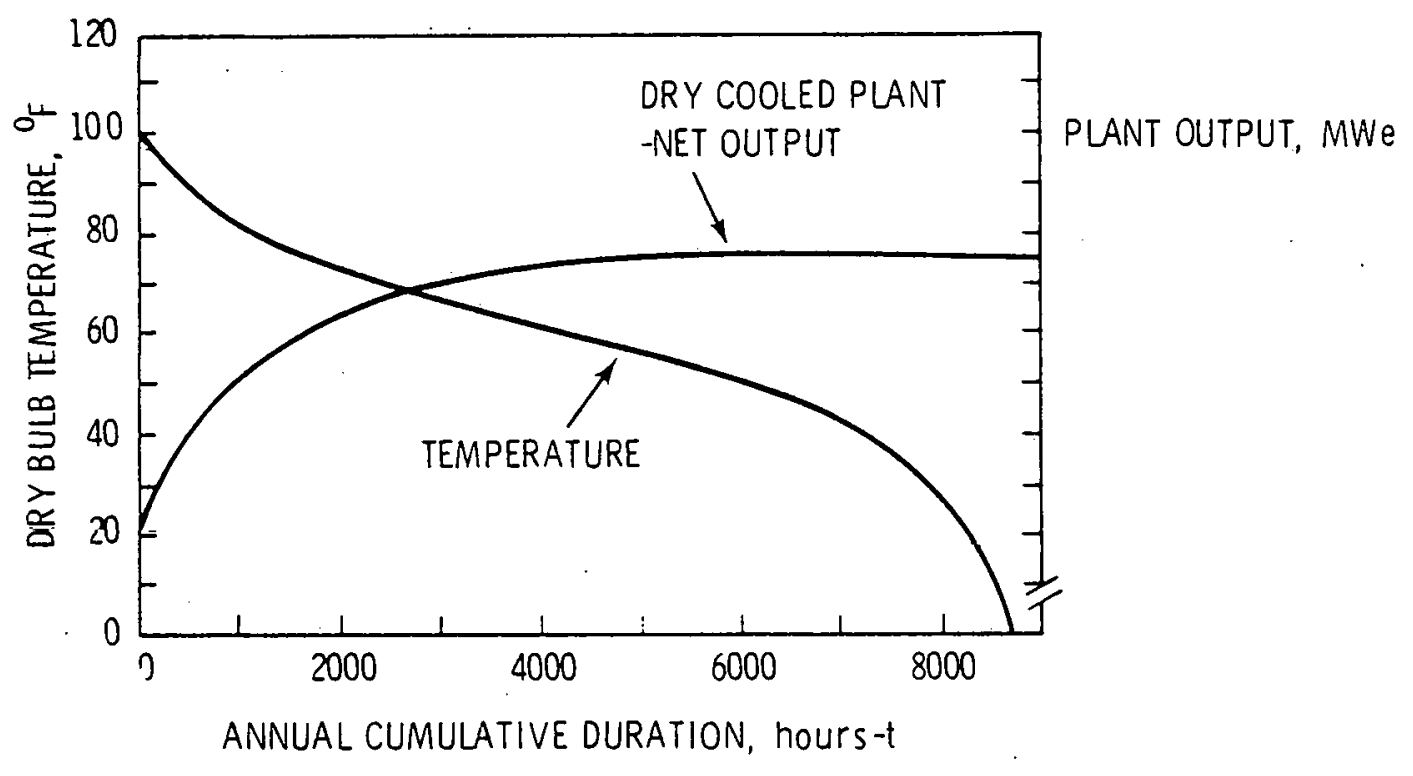

FIGURE 26a. Dry Cooled Plant Output Characteristics

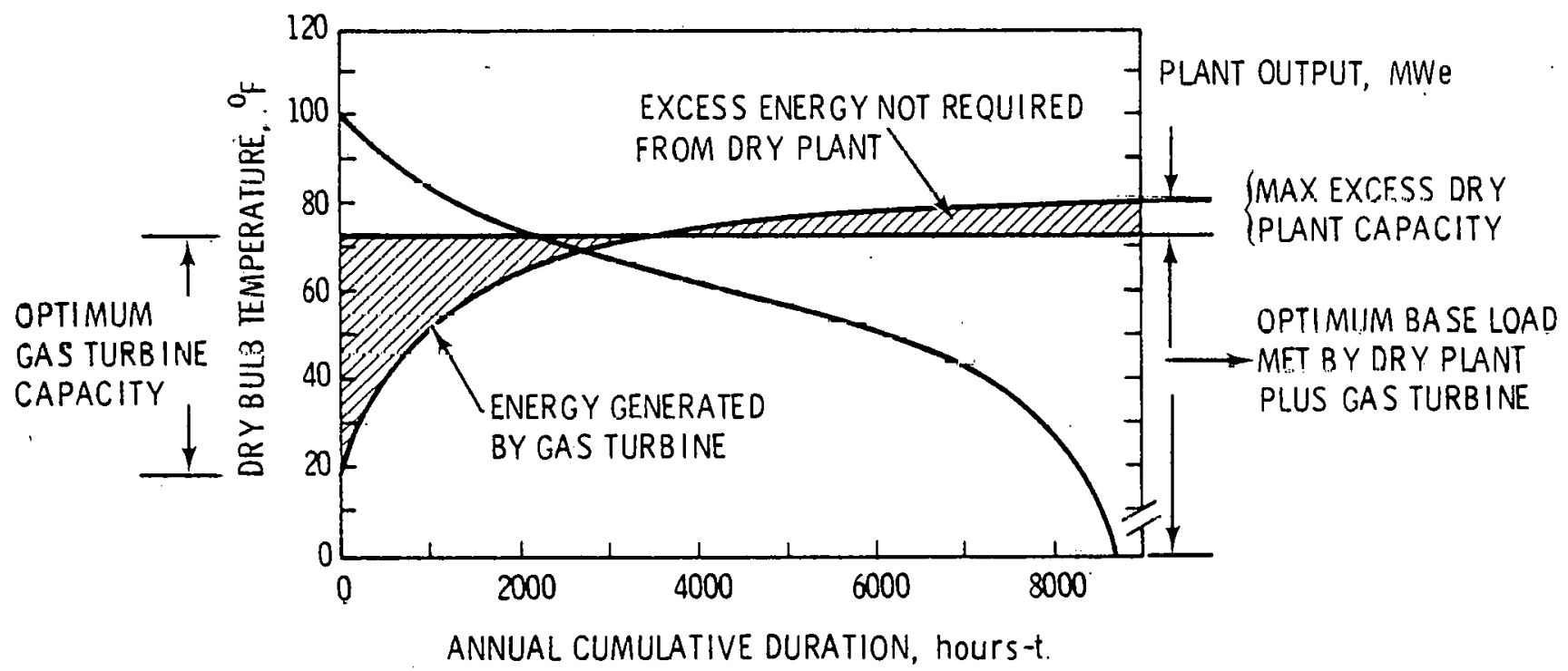

FIGURE 26b. Optimized Load to Impose on the Dry Cooled Plant/Gas Turbine Combination 


\subsection{STUDY BASES AND METHODOLOGIES}

\subsection{GENERAL COMMENTS}

Minimizing the power production costs of a dry cooled plant requires that the details of the cooling system, the balance of plant, and the utility system interface be optimized. This, in turn, requires detailed physical and cost models plus a logic process for selecting the optimum combination of design and operating parameters, physical arrangements, system optjons, etc. Lacking cost or physical modeis, or attempting to avoid complexity, requires that certain assumptions be made. In order to establish reference points, certain constraints are imposed. In some cases these tend to limit the usefulness of the analysis. The assumptions and constraints, as well as the bases for physical and cost models used in the studies reviewed, will be discussed in this section.

This section also outlines, step-by-step, a brief description of the methodology or logic procedure used by the various investigators to design and optimize the dry cooling systems for the plants evaluated in their particular studies. The methods presented here are summarized from the referenced reports and are an interpretation of the methodology presented in those reports. Undoubtedly alterations and improvements in the basis, approach, assumptions, and methodology have been made since the various investigators issued these reports. However, this summary should provide a common ground from which discussions can proceed and improvements can be delineated. The discussion of methodology will proceed in the following order: MIT, Bechtel, R. W. Beck, Westinghouse, United Engineers, and Gilbert Associates.

\subsection{MIT METHOD OF ANALYSIS}

The MIT method of analysis was devcloped to facilitate optimization of the heat exchanger configuration, the heat exchanger unit geometry, and the cooling system operating parameters. The dry cooled plant power production costs are minimized relative to a plant operating with a conventional turbine at the vendor's "rating" back pressure (i.e., $3.5 \mathrm{in}$. HgA in this case) 
and equipped with a zero cost cooling system. The approach is basically the fixed demand/scalable steam source/scalable plant approach described earlier.

The computer program used in the MIT studies is publicly available. Certain portions of the program are certainly relevant to the needs of the DCT Program. However, as discussed above, considerable additional capability would have to be added to meet the needs of the DCT Program.

\subsubsection{Major Assumptions and Constraints}

The major assumptions and constraints were as follows:

- The contact condenser is of negligible cost.

- The TTD of the contact condenser is zero.

- The plant capacity can be scaled up to accommodate lost performance due to back pressure effects by scaling up only the steam supply.

- Plant capacity can be scaled up to accommodate fan and pump power by scaling up the entire plant.

\subsubsection{Optimization Procedure}

The optimization procedure was as follows:

1. Sclect an ambient "design" tomperature.

2. Find the optimum (in terms of minimum incremental power production costs) combination of the following plant and dry cooling system parameters:

- turbine exhaust saturation temperature

- water range

- capacity rate ratio--water/air

- frontal area

- width/length ratio where the plant is assumed to run all year at the "design" ambient temperature. This optimization process involves a technique of "initial exploration" and "hill climbing." 
3. Using the optimum heat exchanger configuration from Step 2, and the associated air and water rates, compute the plant performance over the year and the incremental power costs using the yearly dry bulb temperature distribution for the particular site under consideration.

4. Repeat Steps 1 through 3 with a new "design" ambient dry bulb temperature.

5. Select the final optimum heat exchanger configuration and operating parameters from the values determined in Step 3.

The process is therefore a two-step optimization scheme which involves selecting a final optimum from a set of optimums. Reference 5 contains a detailed description of the optimization algorithms used in Step 2.

\subsubsection{Data and Design Base}

Major areas where improvements in the data or design base are needed to remove uncertainties regarding the conclusions of this study will now be discussed.

The cost model for the heat exchanger is derived from a 1958 Hudson Products publication ${ }^{(29)}$ and is based on total bare tube surface area and number of tube rows in the direction of air flow. The tube is assumed to be admiralty and the fins of aluminum. No unit geometry, material, or fin manufacturing method parameters enter the cost model. A more detailed model is needed to adequately treat optimization of the unit geometry heat exchanger configuraiton, finned tube fabrication method and related structural support.

The piping is assumed to be of a fixed diameter; the number of pipes required is determined by specifying the pressure drop in the piping system to be less than a fixed multiple of the pressure drop across the heat exchanger. Manifolding between main piping runs and heat exchanger headers is not included in the analysis. Improvements are needed here since in actual practice erosion/corrosion defines an upper limit to allowable pipe water velocities. A tradeoff between piping costs and pumping costs is required to determine if operation below the limiting value on water velocity is cost effective. 
The fan system is costed on a $\$ / h p$ basis $p l u s$ a $\$ / f t^{2}$ of fan blade swept area assuming a fixed fan discharge velocity. A more detailed cost and physical model is required to adequately treat optimization of the fan system.

The finned tube heat exchanger surfaces evaluated and the corresponding friction factor and heat transfer data were taken from Reference 30. This reference contains data on many different heat exchange surfaces; however, none of the surfaces described have unit geometries typical of those vendors of dry cooling equipment would offer for a dry cooled plant. A more comprehensive evaluation of unit geometries is needed before final conclusions regarding the most cost effective surface to use can be made.

No physical or cost models are used for the contact condenser. Since there is an interdependent relationship between the design and costing of the contact condenser and the remainder of the cooling system, cost and physical models for the contact condenser must be developed to adequately treat cooling systems which use them. In summary, al though the MIT study has pointed out the need to optimize the unit geometry and the heat exchanger configuration and operating parameters, the resulting conclusions are subject to question, due to the basis upon which the physical and cost models were developed.

\subsection{BECHTEL METHOD OF ANALYSIS}

The Bechtel method of analysis was developed to compare wet and dry cooling systems at a specific site. The approach is the fixed demand/ scalable steam source/scalable plant method where the plant and steam source are scaled up so that the dry cooled plant produces the fixed demand even at the maximum design temperature. Optimization involves determining the optimum size of the dry cooling system based on predesigned vendor equipment. The optimization procedure involved requires both hand and computer calculations.

\subsubsection{Major Assumptions and Constraints}

The major assumptions of this study were:

- The TTO of the condenser is zero. 
- Plant capacity can be scaled up to accommodate reduced output from back pressure effects and cooling system fans and pumps.

- The heat exchanger is replaced after 15 years.

\subsubsection{Optimization Procedure}

The optimization procedure was as follows:

1. Select a maximum design ambient temperature.

2. Select the ITD and corresponding tower size and costs.

3. Determine the maximum turbine back pressure based on Steps 1 and 2, and size the balance of plant for adequate steam supply, etc. Cost plant systems.

4. Operate the plant over the meteorological cycle and compute required fuel input.

5. Calculate power production costs and compare to a wet plant.

6. Repeat Steps 2 through 5 and select the optimum ITD and related cooling.system for minimum cost.

7. Repeat Steps 2 through 6 for different turbines.

\subsubsection{Data and Design Base}

The Bechtel study utilized performance and cost data on vendor designed heat exchange equipment. It did not address the detailed aspects of the cooling system.

\subsection{R. W. BECK AND ASSOC IATES METHOD OF ANALYSIS}

The R. W. Beck and Associates method of analysis was developed to compare wet and dry cooling systems. The analysis was based on predesigned dry cooling equipment offered by vendors. The major options and tradeoffs evaluated are:

- Contact versus surface condensers 
- Single pressure surface condensers versus multipressure surface condensers

- Turbine types

- Mechanical versus natural draft dry cooling towers

- Antifreeze versus water in the cooling loop

- Optimum TTD for the surface condenser

- Optimum ITD for the size of the dry cooling system

- Effect of site parameters.

Ihe analysts is lasically the fixed demand/scalable steam source/scalable plant approach.

The computer program used in the $R$. W. Beck and Associates. studies is described in an updated form in Reference 4 and is publicly available. However, the program was not intended for detailed optimization of cooling system components, but rather optimization of the cooling system size, etc., in terms of predesigned vendor-offered equipment. As was the case with the MIT computer programs, certain portions of the $k$. W. Beck dild Associates computcr program are certainly relevant to the needs of the DCT Program.

\subsubsection{Major Assumptions and Constraints}

The major assumptions and constraints for this series of studies were:

- TTD equals zero for contact condensers.

- Surface condensers were assumed to be 1-in. tubes made of admiralty. However, no physical or other constraint precluded consideration of other sizes or materials.

- The steam source can be scaled to give fixed demand at a rating back pressure of a particular turbine.

- Power can be purchased at base plant costs for fans and pumps (equivalent to plant scaling).

- Heat transfer area of two zone surface condensers is divided, equality. 


\subsubsection{Optimization Procedure}

The computerized optimization procedures developed to optimize the size of the dry cooling system for the three types of condensers considered were as follows:

- For contact condensers:

1. Select an ITD.

2. Assume TTD is zero.

3. Assume range $=1 / 2$ ITD.

4. Size and cost the dry cooling system based on the above ITD and a nominal heat rejection.

5. Operate the plant over the meteorological cycle and determine actual power production costs.

6. Select a new ITO and repeat Steps 2 to 5 .

7. Select the ITD which results in minimum power production costs.

- For single pressure surface condensers:

1. Select an ambient design temperature (taken to be the annual average temperature).

2. Select an ITD.

3. Assume range of the water equals 1/2 ITD.

4. Assume a TTD in the range of 5 to $15^{\circ} \mathrm{F}$, starting at $5^{\circ} \mathrm{F}$.

5. Calculate reject heat and water flow rate.

6. Set water velocity at $7 \mathrm{ft} / \mathrm{sec}$ in condenser tubes and calculate condenser tube length and number.

7. Set tube length to standard length by adjusting water velocity.

8. Size and cost the dry cooling system using the above ITD, nominal plant heat rejection, and vendor data.

9. Operate the plant over the meteorological cycle and determine power production costs. 
10. Repeat Steps 4 through 9 using a different TTD.

11. Repeat Steps 2 through 10 and select the optimum combination of ITD and TTD.

- For multi-pressure surface condensers:

The optimization process is similar to that described above, except that an interactive process is required to solve for the TTD of the low pressure zones. The solution is based on the assumption of equal. steam flow rates to each.zone and equal heat transfer areas in each zone.

\subsubsection{Data and Design Base}

This study utilized performance and cost data from vendor designed dry cooling tower equipment and was therefore not a detailed study of the dry cooling system components. However, detailed design of the surface condensers was included as part of this study. The surface condensers were designed using certain extensions to the procedures outlined by the Heat Exchange Institute standards. Design of the contact condenser was not considered. Costing of the contact condenser was based on $\$ / 1 \mathrm{bm}$ of steam condensed. This appears to be an oversimplification of a rather complex design and costing problem.

\subsection{WESTINGHOUSE METHOD OF ANALYSIS}

The Westinghouse method of analysis was developed to compare wet, wet/dry, and dry cooling systems. The analysis involved optimization of the dry cooling system including the surface condenser. Based on the content of published reports, the major emphas is appears to have been upon turbine types and zoned versus unzoned condensers. Details of the resulting optimized cooling systems are not available in published reports. The analysis was based upon the fixed demand/fixed heat source and a negotiable demand/fixed heat source approach. The negotiable demand/fixed heat source approach assumed that the demand was set at the output of the dry cooled plant at the maximum design ambient temperature. 
The computer code developed by Westinghouse to analyze wet, wet/dry and all-dry cooling systems is proprietary.

\subsubsection{Major Assumptions and Constraints}

Little information of note is found in the published results concerning the assumptions and constraints imposed other than the basic approaches discussed immediately above.

\subsubsection{Optimization Procedure}

The optimization procedure involved optimizing the cooling system including the condenser. There is no detailed optimization procedure outlined in published literature; however, discussions with westinghouse personnel $(31)$ indicate that the following general procedure was followed:

1. Select a combination of independent dry cooling tower heat exchanger parameters and a nominal plant heat load. Using a design computer program, compute the dependent parameters which then completely define the design and operating parameters for the dry tower. Also define an off-design performance map for this tower.

2. Repeat Step 1 for as many combinations as desired.

3. For each tower design defined above, determine the optimum condenser design and the related power production costs for each condenser/dry tower combination using a second computer code.

4. Select the combination with minimum power production costs.

5. Repeat Stejs 1 through 4 using combinations suggested by trends developed in the previous iteration.

\subsubsection{Data and Design Base}

Little information is available on the data and design base used for the Westinghouse studies.

\subsection{UNITED ENGINEERS METHOD OF ANALYSIS}

The United Englneers method of analysis was developed to facilitate comparison of dry and several types of wet cooling systems. The analysis 
was based on the fixed demand/fixed heat source approach. The following were optimized in the analysis of the dry cooling system:

- The number of mechanical draft cooling tower cells of fixed design or the number of natural draft cooling tower modules of fixed design for minimum cost. (This basically defines the ITD.)

- The optimum water range.

\subsubsection{Major Assumptions and Constraints}

The major constraint. In this study was the fixed demand/fixed heat source approach to the analysis. The additional constralnis were:

- High back pressure turbines only were considered for the dry cooled plants.

- Stainless steel 304 tubing only was considered for the surface condensers.

\subsubsection{Optimization Procedure}

The computerized optimization procedure used for this analytical study was as follows:

1. Size the major components of the cooling system for a set of design parameters.

2. Evaluate the performance of the plant and cooling system over the yearly meteorological cycle and determine the incremental power production costs.

3. Change the dry cooling tower and condenser design parameters and repeat Steps 1 and 2 .

4. Select the most cost effective system.

\subsubsection{Data and Design Base}

This study was based on fixed design mechanical draft dry tower cells and fixed design natural draft dry tower modules. The details by which these cells or modules were designed or whether they were vendor designed 
are not described within the published study. Hence, there is little to discuss regarding either the adequacy or potential improvements of the design and data base.

\subsection{GILBERT ASSOCIATES METHOD OF ANALYSIS}

The Gilbert Associates method of analysis was used to compare dry and wet cooling systems. Only mechanical draft dry cooling systems were considered. The analysis was based on predesigned dry cooling equipment offered by vendors. The analytical approach was that of fixed demand/fixed. heat source. The extent to which the analysis is computerized is not discussed in the related report.

\subsubsection{Major Assumptions and Constraints}

The major constraint in this study was the fixed demand/fixed heat source approach to the analysis. The additional constraints were:

- High back pressure turbines only were considered for the dry cooled plants.

- Optimization of the cooling system for a given site was based on a fixed design ambient temperature.

- Stainless steel 304 tubing only was considered for the surface condensers.

- TTD for the surface condensers was fixed at $7^{\circ} \mathrm{F}$.

\subsubsection{Optimization Procedure}

The optimization procedure used for this analytical study followed these steps:

1. Fix the design ambient for the site.

2. Select combinations of ITD and water range to fix the cooling system size and costs.

3. Select the cooling system which results in minimum power production costs, assuming the plant operates only at the design ambient. 
4. Determine the power production costs based on running the plant at the four seasonal average temperatures.

\subsubsection{Data and Design Base}

This study was based on fixed design mechanical draft dry cooling equipment offered by a vendor. Discussion on the detailed design of the cooling system relative to this study is therefore irrelevant. A comment regarding the selection of the site design ambient should be made, however. The site design ambient was defined as the mean of the $1 \%$ air conditioning dry bulb temperature and the average annual dry bulb temperature. This was $67^{\circ} \mathrm{F}$ for the site considered. A value of $65^{\circ} \mathrm{F}$ was actually selected since it was the closest study temperature. The optimum cooling system was then selected assuming the plant to operate at this temperature all year. Subsequently, power production cost were recalculated for the optimum cooling system where the operation was at the four seasonal average temperatures. This process could result in an uneconomic selection for the cooling system since the loss in performance at the actual maximum ambient temperatures is a significant factor in the selection of an optimum cooling system. 


\subsection{CONCLUSIONS AND RECOMMENDATIONS}

The primary deterrent to the use of state-of-the-art dry cooling systems by utilities as an alternate to once through cooling, cooling ponds, spray canals, or evaporative towers has been the large incremental power production costs assessed to dry cooling by published (and perhaps unpublished) studies. The major goal of the ERDA Dry Cooling Tover Program is to develop and demonstrate the reliability and performance of dry cooling systems which have definite potential to reduce the power production costs of dry cooled plants. In order to determine the potential feasibility of achieving that goal, the following steps are required:

1. Establish a basis for determining the power production costs of dry cooled plants.

2. Determine the level of detail to which state-of-the-art dry cooling systems have been investigated for resulting reductions in power production costs.

3. Evaluate the potential for cost improvements using state-of-the-art equipment.

4. Evaluate the potential for further cost improvements using advanced concepts.

\subsection{CONCLUSIONS}

As a result of lhe review, three main conclusions relative to the above steps can be drawn:

1. There is no unified method for defining the power production costs of dry cooled plants. No published studies rigorously address the problem of how to interface the diy cooled plant with the utility system in order to minimize power production costs. Instead, in most studies the power production costs are arrived at indirectly by defining "incremental costs" relative to some reference plant. Calculation of the incremental costs is based on certain arbitrary 
constraints and certain capacity and energy penalties which do not reflect a rational approach to minimizing power production costs of a dry cooled plant. This involves more than a simple matter of "bookkeeping." The method used can affect not only the absolute costs of dry cooling but also the design of the cooling system.

2. Adequate detailed evaluation of state-of-the-art dry cooling systems has not been conducted and subsequently published. As a result, the potential for reduced power production costs through changes in state-of-the-art equipment is not known.

3. Comprehensive computer programs capable of thorough detailed evaluation of state-of-the-art systems are not publicly available. However, certain portions of available computer programs appear to be useful as building blocks from which to develop a more comprehensive tool with which to analyze both state-of-the-art and advanced dry cooling systems.

\subsection{RECOMMENDATIONS}

Based on this review and the resulting conclusions, the following are recommended:

1. A method for determining power production costs of dry cooled plants should be developed which reflects the actual way a utility would interface a dry cooled plant with a utility system to minimize power production costs. A workshop sponsored by ERDA UI EPRI could be beneficial in this regard.

2. A comprehensive detailed evaluation of metal finned tube state-ofthe-art dry cooling systems should be conducted to determine if, and where, potential exists for reducing the costs uf dry cooling.

3. Advanced dry cooling concepts should be evaluated for potential savings in power production costs. The cost comparisons should be made against the most cost effective cooling system defined in Recommendation 2. 


\section{REFERENCES}

1. J. P. Rossie and E. A. Cecil, Research on Dry-Type Cooling Towers for Thermal Electric Generation, R. W. Beck and Associates, Denver, CO, November 1970.

2. J. P. Rossie, E. A. Cecil and R. 0. Young, Cost Comparison of Dry-Type and Conventional Cooling Systems for Representative Nuclear Generating Plants, TID-26007, R. W. Beck and Associates, Denver, C0, March 1972.

3. J. P. Rossie, R. D. Mitchell and R. O. Young, Economics of the Use of Surface Condensers with Ory-Type Cooling Systems for Fossil-Fueled and Nuclear Generating Plants, TID-26514, R. W. Beck and Associates, Denver, C0, December 1973.

4. R. D. Mitche11, A Method for Optimizing and Evaluating Indirect DryType Cooling Systems for Large Steam-Electric Generating Plants, R. W. Beck and Associates, Denver, Co, June 1975.

5. B. R. Andeen and L. R. Glicksman, Dry Cooling Towers for Cooling Plants, DSR 73047-1, Massachusetts Institute of Technology, Cambridge, MA, February 1972.

6. L. R. Glicksman and B. R. Andeen, "Sensitivity of Power Generating Costs with Dry Cooling Towers," gth Intersociety Energy Conversion Engineering Conference Proceedings, 1974, American Society of Mechanical Engineers, New York, NY, pp. 566-571, 1974.

7. B. R. Andeen, L. R. Glicksman and W. M. Rohsenow, Improvement of the Environmental and Economic Characteristics of Cooling Towers, Part I: Optimized Design Program, Fluidized Beds, and Non-Metallic Heat Exchangers, Massachusetts Institute of Technology, Cambridge, MA, June $30,7973$.

8. P. Leung, G. R. Retti and J. R. Schilling, Dry Cooling Tower Plant Thermodynamic and Economic Optimization, ASME 72-PWR-5, Bechtel Corporation, San Francisco, CA, September 1972.

9. Dry Cooling Towers Study, Report prepared for WEST Associates by Bechtel Corporation, San Francisco, CA, April 1971.

10. K. A. Oleson, et al., Dry Cooling for Large Nuclear Power Plants, GEN-72-004, Westinghouse Power Generation Systems, Philadelphia, PA, February 1972.

11. Heat Sink Design and Cost Study for Fossil and Nuclear Power Plants, WASH-1360, United Engineers \& Constructors, Philadelphia, PA, December 1974. 


\section{REFERENCES (Continued)}

12. Site and Design Temperature Related Economics of Nuclear Power Plants with Evaporative and Non-Evaporative Cooling Tower Systems, GAI Report No. 1869, Gilbert Associates, Inc., Reading, PA, November 1975.

13. U.S. ERDA Dry Cooling Tower Development Program Plan, Revision 1, BNWL-B-393, Battelle-Northwest, Richland, WA, July 1975.

14. "New Generating Plants," Power Engineering, Technical Publishing Company, Barrington, IL, May 1975.

15. "1975 Annual Plant Design Report: Fossil-Firend R.entral Stations,"

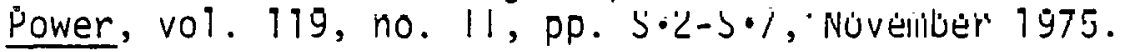

16. H. W. Kohn, "Reactor Performance Evaluations," Power Engineering, vol. 79, no. 12, pp. 52-55, December 1975.

17. J. W. Currie, Costing Electric Power: Implications for Dry Cooling Technology, BNWL-1998, Battelle-Northwest, Richland, WA, July 1976.

18. A. B. Johnson, Jr., U. R. Prate and G. E. Zima, A Survey uf Materials and Corrosion Performance in Ory Cooling Applications, BNWL-1958, Battelle-Northwest, Richland, WA, March 1976.

19. L. M. O1msted, "19th Steam Station Cost Survey: Busbar-Energy Costs Set Record." Electrical World, p. 43, November 15, 1975.

20. Economic and Technical Feasibility Study of Compressed Air Storage, ERDA 76-76, Ndvanced, Energy Programs Operations, Corporate Restarch and Development, General Electric Company, Schenectady, NY, March 1976.

21. "TVA Award EXXON gt Fuel Contract," Gas Turbine International, p. 43, May-June 1975.

22. T. W. Johnson and R. S. Farrell, "Gas Turbine Facility Responds Reliably," Electrical World, pp. 41-42, January 1, 1976.

23. Turbines for High Exhaust Pressure, Marketing Information Letter No. 922, General Electric Company, Schenectady, NY, June 28, 1971.

24. R. C. Norton, W. J. Westre and G. L: Larsen, Dry Cooling Design Characteristics of a Large Power Plant, Wyodak Resources and Development Corporation, Gillette, WY.

25. R. 0. Brown, Strategic Planning Manager, Power Systems Division, Westinghouse Electric Corporation, Philadelphia, PA, private communication, November 6, 1975. 


\section{REFERENCES (Continued)}

26. "Westinghouse to Offer Low Pressure Turbines for Nuclear." Electric Light and Power, June 23, 1975.

27. Letter, D. F. Kysely, Thermodynamic Engineer, Allis-Chalmers Power Systems, Inc., West Allis, WI, to D. W. Faletti, Battelle-Northwest, Richland, WA, June 27, 1975.

28. Standards for Steam Surface Condensers, Sixth Edition, Heat Exchange Institute, New York, NY, 1970.

29. E. C. Smith, "Air Cooled Heat Exchangers," Cost Engineering in the Process Industries, C. H. Chilton, editor, MCGraw-Hi11, New York, NY, 1960.

30. W. Kays and A. L. London, Compact Heat Exchangers, Second Edition, McGraw-Hi11, New York, NY, 1964.

31. K. A. Oleson, H. C. Gangloff and R. C. Twombley, Power Systems Division, Westinghouse Electric Corporation, Broomal1, PA, private communication, March 12, 1975. 
No. of

Copies

\section{OFFSITE}

A. A. Churm

Chicago Patent Group

Energy Research and

Development Administration

9800 South Cass Avenue

Argonne, IL 60439

Office of Assistant General

Counsel for Patents

Energy Research and

Development Administration

Washington, DC 20545

27 ERDA Technical Information Center

W. F. Savage

Advanced Concepts Evaluation Branch - F-309

ERDA Division of Nuclear

Research and Application

Washington, DC 20545

T. Beresovski

Chief, Advanced Concepts

Evaluation Branch

ERDA Division of Nuclear

Research and Application

Washington, DC 20545

D. C. Bauer

Director, Division of Nuclear Research and Application

Energy Research and

Development Administration

Washington, DC 20545

B. R. Dickey

Allied Chemical Cuminany

550 2nd Street

Idaho Falls, ID 83401
No. of

Copies

J. S. Joyce

All is-Chalmers Power Systems, Inc.

1135 South 70th Street

West Allis, WI 53214

E. T. Wanderer

Aluminum Company of America

Alcoa Technical Center

Alcoa Center, OH 45069

H. J. Janzon

American Electric Power

2 Broadway

New York, NY 10004

T. Woods

Arizona Public Service Co. $2121 \mathrm{~W}$. Cheryl Drive

Phoenix, AZ 85021 .

M. W. Peterson

Babcock \& Wilcox

Fossil Power Division

20 South Van Buren

Barberton, $\mathrm{OH} 44203$

G. C: Creel

Baltimore Gas \& Electric Co.

Gas \& Electric Building

Baltimore, MD 21203

E. Schinner

Baltimore Aircoil Co., Inc.

P.0. Box 7322

Baltimore, MD 21227

J. P. Budliger

Battel le-Geneva

7 Route De Orizi

1227 Geneva, SWITLERLAND 
No. of

Copies

P. Leung

Bechtel Corporation

P.0. Box 60860

Terminal Annex

Los Angeles, CA 90060

G. R. Retti

Bechtel Corporation

P.0. Box 3965

San Francisco, CA 94119

J. P. Rossie

R. W. Beck and Associates

400 Prudential Plaza

Denver, CO 80202

B. Westre

Black Hills Power and Light Company

P.0. Box 1400

Rapid City, SD 57701

J. Sell

Carolina Power \& Light Co. 336 Fayettesville Street

Raleigh, NC 27602

J. Morse

Catalytic Construction Corp.

P.0. Box 11402

Charlotte, NC 28029

H. H. Osborn

Combustion Engineering

Air Preheater Company

Wellsville, NY 14895

R. H. Holyoak

Commonwealth Edison

One First Plaza

P.0. Box 767

Chicago, IL 60690

C. L. Newman

Consolidated Edison Co. of New York, Inc.

4 Irving Place

New York, NY 10003
No. of

Copies

W. A. Messner

Consolidated Edison Co. of New York, Inc.

4 Irving Place

New York, NY 10003

L. E. Wilkinson

Consultant

6582 Ganon Street, S. E.

Salem, OR 97301

P. Sporn

Consultant Engineer

74 Trinity P1., Suite 511

New York, NY 10006

F. K. Moore

Cornell University

I thaca, NY 14850

R. J. Haberski

Curtiss-Wright Corp.

One Passaic Street

Wood Ridge, NJ 07075

S. K. Blackley

Duke Power Company

P.0. Bux 2178

Chartulle, NC 28201

J. K. Swindt

Ecodyne Cooling Products Co.

San Rosa, CA 95403

J. Maulbetsch

Elertric Power Research Institute

$3412 \mathrm{Hillview}$ Avenue

P.0. Box 10412

Palo Alto, CA 94304

L. Geller

Empire State Electric Energy Research Corp.

1250 Broadway

New York, NY 10001 
No. of

Copies

F. H. Rainwater

Environmental Protection Agency

Pacific Northwest Water Laboratory

200 S.W. 35 th Street

Corvallis, OR 97330

W. Hoydisch

Environmental Sciences and

Services

44-43 37th Street

Long Island City, NY. 11101

A. M. Rubin

Frank I in Institute

Twentieth \& Parkway

Philadelphia, PA 19103

B. Davis

GEA Airexchangers, Inc.

46 Worthington Drive

Maryland Heights, MD 63043

A. C. Eulberg

General Atomic

P.0. Box 81608

San Diego, CA 92138

E. H. Miller

General Electric Co.

Large Steam Turbine Division

300 Nott Street

Schenectady, NY 12301

R. K. Shah

Harrison Radiator Division

General Motors Corp.

Lockport, NY 14094

J. F. Sebald

Gilbert Associates, Inc.

525 Lancaster Avenue

Reading, PA 19603

J. E. Taboric

Heat Transfer Research Ine.

$1000 \mathrm{~S}$. Fremont Avenue

Alhambra, CA 91802
No. of

Copies

E. C. Smith

Hudson Products

6855 Horwin Drive

Houston, TX 77036

M. W. Larinoff

Hudson Products

6855 Horwin Drive

Houston, TX 77036

C. Rocco

Italimpianti - Societa

Italiana Impianti p.a.

Piazza, Piccapietra 9

18121 Genoa, ITALY

J. L. Mulloy

Los Angeles Department of Water and Power

$111 \mathrm{~N}$. Hope Street

Los Angeles, CA 90012

R. J. Meyer

Louisiana Power \& Light Co.

142 Delaronde Street

New Orleans, LA 70174.

R. Landon

Marley Co.

5800 Fox Ridge Drive

Mission, KS 66202

L. R. Glicksman

Massachusetts Institute of

Technology

77 Massachusetts Avenue

Cambridge, MA 02139

R. Hofacher

Montana Power Co.

40 E. Broadway

Butte, MT 59701

W. G. Hoydysn

New York University

University Heights

New York, NY 10453 
No. of

Copies

W. Kals

Niagara Blower

405 Lexington Avenue

New York, NY 10017

R. H. Meyer

Northeast Utilities

P.0. Box 270

Hartford, CT 06101

L. P. Davis

Department of Mechanical Engineering

Oregon State University

Corvallis, OR 97330

C. E. Wicks

Department of Chemical Engineering

Oregon State University

Corvallis, OR 97330

J. W. Michel

OTEC Heat Exchange Project Activity

Oak Ridge National Laboratory

BoX Y

nak Ridge, TN 37830

F. F. Mautz

Pacific Gas \& Electric

77 Beale Street

San Francisco, CA 94106

P. G. Humphries

Pacific Power \& Light Co.

Public Service Bldg.

Portland, OR 97204

T. Rozenmann

PFR Engineering Systems, Inc.

Suite 832

4676 Admiralty Way

Marina del Rey, CA 9029]

Prof. Ing. Carlo Roma

Piazza delle Muse 8

Rome, ITALY
No. of

Copies

A. C. Smith

Power Generation Cooling

Systems

4714 - 52nd Street S.

Seattle, WA 98118

R. F. Walker

Public Service of Colorado

5900 E. 39th Avenue

Denver, CO 80207

E. D. Kist

Public Service of New Mexico Corporate Planning Dept.

Albuquerque, NM 87103

G. E. Collins

Research Cottrell

Hamon Cooling Tower Division

Box 750

Bound Brook, NJ 08805

R. Lindberg

Reynolds Aluminum Co.

Reynolds Metallurgical

Research Laboratory

Richmond, VA 23261

R. G. Lacy

Sun Diego Gas \& Elestric.

101 Ash Street

San Diego; CA 92107

R. L. Skone

Seattle City Light

1015 Third Ave.

Seattle, WA 98104

J. Rasband

Suuthern California Edison 2244 Walnut Grove Avenue Rosemead, CA 91770

A.L. London

Department of Mechanical

Engineering

Stanford University

Stanford, CA 94305 
No. of

Copies

J. Y. Parce

Stearns and Rogers

$700 \mathrm{~S}$. Ash Street

Denver, CO 80222

D. H. Guild

Stone \& Webster Engineering Corp.

225 Franklin Street

Boston, MA 02107

H. I. Wilson

Tampa Electric Co.

P.0. Box 111

Tampa, FL 33601

W. Keel

Texas Electric Service Co.

$115 \mathrm{~W}$. Seventh Street

Fort Worth, TX 76102

G. J. Kidd

Union Carbide Corp.

ORGDP - K-25

P. 0. Box D

Oak Ridge, TN 37803

G. A. Englesson

United Engineers \&

Constructors

1401 Arch Street

Philadelphia, PA 19105

K. Simhan

University of Bremen

Bremen, WEST GERMANY

J. F. Kennedy

University of Iowa

Hydraulic Research Institute

Iowa City, IA 52240

J. H. Hutchinson

Utah Power \& Light

1407 W. N. Temple.

Salt Lake City, UT 84103
No. of

Copies

S. Ragone

Virginia Electric \& Power Co.

700 E. Frankl in Street

Richmond, VA 23261

G.H. Soule

WEST Associates

Sierra Pacific Power Co.

100 E. Moana Lane

Reno, NV 89510

J. A. Barnett

Executive Director

Western States Water Council

Room 1725

University Club Building

Salt Lake City, UT 84111

G. J. Silvestri

Westinghouse Electric Corp.

Steam Turbines Division

Lester Branch

Box 9175

Philadelphia, PA 19113

K. A. Oleson

Westinghouse Electric Corp.

Steam Turbines Division

Lester Branch

Box 9175

Philadelphia, PA 19113

\section{ONSITE}

2 ERDA Richland Operations Office, Program Division

P. G. Holsted

W. A. Burns

Westinghouse Hanford Company Hanford Engineering Development Laboratory

J. Fletcher 
R. T. Alleman

P. A. Ard

D. J. Braun

D. J. Braun

J. W. Currie

D. E. Deonigi

J. G. DeSteese

R. L. Dillon

D. W. Dragnich

R. L. Drake

D. W. Faletti

J. W. Finnigan

B. C. Fryer (30)

C. H. Henager

A. B. Johnson

W. S. Kelly

R. S. Kemper

C. J. Knoll

W. V. Loscutoff

R. P. Marshall

D. E. Olesen

Y. Onishi

L. T. Pedersen

D. R. Pratt

H. C. Riches

J. B. Schuettc

G. C. Smith

1. S. Stoakes

A. M. Sutey

ก. S. Trent

M. Vagins

R. A. Waiter

R. L. Watts

R. D. Widrig

L. E. Wiles

File - B. M. Johnson (30)

Technical Information (3)

Technical Publications 